\title{
Review Article \\ Platinum and Palladium Polyamine Complexes as Anticancer Agents: The Structural Factor
}

\author{
M. P. M. Marques \\ Research Unit "Molecular Physical Chemistry," Department of Life Sciences, Faculty of Science and Technology, University of Coimbra, \\ Apartado 3046, 3001-401 Coimbra, Portugal \\ Correspondence should be addressed to M. P. M. Marques; pmc@ci.uc.pt
}

Received 13 November 2012; Accepted 11 December 2012

Academic Editors: J. Casado, A. A. Ensafi, and M. Mączka

Copyright (C) 2013 M. P. M. Marques. This is an open access article distributed under the Creative Commons Attribution License, which permits unrestricted use, distribution, and reproduction in any medium, provided the original work is properly cited.

Since the introduction of cisplatin to oncology in 1978, Pt(II) and Pd(II) compounds have been intensively studied with a view to develop the improved anticancer agents. Polynuclear polyamine complexes, in particular, have attracted special attention, since they were found to yield DNA adducts not available to conventional drugs (through long-distance intra- and interstrand cross-links) and to often circumvent acquired cisplatin resistance. Moreover, the cytotoxic potency of these polyamine-bridged chelates is strictly regulated by their structural characteristics, which renders this series of compounds worth investigating and their synthesis being carefully tailored in order to develop third-generation drugs coupling an increased spectrum of activity to a lower toxicity. The present paper addresses the latest developments in the design of novel antitumor agents based on platinum and palladium, particularly polynuclear chelates with variable length aliphatic polyamines as bridging ligands, highlighting the close relationship between their structural preferences and cytotoxic ability. In particular, studies by vibrational spectroscopy techniques are emphasised, allowing to elucidate the structure-activity relationships (SARs) ruling anticancer activity.

\section{Introduction}

Cancer represents one of the major causes of death in humans worldwide, only overcome by cardiovascular diseases, and represents a huge burden on society (both sociologically and economically). About 20 million cancer cases are expected to occur in the next two decades, which renders the quest for new and improved antineoplastic agents (namely, based on natural compounds [1]) an urgent issue in the field of Biomedicine and Human Health. Over the past decade, efforts have been made in the way of understanding the carcinogenesis process, which is recognised to consist in a progressive disorganisation at both the cellular and tissue levels. This knowledge is essential to develop new chemotherapeutic strategies, in order to control the incidence of the most recurrent cancer types.

While many drug molecules are "organic" in nature, other elements in the periodic table, particularly metals, offer a much more diverse chemistry and have important therapeutic applications [2]. The use of metal-based compounds as therapeutic drugs dates back to over 5000 years. In modern days, the study of organometallic pharmaceuticals started with the pioneering work of Köpf and Köpf-Maier (in the late 1970's), who investigated the antitumor activity of early transition metal cyclopentadienyl complexes [3]. Since the introduction of cisplatin (cis-dichlorodiammineplatinum(II), cis$\operatorname{Pt}\left(\mathrm{Cl}_{2}\left(\mathrm{NH}_{3}\right)_{2}\right)$ to oncology, in the 1970's, organometallic compounds have gained a progressively increasing interest in medicinal chemistry [4-9]. Particularly in the treatment of malignant formations, inorganic compounds have had an enormous impact [7,10-15], their activity relying mostly on specific interactions with DNA, leading to damage and ultimately to cell death. The development of inorganic anticancer agents is widening rapidly beyond platinum chemistry, encompassing a large variety of metal ions and ligands, and many diverse designs tailored according to the specific receptor or biological target. So far, the major classes of metal-based anticancer drugs include platinum(II) and platinum(IV), palladium(II), gold(I) and gold(III), ruthenium(II) and ruthenium(III), bismuth(III), rhenium(I), and 


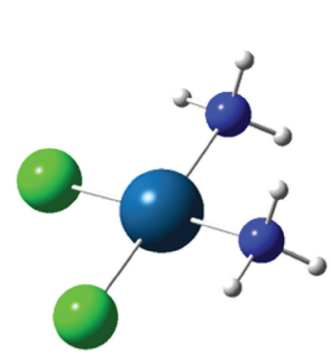

(a)

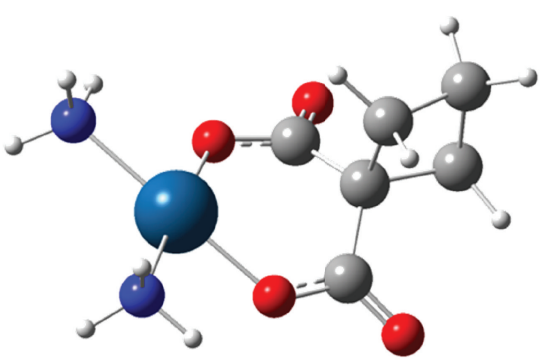

(b)
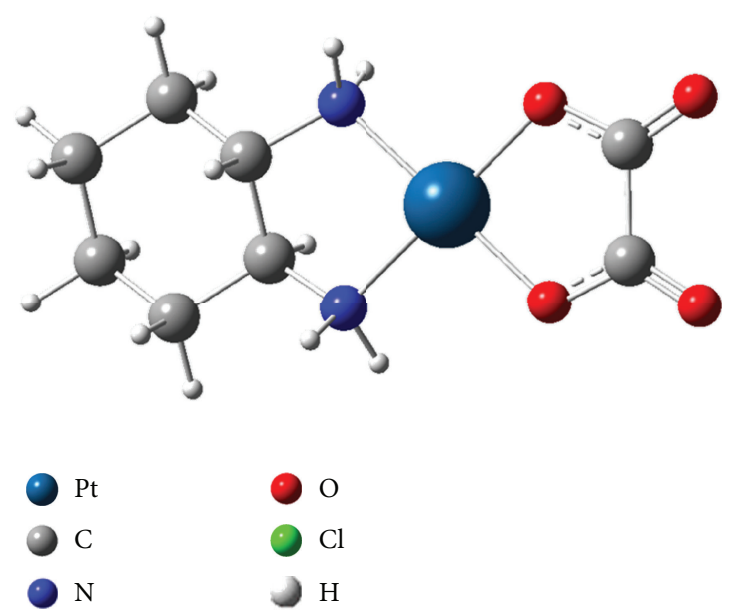

(c)

FIGURE 1: Platinum anticancer agents in clinical use: cisplatin (a), carboplatin (b), and oxaliplatin (c). (The represented structures correspond to optimised geometries, calculated with dedicated theoretical methods, at the Density Functional Theory level).

copper(II) compounds, as well as gallium(III) and tin(IV) derivatives, some of them having been reported to demonstrate higher in vitro anticancer activity than cisplatin [16].

The design of metal-based anticancer drugs was thus initiated by cisplatin (cis- $\mathrm{Pt}\left(\mathrm{NH}_{3}\right)_{2} \mathrm{Cl}_{2}$, Platinol, Figure 1), one of the leading agents in clinical use [17-21] with a high cytotoxic effect upon a variety of tumour types, in particular against testicular, ovarian, head and neck, and bladder carcinomas, as well as lymphoma [22-30]. The therapeutic target of platinum complexes is DNA, via binding to the purine bases through 1,2-intrastrand cross-links, yielding one or more $1,2-\mathrm{d}(\mathrm{GpG})$ and $1,2-\mathrm{d}(\mathrm{ApG})$ bifunctional adducts in which the two chlorine atoms of the cisplatin molecules are replaced (upon hydrolysis) by $\mathrm{N}_{7}$ atoms of adjacent purines [31-34]. These adducts activate several cellular processes that mediate cytotoxicity, namely, bending and unwinding of the double helix leading to the disruption of DNA duplication and inducing cell death by apoptosis [35-40].

The importance of platinum-based anticancer agents is reflected by the fact that they are presently used in 50 to $70 \%$ of all chemotherapy schemes administered to cancer patients. However, the use of cisplatin and related drugs (secondgeneration carboplatin and third-generation oxaliplatin) is restricted by their dose-limiting deleterious side effects (e.g., nephro- and hepatotoxicity) and by acquired resistance upon prolonged administration [41-45], as well as by their lack of efficiency against many cancer types, specifically metastatic ones. Hence, one of the main challenges in the rational design of metal-containing chemotherapy agents is to enhance their cytostatic activity while simultaneously reducing toxicity [7, 15, 46-53]. Crucial progress encompasses the elucidation of mechanisms of tumour resistance to these drugs, the introduction of new platinum agents (e.g., picoplatin and satraplatin), the development of combination therapeutic schemes with specific resistance modulators, and novel targeting strategies (liposomal formulations and nanodelivered drugs).

Based on the substantial expertise acquired on metalbased (both organometallic and inorganic) anticancer drugs for the last thirty years, with a special emphasis on their interaction with particular receptors and protein targets associated with tumour malignancy, it is reasonable to expect that innovative agents capable of modifying cell behaviour and cancer growth will be discovered [54]. In fact, carefully designed platinum and palladium complexes structurally different from cisplatin and its second-generation analogues are prone to display an altered spectrum of clinical activity and toxicity, due to differences in cellular biochemical pharmacology [53]. Therefore, the parameters ruling their cytotoxicity may not follow the patterns applied to cisplatinlike agents. A tailored drug design and drug reprofiling (rational modification of known drugs [55]) envisage an 


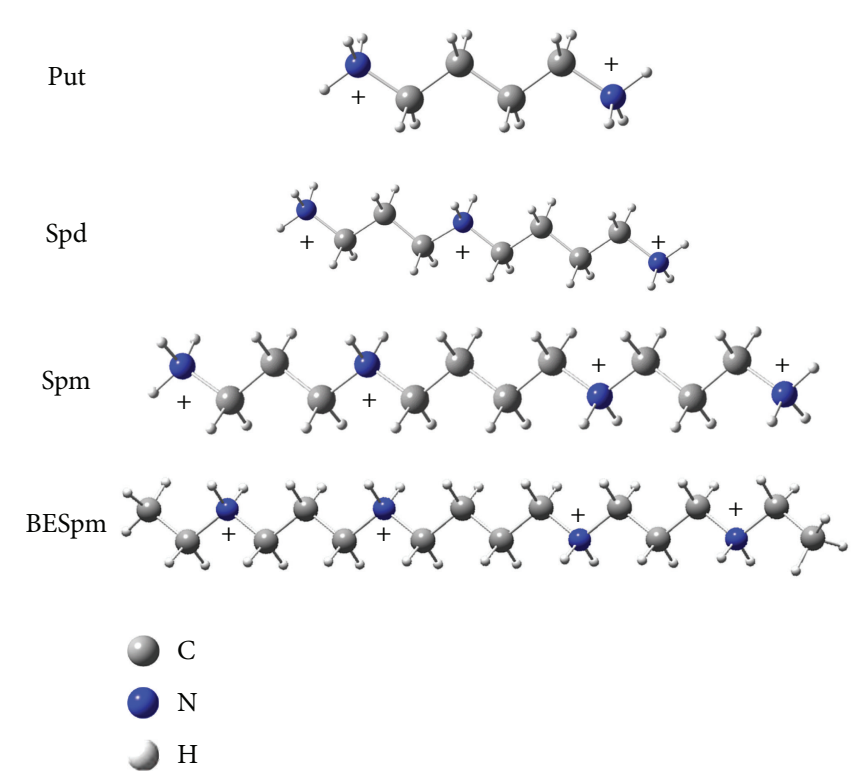

FIGURE 2: Linear alkyl polyamines putrescine (Put), spermidine (Spd), spermine (Spm), and bis(ethyl)spermine (BESpm)-all-trans conformations, in their totally protonated form (physiological species). (The represented structures correspond to optimised geometries, calculated with dedicated theoretical methods, at the Density Functional Theory level).

improved cytostatic activity, optimised modes of delivery, and reduced toxicity and acquired resistance. Somewhat disappointingly, however, from thousands of compounds tested only about 20 new drugs have entered clinical trials since the discovery of cisplatin $[49,51,56-58]$. Actually, it is estimated that more than 10000 compounds need to be screened in order to achieve one new successful anticancer drug.

The present paper accounts for the latest developments in the design of novel antitumor agents based on palladium and platinum with amine ligands, particularly polynuclear chelates with aliphatic polyamines as bridging linkers (e.g., biogenic polyamines). Special emphasis is placed on the close relationship between the compound's structural and conformational preferences, and their cellular uptake, biodistribution, and ability to affect DNA.

\section{Linear Polyamines as Ligands}

Amines are suitable chelating ligands for transition metal ions such as platinum, yielding stable, and reasonably water soluble coordination compounds. Linear aliphatic amines, in particular, are recognised to have a high conformational freedom and may be designed to display suitable flexibility and polidenticity features, which constitutes an advantage for an efficient interaction with metal ions and biological receptors. The conformational preferences of alkylamines depend on different factors, from steric, dipolar, and hyperconjugative effects to the relative importance of intra versus intermolecular interactions, namely, hydrogen-bond type close contacts [59-72].
In particular, the biogenic polyamines (PAs) putrescine (Put, $\mathrm{H}_{2} \mathrm{~N}\left(\mathrm{CH}_{2}\right)_{4} \mathrm{NH}_{2}$ ), spermidine (Spd, $\mathrm{H}_{2} \mathrm{~N}\left(\mathrm{CH}_{2}\right)_{3} \mathrm{NH}\left(\mathrm{CH}_{2}\right)_{4} \mathrm{NH}_{2}$ ), and spermine (Spm, $\mathrm{H}_{2} \mathrm{~N}\left(\mathrm{CH}_{2}\right)_{3} \mathrm{NH}\left(\mathrm{CH}_{2}\right)_{4} \mathrm{NH}\left(\mathrm{CH}_{2}\right)_{3} \mathrm{NH}_{2}$ ) (Figure 2) are physiological polycations essential for cell growth and differentiation and recognised to be closely related to neoplastic processes $[2,73,74]$. Also, modified biogenic polyamines have been synthesised in view of their use in cancer chemotherapy [75-77], either symmetrically or unsymmetrically alkylated, at the terminal and/or central nitrogens (e.g., ethyl-substituted spermine, BENSpm, Figure 2 ), conformationally restricted (e.g., by addition of cyclic and/or aromatic moieties), or differing in the $\mathrm{N}$-to- $\mathrm{N}$ alkyl bridges. In fact, structural changes at the terminal amines of linear PAs are known to drastically affect their biological activity, which relies mostly on these molecular moieties. Additionally, this type of chemical modification has been shown to affect the regulatory paths associated with biogenic PA biosynthesis, catabolism, and transport, through a Trojan horse mechanism. The cell recognises these polyamine analogues as natural polyamines, and they are promptly taken up and accumulated to high levels, stimulating PA catabolism while inhibiting the cellular uptake of biogenic PAs (thus lowering the intracellular polyamine pool) [78].

Apart from being potential modulators of polyamine function, this type of linear polyamines can act as multidentate ligands with a considerable affinity for both Pt(II) and $\mathrm{Pd}(\mathrm{II})$ ions. Linkage of some of these molecules to previously tested anticancer drugs (such as cisplatin)-yielding monoor polynuclear chelates-has been reported to lead to an enhancement of their cytotoxic effect [79-88]. In fact, the high conformational freedom and the dual hydrophiliclipophilic character of the polyamine ligands, comprising both cationic amine and imine groups and variable length hydrophobic alkyl linkers, allow these metal complexes to interact with DNA through a nonconventional way, both covalently (through direct binding of the metal centre to the purine bases) and noncovalently (via hydrophobic and hydrogen-bonding close contacts) (Table 1). The hydrophobic bridging moiety can interact with the DNA minor groove prior to covalent bond formation, and this preassociation affects the kinetics of crosslink formation as well as the local structure of the resulting adducts [89]. Additionally, the kinetics of this type of noncovalent interactions is rapid, taking place once the compounds enter the cell, as compared to the considerably slower covalent binding of the metal to DNA. Furthermore, the presence of nitrogen donor groups assists the molecular recognition of the drug by the polyphosphate backbone of DNA and related targets, due to the formation of favourable $(\mathrm{N}) \mathrm{H} \cdots \mathrm{O}$ interactions. Additionally, the amphiphilic nature of the amine linkers, coupled to a charge dispersion along their carbon backbone, may result in an enhanced cellular uptake of the drug. The hydrophiliclipophilic balance in this kind of metal polyamine complexes depends on the relationship between the length of the carbon bridging chains and the number of coordinating amine/imine moieties and metal centres. Substituted polyamines (e.g., aminocarboxylic [90] or ethylenediamine esters $[91,92])$ have been shown to coordinate efficiently 
TABLE 1: Platinum anticancer agents with amine ligands.

\begin{tabular}{|c|c|c|c|c|}
\hline Compound & CAS no. & ${ }^{\mathrm{g}} \mathrm{MOA}$ & Development phase & Toxicity \\
\hline $\begin{array}{l}\text { Cisplatin } \\
{[17,18,21]}\end{array}$ & $15663-27-1$ & $\begin{array}{l}\text { Covalent binding } \\
\text { short-range, intrastrand }\end{array}$ & Clinically approved & Nephrotoxicity \\
\hline $\begin{array}{l}\text { Carboplatin } \\
{[12,303]}\end{array}$ & $41575-94-4$ & $\begin{array}{l}\text { Covalent binding } \\
\text { short-range, intrastrand }\end{array}$ & Clinically approved & $\begin{array}{l}\text { Myelosuppression } \\
\text { reduced nephrotoxicity }\end{array}$ \\
\hline $\begin{array}{l}\text { Oxaliplatin } \\
{[105-107]}\end{array}$ & $61825-94-3$ & $\begin{array}{l}\text { Covalent binding } \\
\text { short-range, intrastrand }\end{array}$ & Clinically approved & Neurotoxicity \\
\hline $\begin{array}{l}\text { Satraplatin } \\
{[113,114,355]}\end{array}$ & $129580-63-8$ & $\begin{array}{l}\text { Covalent binding } \\
\text { short-range, intrastrand }\end{array}$ & Phase III clinical trials & $\begin{array}{l}\text { Myelosuppression } \\
\text { no significant oto-, neuro-, or nephrotoxicity }\end{array}$ \\
\hline $\begin{array}{l}\text { Picoplatin } \\
{[114,122-124]}\end{array}$ & $181630-15-9$ & $\begin{array}{l}\text { Covalent binding } \\
\text { short-range, intrastrand }\end{array}$ & Phase III clinical trials & $\begin{array}{l}\text { Neutropenia } \\
\text { no neuro- or nephrotoxicity }\end{array}$ \\
\hline $\begin{array}{l}\text { BBR3464 } \\
{[185]}\end{array}$ & $172903-00-3$ & $\begin{array}{l}\text { Covalent binding } \\
\text { long-range, interstrand }\end{array}$ & $\begin{array}{l}{ }^{\mathrm{h}} \text { Phase II clinical } \\
\text { trials }\end{array}$ & $\begin{array}{l}\text { Neutropenia } \\
\text { anemia }\end{array}$ \\
\hline $\begin{array}{l}{ }^{\mathrm{a}} \mathrm{AH} 44 \\
{[186,216]}\end{array}$ & - & $\begin{array}{l}\text { Non-covalent interaction } \\
\text { electrostatic, H-bonding } \\
\text { phosphate clamps }\end{array}$ & - & - \\
\hline $\begin{array}{l}{ }^{\mathrm{b}} \text { TriplatinNC } \\
{[186-188]}\end{array}$ & - & $\begin{array}{l}\text { Non-covalent interaction } \\
\text { electrostatic, H-bonding } \\
\text { phosphate clamps }\end{array}$ & - & - \\
\hline $\begin{array}{l}{ }^{\mathrm{c}} \text { Lipoplatin } \\
{[136]}\end{array}$ & $15663-27-1$ & $\begin{array}{l}\text { Covalent binding } \\
\text { short-range, intrastrand } \\
\text { controlled drug delivery }\end{array}$ & $\begin{array}{l}\text { Phases II and III } \\
\text { clinical trials }\end{array}$ & Negligible neuro- and nephrotoxicity \\
\hline $\begin{array}{l}{ }^{\mathrm{d}} \text { Lipoxal } \\
{[141,142]}\end{array}$ & & $\begin{array}{l}\text { Covalent binding } \\
\text { short-range, intrastrand } \\
\text { controlled drug delivery }\end{array}$ & Phase I clinical trials & $\begin{array}{l}\text { Mild neutropenia } \\
\text { no reno-, cardio-, or hepatotoxicity }\end{array}$ \\
\hline $\begin{array}{l}{ }^{\mathrm{e}} \text { Aroplatin } \\
{[144]}\end{array}$ & $114488-24-3$ & $\begin{array}{l}\text { Covalent binding } \\
\text { short-range, intrastrand } \\
\text { controlled drug delivery }\end{array}$ & $\begin{array}{l}{ }^{\mathrm{i}} \text { Phases I and II } \\
\text { clinical trials }\end{array}$ & $\begin{array}{l}\text { Myelosuppression } \\
\text { mild nephrotoxicity }\end{array}$ \\
\hline $\begin{array}{l}{ }^{\mathrm{f}} \text { Prolindac } \\
{[130]}\end{array}$ & $674289-90-8$ & $\begin{array}{l}\text { Covalent binding } \\
\text { short-range, intrastrand } \\
\text { controlled drug delivery }\end{array}$ & Phase II clinical trials & Negligible neurotoxicity \\
\hline
\end{tabular}

${ }^{\mathrm{a}}$ Comprising two $\left.\left(\mathrm{H}_{2} \mathrm{~N}\left(\mathrm{CH}_{2}\right)_{6} \mathrm{NH}_{2}\right)_{2}\right)$ groups substituting the leaving chlorides in BBR3464, $n=8+{ }^{\mathrm{b}}$ Comprising two $\mathrm{NH}_{3}{ }^{+}$groups substituting the leaving chlorides in BBR3464, $n=6+{ }^{\mathrm{c}}$ Lipoplatin: liposomal formulation of cisplatin; ${ }^{\mathrm{d}}$ Lipoxal: liposomal formulation of oxaliplatin; ${ }^{\mathrm{e}}$ Aroplatin: liposomal formulation of an oxaliplatin analogue. ${ }^{\mathrm{f}}$ Nanopolymer-oxaliplatin conjugate. ${ }^{\mathrm{g}} \mathrm{MOA}$ : mechanism of action. ${ }^{\mathrm{h}}$ Did not progress to Phase III, due to plasma decomposition and severe toxicity in Phase II human clinical trials. ${ }^{\mathrm{i}}$ Development halted due to economic reasons.

to both $\mathrm{Pt}(\mathrm{II})$ and $\mathrm{Pd}(\mathrm{II})$ [90] and to act as modulators of the hydrophilic/lipophilic properties of the resulting chelates (thus improving their administration and bioavailability). The dimensions and flexibility of the alkylamine linkers also determine the type of DNA interplay, usually allowing longrange and interstrand interactions as opposed to mononuclear $\mathrm{NH}_{3}$-containing drugs such as cisplatin or carboplatin. Moreover, combination of linear polyamine ligands to distinct coordinating moieties-namely, aromatic groups such as phenyl, pyridyl [93] or bipyridyl [94], selenium [95], or sulphur-containing assemblies [96]-is often used to improve antiproliferative ability, as well as to enhance selectivity and lower toxicity. Moreover, functionalization with biologically active molecules such as amino acids helps improving the antineoplastic ability [97].

\section{Platinum Amine Complexes as Chemotherapeutic Agents}

Since the serendipitous discovery of the antitumor properties of cisplatin (cis-(diamminodichloro)platinum(II), cis$\operatorname{Pt}\left(\mathrm{Cl}_{2}\left(\mathrm{NH}_{3}\right)_{2}\right.$, Figure 1) by Rosenberg et al. [17, 18] and its introduction to oncology, bioinorganic compounds have gained an increasing interest in the design of both therapeutic and diagnostic agents $[21,38,49,98]$.

Presently, platinum-based chemotherapeutics are among the most widely prescribed drugs in modern oncology (administered to $\mathrm{ca}$. 50\% of all cancer patients), either alone or in combination with other systemic compounds and/or radiation therapy. They are known to be active in a wide range of solid tumours, including lung, head and neck, colon, 


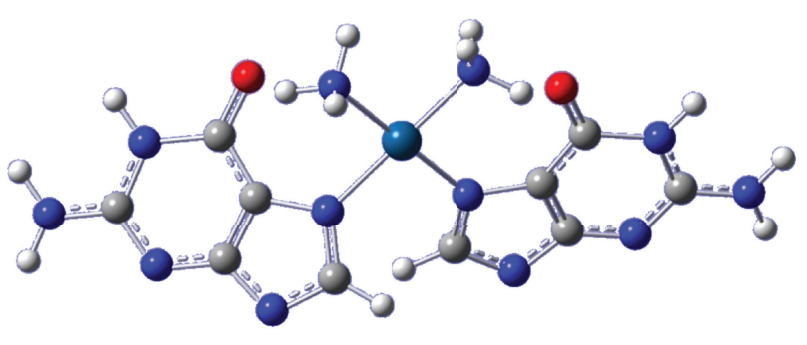

(a)

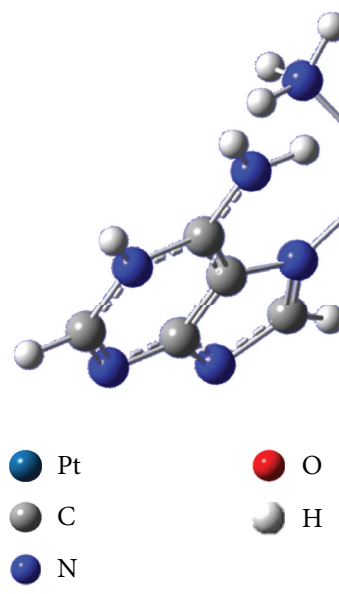

(b)

FIGURE 3: Structural representation of DNA platination: cisplatinguanine (a) and cisplatin-adenine (b) $1: 2$ adducts. (The represented structures correspond to optimised geometries, calculated with dedicated theoretical methods, at the Density Functional Theory level).

bladder, ovarian, and testicular. This type of compounds exert their cytotoxic action through specific interactions with DNA [98-100], covalent binding, the nitrogen in position 7 of guanine being the preferential platination site, followed by adenine's $\mathrm{N}_{7}$ (Figure 3, Table 1). DNA crosslinking due to formation of these stable adducts (both intra- and interstand) leads to distorted conformations (either $\mathrm{A}$ or $\mathrm{Z}$ ) relative to the native $\mathrm{B}$ form and triggers apoptosis, thus suppressing proliferation [49].

3.1. Drugs in Clinical Use. Despite the high number of studies in this field, only three platinum-based compounds are currently approved for clinical use: cisplatin, carboplatin, and oxaliplatin (Figure 1 ) which comprise ammine $\left(\mathrm{NH}_{3}\right)$ or bidentate amine ligands and either chloride or carboxylate leaving groups. Nevertheless, apart from requiring intravenous administration, they are associated with severe side effects (e.g., nephrotoxicity, myelosuppression, ototoxicity, and neurotoxicity) as well as with acquired resistance, which strongly limits their application in the clinic.

Cisplatin. Since its approval for clinical use (in 1978), this square planar $\mathrm{Pt}(\mathrm{II})$ complex (cis-(diamminodichloro)platinum(II), trade name Platinol, Figure 1) has become one of the leading metal-based antineoplastic drugs and the first-line therapy for several human cancer types. Cisplatin damaging effect on DNA is due to short-range inter- and intrastrand cross-links (mainly at the double-helix purine bases) [38, 101, 102]. Unfortunately, it presents several major drawbacks, such as cumulative toxicities of nephrotoxicity and ototoxicity, and treatment-induced resistance, which has prompted the development of novel cisplatin-like agents.

Carboplatin. Carboplatin (cis-diammine(1,1-cyclobutanedicarboxylato)platinum(II), approved in 1989, trade name Paraplatin, Figure 1) is a second-generation Pt(II) compound that differs from cisplatin by the presence of a bidentate dicarboxylate ligand as its leaving group instead of the more labile cisplatin's chlorides [103]. This renders the complex activation kinetics much slower in relative to cisplatin [104] and consequently leads to a significantly lower toxicity, while yielding the same type of DNA adducts. The higher stability relative to cisplatin allows more time for the drug to reach the target molecule [12], leading to a longer lasting effect: carboplatin has a retention half-life of 30 hours, as compared to 1.5-3.6 hours for cisplatin. Moreover, it presents reduced side-effects relative to cisplatin, particularly regarding nephrotoxicity (which is negligible), and was shown to be effective in some strains of cancer that are not responsive to cisplatin.

Oxaliplatin. Oxaliplatin ([(1R,2R)-cyclohexane-1,2-diamine](ethanedioato- $O, O^{\prime}$ )platinum(II), approved in 2002, trade name Eloxatin, Figure 1) is a $\mathrm{Pt}(\mathrm{II})$ complex comprising a bidentate 1,2-diaminocyclohexane stable ligand (instead of two monodentate ammine ligands) and an oxalate leaving group $[105,106]$. Inclusion of the diaminocyclohexane moiety was intended to contribute to a larger cytotoxicity when compared to cisplatin and carboplatin (more damaging Pt-DNA adducts), as well as to avoid cross-resistance with those widely used drugs [107]. The particularly high activity of this third-generation agent, even in cisplatin-resistant tumour models, coupled to its decreased toxicity, prompted further studies on its use as a treatment option after the failure of the cisplatin or carboplatin therapy.

Although oxaliplatin is typically administered in combination regimes (e.g., with fluorouracil and leucovorin) for the treatment of colorectal cancer, it is also being screened against advanced cancers such as gastric and ovarian. Presently, several oxaliplatin analogues are being synthesized and tested as to their cytotoxicity in comparison to oxaliplatin [108-110], including dinuclear complexes comprising a cisplatin-like moiety [111]. These have shown promising results, namely, identical cytotoxicity in ovarian cancer cells with significantly higher tolerability.

3.2. Agents in Advanced Clinical Trials. Only four Pt-based drugs are presently under advanced clinical trials: two of them active upon orally administration-satraplatin and picoplatin-and two others constituting first approaches to polymer and liposomal encapsulated agents, aiming at an 


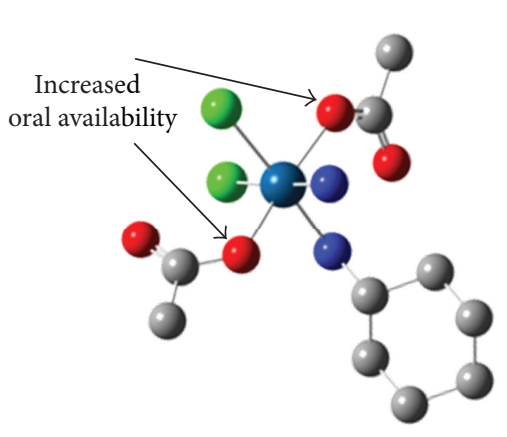

(a)

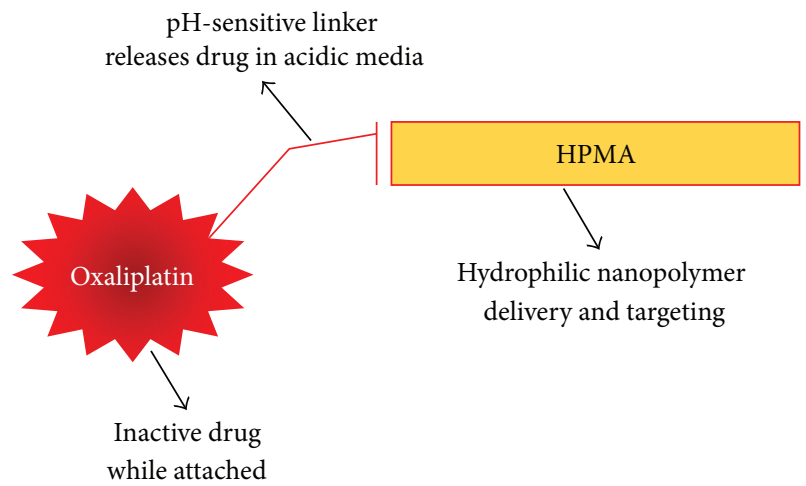

(c)
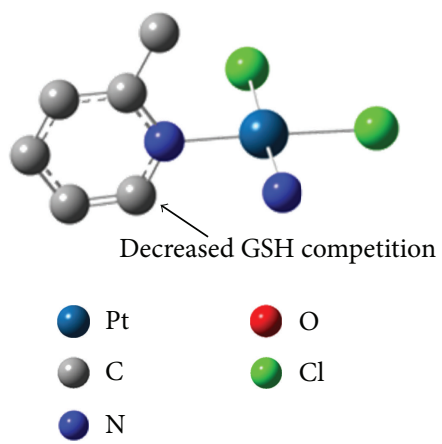

(b)

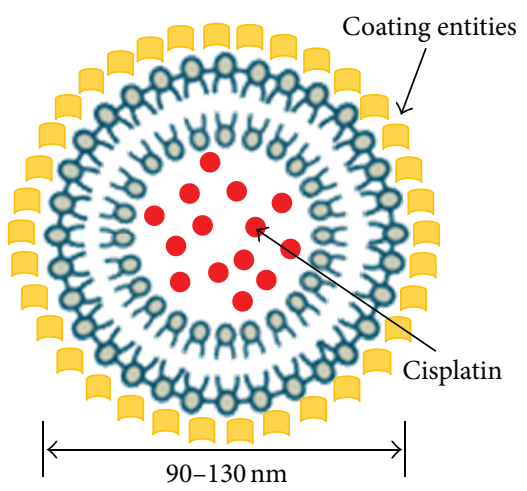

(d)

Figure 4: Platinum anticancer agents under advanced clinical trials: Satraplatin (a), picoplatin (b), Prolindac (c), and Lipoplatin (d). (Structures (a) and (b) correspond to optimised geometries, calculated with dedicated theoretical methods, at the Density Functional Theory level. GSH-reduced glutathione).

improved delivery (and consequently lower toxicity), ProLindac and Lipoplatin.

Satraplatin. Satraplatin (bis-(acetato)amminedichloro(cyclohexylamine)platinum(IV), trade name Orplatna, Figure 4) is a third-generation $\mathrm{Pt}(\mathrm{IV})$ compound, structurally similar to cisplatin but comprising two axial acetate groups responsible for an improved oral bioavailability that renders satraplatin the first platinum agent susceptible of oral administration [112]. The lower reactivity of $\mathrm{Pt}(\mathrm{IV})$ as compared to $\mathrm{Pt}(\mathrm{II})$ is prone to diminish loss of active drug during the pharmacokinetic phase and to decrease the incidence of side reactions usually responsible for unwanted deleterious side effects.

Satraplatin displays improved therapeutic properties compared to other platinum agents such as cisplatin, carboplatin, and oxaliplatin [48, 113-115], namely, the potential to overcome platinum resistance [116] and the significantly milder toxicity profile [117]. Additionally, since satraplatin is more hydrophobic than cisplatin or oxaliplatin, it has demonstrated efficacy in cisplatin-resistant tumours. Moreover, the lack of cross-resistance of taxane-resistant cells to satraplatin is of particular importance in cancers for which the former are standard chemotherapeutics (e.g., hormone-refractory prostate cancer).

Upon oral administration, satraplatin is rapidly metabolised into several (at least six) cisplatin analogues, by removal of the acetate moieties [115]. (cis-amminedichloro(cyclohexylamine)-platinum(II)), the most abundant one, is rapidly absorbed through the gastrointestinal mucosa, reaching peak plasma levels within 2 hours. This metabolite binds to DNA through 1,2-intra- and interstrand crosslinks, leading to cell-cycle arrest at the $G_{2}$ phase and subsequent induction of apoptosis [118]. Both the administered agent and its metabolites are largely bound to blood constituents (e.g., plasma proteins), only a small percentage occurring as free platinum.

Satraplatin has overcome Phase III clinical trials, having shown great efficacy against several platinum-resistant human cancer cell lines $[115,116,119]$, including lung, ovary, cervix, and prostate (pivotal SPARC trial, Satraplatin and Prednisone Against Refractory Cancer [120, 121]).

Picoplatin. Picoplatin (cis-(amminedichloro-2-methylpyridine)platinum(II), Figure 4) is a sterically hindered $\mathrm{Pt}(\mathrm{II})$ mixed amine complex, designed to overcome glutathionemediated platinum resistance [122-124]. Since one of the amines is substituted by a bulkier group (2-methylpyridine or $\alpha$-picoline), glutathione competition occurs through a dissociative thiol substitution reaction instead of an associative one (as for cisplatin). This leads to a slower substitution kinetics, therefore unfavouring the glutathionemediated resistance mechanisms [125]. Picoplatin displays an improved safety compared to other platinum agents (particularly regarding nephro- and neurotoxicities) [114, $122,126,127]$ and has shown activity against cisplatin, carboplatin, and oxaliplatin-resistant cancer lines [126, 128] 
such as small cell lung, colorectal, and hormone-refractory prostate cancers.

The favourable results obtained for this experimental Pt(II)-drug (Phases I and II), specifically developed for the treatment of patients with solid tumours, pave the way for late-stage studies aiming at an anticancer activity similar to that of other platinum agents, such as oxaliplatin, combined to a lower toxicity and the ability to overcome resistance.

Studies on oral versus intravenous administration of picoplatin have demonstrated that it achieves linear and dosedependent plasma exposure when administered orally, yielding sufficient bioavailability to support further clinical studies [129]. Furthermore, oral picoplatin has shown significant potential for use in combination therapies.

Liposomal and Polymer-Based Agents. Liposomal and polymer-conjugated drugs are known to display a better tolerance profile and a higher accumulation in the tumour environment. In fact, encapsulation of metal-based drugs in a liposome or linkage to a specifically designed polymer is quite successful strategy aimed at improving delivery, optimising the tumour response to treatment, and reducing systemic toxicity.

In these formulations, the drug-delivery vehicle complexes should obey a set of parameters in order to better attain the required goals: (i) solubility and biocompatibility with the physiological media; (ii) suitable composition, size/shape, and charge, to allow easy membrane permeation; coating with specific compounds (e.g., polyethylenoglycol (PEG)) is sometimes required to avoid rapid excretion; (iii) control of the rate and site of drug release; (iv) release of the intact drug from the delivery entity (without changes in the pharmacophore); (v) in vivo drug stability within the delivery cluster.

ProLindac. ProLindac is a nanopolymer-oxaliplatin conjugate where the active moiety of oxaliplatin $[\mathrm{Pt}(\mathrm{R}, \mathrm{R}-$ diaminocyclohexane)] is bound to the hydrophilic biocompatible polymer HPMA (hydroxypropylmethacrylamide) (Figure 4), which increases the drug's plasma clearance halftime. This polymeric entity acts both as a delivery and targeting vehicle, with a view to enhance the drug's bioavailability at the target due to a higher retention and better permeability $[130,131]$. ProLindac undergoes decomposition-at the $\mathrm{pH}$-sensitive Pt-polymer linker-thus releasing the pharmacophore, preferably at low $\mathrm{pH}[128,132]$. Since tumours are generally more acidic than the surrounding normal tissue, this constitutes a quite effective targeting strategy.

Clinical trials (Phase II) in a panel of cancer lines evidenced a higher efficacy when compared to carboplatin's or oxaliplatin's, coupled to an excellent tolerability (with no signs of acute neurotoxicity) [133, 134]. Actually, a significantly greater tumour growth inhibition was observed in several models, including human breast, ovarian, lung, and prostate.

In addition to cytotoxicity against cisplatin-resistant cell lines, ProLindac also showed anticancer activity towards metastatic melanoma and advanced ovarian cancer [135].
Lipoplatin. Several liposomal formulations of platinum agents have been developed in recent years: Lipoplatin (the liposomal-encapsulated cisplatin [136-140]), Lipoxal (the liposomal formulation of oxaliplatin) [141-143], and Aroplatin (a liposomal formulation of an oxaliplatin analogue) [144-146].

Lipoplatin (Figure 4), which has a small particle size (from 90 to $130 \mathrm{~nm}$ ), is able to cross cell membranes more easily than its guest molecule cisplatin and causes significantly less deleterious side effects (almost negligible nephrotoxicity, ototoxicity, and neurotoxicity). Liposomeincluded cisplatin was found to be active against metastatic tumours, namely, refractory prostate cancer, as well as colon, gastric, and nonsmall cell lung cancers $[147,148]$, through a mechanism similar to cisplatin's. Gastric cancer, in particular, displayed the highest levels of total platinum accumulation (up to $260 \mathrm{mg} / \mathrm{g}$ tissue) [149].

Additionally, cisplatin encapsulated in polyethylene glycol-coated liposomes containing a new cationic lipid (TRX20) were found to lead to an increased delivery of the platinum agent to some metastatic tumours (such as prostate cancer) [150], which constitutes a very promising approach for increasing the drug's bioavailability at its target, and hence its effectiveness. The presence of a PEG coating, in particular, prevents drug detection by immunogenic entities and consequent rapid excretion [148].

Lipoplatin has successfully overcome Phases I, II, and III human clinical trials [136, 151-154].

3.3. Polyamine-Bridged Polynuclear Complexes. In the last two decades, mononuclear platinum complexes have given way to polynuclear compounds, comprising 2 or 3 metal centres (Figure 5), expected to display a higher cytotoxicity due to a more severe (less repairable) DNA damage. Within these, polyamine-bridged polynuclear $\mathrm{Pt}(\mathrm{II})$ chelates have been introduced as promising anticancer agents by Farrell and coworkers [15]. These new generation compounds, comprising di-, tri-, or tetranuclear-charged moieties and linear aliphatic polyamines as bridging ligands (Figure 6), induce an enhanced cytotoxic effect in comparison to the Pt-drugs currently approved for clinical use which comprise only one coordinating metal ion and are much more restricted conformationally. Actually, the cisplatin-like chelates have a distinct mechanism of action, being able to bind at several sites along the DNA helix simultaneously, through longrange intra- and interstrand cross-links are not accessible to classical platinum agents [15, 102, 155-158].

Several of these polyfunctional chelates using di-, tri-, and tetramines as linkers have been the object of intense research $[26,81,159-167]$, in view of developing novel anticancer agents with a broad spectrum of pharmacological activity, coupling an improved therapeutic profile to a lower toxicity, and hopefully overcoming acquired cisplatin and carboplatin resistance (Table 1). The biogenic polyamines putrescine, spermidine, spermine, and their $\mathrm{N}$-alkylated counterparts, in particular, have been used as bridging ligands, yielding $\mathrm{Pt}(\mathrm{II})$ and $\mathrm{Pd}(\mathrm{II})$ complexes differing in the geometry and coordination type of the metal centres (Figure 6), and leading 


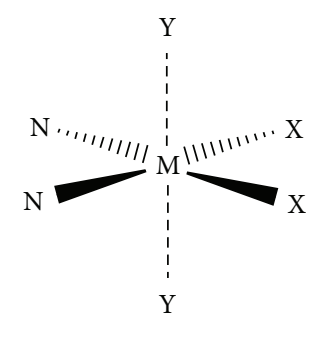

(a)
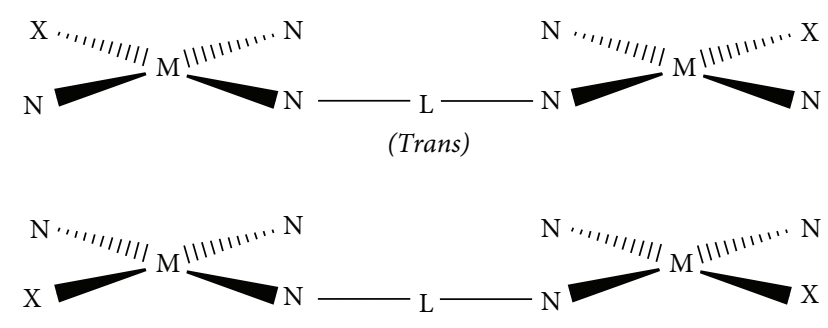

(Cis)

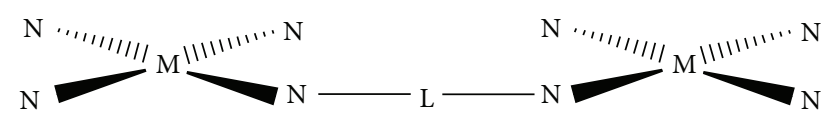

(b)

FIGURE 5: Schematic representation of mono- (a) and polynuclear (b) platinum and palladium complexes with amine ligands. (M: $\mathrm{Pt}$ or Pd; $\mathrm{N}$ : coordinating amine ligand(s); X: leaving group (chloride or carboxylate); Y: axial ligands, for Pt(IV) complexes (chloride, hydroxyl, or carboxylate); L: variable length alkyl diamine linker).

to distinctive and very effective interactions with DNA [52, 160, 165-182].

In these chelates, designed to emphasize innovative modes of binding with DNA, two or three Pt(II) centers are tightly assembled by linear amine linkers, their biological activity being ruled by the diverse spacings and relative orientations of the metal ions' coordinating environment, according to specific structure-activity relationships (SARs). This kind of interplay, through nonconventional interactions, results in different types of drug-induced DNA lesions - at more than one base, interstrand and long range-responsible for a more severe damage, less easily repairable, which will be reflected in a higher antineoplastic efficacy [158, 165-168, 175, 177, 183, 184]. Within this group of compounds, the set of polynuclear platinum complexes bridged by aliphatic diamines developed by Farrell and collaborators deserve special attention, since they constitute a unique class of potential anticancer agents with activity in cisplatin-resistant model systems $[15,81,84-86,159$, 185205]. Their DNA-binding profile produces an array of structurally distinct adducts, not available to mononuclear analogues such as cis- $\left[\mathrm{PtCl}_{2}\left(\mathrm{NH}_{3}\right)_{2}\right]$. The possibility of triand tetrasubstitution inherent to the polynuclear structure opens interesting challenges for the design of agents capable of specific DNA binding. These agents are expected to lead to a higher efficacy and specificity regarding DNA binding (e.g., increased number of long-range interstrand cross-links, usually at more than one site along the double helix), each type of platinum structure displaying its own particular cytotoxic characteristics, which may therefore be varied in order to modulate DNA binding and activity. One such complex, triplatinum BBR3464 (Triplatin, [\{trans$\left.\operatorname{PtCl}\left(\mathrm{NH}_{3}\right)_{2}\right\}_{2}$-trans-Pt $\left.\left(\mathrm{NH}_{3}\right)_{2}\left\{\mathrm{H}_{2} \mathrm{~N}\left(\mathrm{CH}_{2}\right)_{6} \mathrm{NH}_{2}\right\}_{2}\right]\left(\mathrm{NO}_{3}\right)_{4}$, Figure 6) [89, 156, 159, 185, 187, 191, 199, 206-212], was the only platinum compound not based on the cisplatin chemotype to have entered human clinical trials [15]. It showed very promising results, namely, towards melanoma, pancreatic, lung, and ovarian cancers, but it was discarded during Phase II clinical trials due to poor response rates [48] and severe toxicity (extensive metabolism and irreversible protein bonding in human plasma, Table 1) [184, 213].

Apart from these polyamine-based coordinative compounds, affecting DNA through interaction modes typical of platinum agents-covalent groove binding-a novel approach was recently disguised, consisting in noncoordinative compounds that interact with DNA exclusively by noncovalent modes [186, 188, 189, 203, 214, 215]. These innovative DNA-backbone binders do not contain hydrolysable groups, displaying positively charged $\mathrm{NH}_{3}$ or "dangling" alkylamine moieties instead. TriplatinNC, an octacationic trinuclear platinum(II) chelate ([ $\left\{\right.$ trans $-\mathrm{Pt}\left(\mathrm{H}_{2}\right.$ $\left.\left.\mathrm{N}\left(\mathrm{CH}_{2}\right)_{6} \mathrm{NH}_{3}\right)\left(\mathrm{NH}_{3}\right)_{2}\right\}_{2} \mu$ - (trans - $\mathrm{Pt}\left(\mathrm{NH}_{3}\right)_{2}\left(\mathrm{H}_{2} \mathrm{~N}\left(\mathrm{CH}_{2}\right)_{6}\right.$ $\left.\left.\left.\mathrm{NH}_{2}\right)_{2}\right)\right]^{8+}$, Figure 6 , Table 1 ), is the first reported $\mathrm{Pt}(\mathrm{II})$ antitumor complex that interacts with biomolecules solely in a noncoordinative fashion. While these compounds cannot yield covalent metal-purine base adducts, they associate with DNA through hydrogen bond and electrostatic interactions [163, 186-191, 193, 194, 201, 202, 206, 216-219], mainly involving the phosphate oxygen atoms via bidentate $\mathrm{NH} \cdots \mathrm{O} \cdots \mathrm{HN}$ "phosphate clamps" $[52,186,220]$. These were found to produce structural changes in DNA and key proteins which are different from those induced by currently used Pt-drugs (through conventional interactions), leading to a quite high cytotoxicity in several human cancer lines [52, 157, 186, 215]. In addition, TriplatinNC shows selectivity for DNA oxygen atoms and against DNA nitrogen atoms. The cellular uptake of these cationic nonreactive agents is remarkably enhanced relative to neutral cisplatin and cisplatin-like polynuclear complexes [157, 163, 188], and it increases as the overall positive charge increases due to the weak molecular interactions on the cells' surface which leads to an increased bioavailability at the target. Additionally, this "noncoordinative" approach may help to decrease the toxic side effects of conventional platinum agents by minimising potentially deleterious parallel reactions. Accordingly, this kind of compounds may be able to circumvent the pharmacokinetic problems associated with sulphur deactivation of conventional Pt(II)-based drugs (e.g., by glutathione competition $[221,222]$ ), since no metal coordination to thiol groups can occur.

Recently, functionalized platinum agents have been developed, of general formula $\left[\mathrm{PtL}_{3} \text { (nucleobase) }\right]^{n+}$, L representing a linear polyamine ligand and the nucleobase being either guanine or cytosine based [223, 224]. 


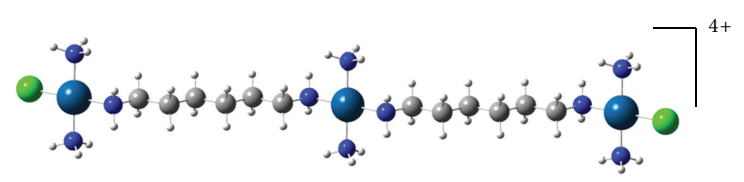

(a)

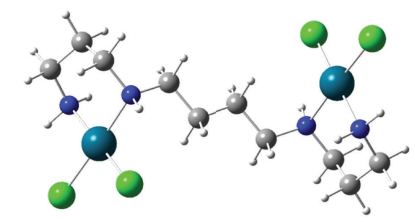

(b)

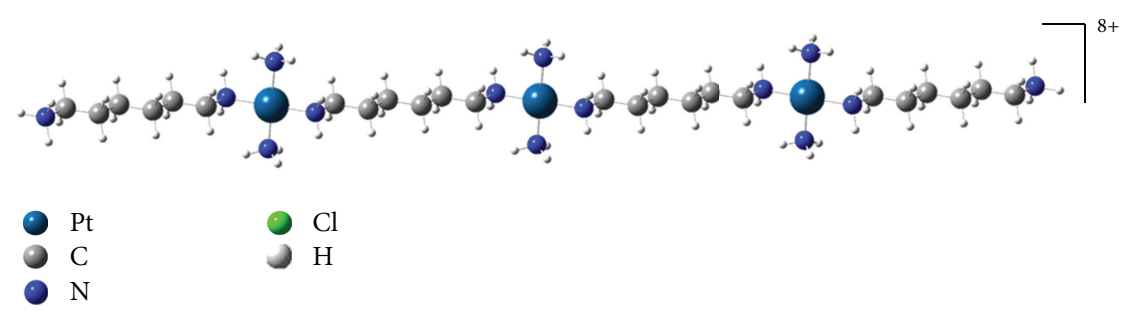

(c)

FIgURE 6: Polyamine-bridged polynuclear Pt(II) complexes: BBR3464 (Triplatin) [185] (a), $\mathrm{Pt}_{2} \mathrm{Spm}(\mathrm{Spm}=$ spermine) [168] (b), and TriplatinNC [189] (c). (The represented structures correspond to optimised geometries, calculated with dedicated theoretical methods, at the Density Functional Theory level).

3.4. Palladium for Platinum Substitution in Polyamine Complexes. Although platinum(II) is a well-established pharmacophore for the development of cytotoxic agents [37, 225], numerous $\mathrm{Pt}(\mathrm{II})$-based chemotherapeutic strategies being reported to this date; its high thiophilicity is responsible for several severe drawbacks: drugs' inactivation and development of resistance via reaction with endogenous sulphur-containing biomolecules present in high concentrations inside the cell (e.g., cysteine and methionine-rich proteins, glutathione, metallothionein, and albumin [226230]) and high nephrotoxicity due to interaction with renal thiol enzymes [231, 232].

Since palladium is known to bind strongly to DNA [233], and in view of its significantly resemblance to $\mathrm{Pt}(\mathrm{II})$ as to its structural and coordination behaviour, research has been pursued on the development of compounds having one or more $\mathrm{Pd}(\mathrm{II})$ centres as an alternative to $\mathrm{Pt}(\mathrm{II})[77,87,88,93$, 96, 97, 165, 168-170, 174, 175, 177-180, 234-248]. Careful design of palladium complexes may allow targeting strategies which will hopefully lead to different profiles of drug activity and to lack of cross-resistance as compared with platinumbased agents. Adverse effects, namely, nephrotoxicity, were found to be reduced when substituting $\mathrm{Pt}(\mathrm{II})$ by $\mathrm{Pd}(\mathrm{II})$ and using strongly coordinating ligands such as polyamines, which are hardly displaced by sulfhydryl groups from key proteins for kidney function [249, 250].

The main reason for having neglected palladium compounds in the search for new metal-based antitumor agents up to about three decades has been their high liability regarding ligand exchange $\left(\mathrm{Pd}(\mathrm{II})\right.$ complexes are $c a \cdot 10^{5}$ times more labile than their $\mathrm{Pt}(\mathrm{II})$ counterparts), as well as their ability to form predominantly trans isomers. Actually, a low antitumoral capacity has long been attributed to $\mathrm{Pd}(\mathrm{II})$ complexes due to the rapid hydrolysis of their leaving groups (e.g., $\mathrm{Cl}^{-}$) in aqueous solution, yielding highly reactive species unable to reach their pharmacological target. Such features were in opposition to the commonly established structure-activity relationships (SARs) based on platinum cytostatics. However, the growing progress in anticancer chemotherapy has showed that these early SAR rules are not obeyed by numerous active platinum compounds. Furthermore, although it is generally accepted that the mode of action of $\mathrm{Pd}(\mathrm{II})$ complexes as cytotoxic agents is similar to that described for their structural Pt(II) analogues, it is unlikely that structure-activity relationships based on the latter can successfully be extended to Pd(II) systems, due to their difference in relative reactivity [251, 252].

The much higher liability of $\mathrm{Pd}(\mathrm{II})$ complexes as compared to their $\mathrm{Pt}$ (II) counterparts-namely the fast hydrolysis of the leaving groups (e.g., $\mathrm{Cl}$ ) in physiological medium and the rapid cis $\rightarrow$ trans isomerisation kinetics-is a drawback to their use as pharmaceutical agents, due to a possible deactivation by reaction with biomolecules other than DNA and to a lower stability of the corresponding drugDNA adducts. Accordingly, the development of an efficient $\mathrm{Pd}(\mathrm{II})$ antitumor drug involves particular requisites: stabilisation by a strongly coordinated ligand (e.g., Ncontaining donor), coupled to a careful choice of leaving group(s) (reasonably nonlabile), in order to ensure the in vivo structural integrity of the compound for a long enough period to enable it to perform its therapeutic action. 
Hence, $\mathrm{Pd}(\mathrm{II})$ chelates with linear polyamines deserve special attention, since, similarly to their Pt(II) counterparts, they are expected to couple a quite high stability (both kinetic and thermodynamic, due to chelation) to significant antitumor properties in view of the possibility of formation of nonconventional interactions with DNA. In fact, as a soft metal ion $\mathrm{Pd}(\mathrm{II})$ yields stable coordination compounds with nitrogen-containing ligands (preferred over oxygen), namely, with polydentate aliphatic amines [93, 95, 97, 252256] (Table 2). Particular care should be taken in choosing these chelating ligands, since their chemical characteristics have been shown to influence the stability and the selfassembly properties of the corresponding $\mathrm{Pd}(\mathrm{II})$ complexes (e.g., formation of oligomeric species) [97, 257]. Actually, it has been observed that the square-planar geometry typical of $\mathrm{Pd}(\mathrm{II})$ coordination compounds is slightly distorted according to the nature of the ligands. When these bear only ethylenic chains, the N-Pd-N bond angles within the complex are significantly smaller than the ideal value $\left(90^{\circ}\right)$, while replacement by longer chains (such as propylene) leads to more regular square coordination arrangements around the metal centre (with less steric hindrance), accompanied by a higher thermodynamic stability.

Among the $\mathrm{Pd}(\mathrm{II})$ coordination compounds with $\mathrm{N}$ chelating amines, polynuclear $\mathrm{Pd}(\mathrm{II})$ agents with polyamines comprising $\mathrm{N}_{2}$ and $\mathrm{N}_{3}$ donor sets have been prepared with a view to enforce an effective coordination template around the ion and reported to display significant cytotoxicity, often coupled to a clear selectivity (Table 2). Chelates with the biogenic amines spermidine (triamine) and spermine (tetramine) were newly synthetized and assessed as to their antitumor properties by Navarro-Ranninger and coworkers [169-171, 258, 259], some of them having yielded lower ID $_{50}$ (inhibition dose 50) values when compared to cisplatin [169, 170]. More recently, their effect on several human cancer cell lines has been further evaluated $[165,168,175,180]$ and related to their conformational preferences at physiological conditions $[174,178,179,260,261]$. These cationic polynuclear $\mathrm{Pd}(\mathrm{II})$ chelates comprise two or three cisplatin-like moieties linked by variable length aliphatic polyamines, in analogy to previously reported $\mathrm{Pt}(\mathrm{II})$ compounds [15, 81, 84$86,90-97,159,165,169,170,185-199,201,202,234,240-$ $246,262-280]$. The DNA adducts yielded by these complexes were found to be nondirectional and mainly interstand (both short and long range). Similarly to their $\mathrm{Pt}(\mathrm{II})$ homologues, the presence of more than one metal centre is expected to enhance conformational changes in the double helix, and consequently the agent's antitumor activity, since the repair mechanisms are likely to be less efficient. Although they have shown to be promising agents both in vitro and in vivo, when compared to many platinum-based anticancer drugs, none of these compounds has yet entered clinical trials.

Aiming at overcoming cis $\rightarrow$ trans isomerisation around the metal ion, the presence of bidentate amines has been an almost constant feature of new Pd(II) agents [90, 94, 240, 281-284]. Various chelating nonleaving groups have been evaluated, from amine neutral ligands such as ethylenediamine $[262,285,286]$ and diaminocyclohexane (DACH)
[240] to alkylaminophosphine oxides [274], mercaptoimidazoles, and pyridine and pyrimidine derivatives [275, $276,287]$. Several strategies have therefore been attempted to imposing a lower liability to palladium(II) complexes, from the use of polydentate amines, for example, ethylenediamine $[93,95], \mathrm{NH}_{3}$ and diaminocyclohexane [288], or tetradentate phenanthroline-type $\mathrm{N}_{4}$ ligands [289] to the combination of two distinct molecular sub units around a metal centre, for example, a diamine and a pyridine derivative [282] or tridentate NNS ligands [267]. As to the leaving groups, two chlorides, a nitrato or a chelating dicarboxylate moiety have yielded good results.

In order to modulate activity and toxicity, new strategies are under study, such as the development of mixed Pd(II) and $\mathrm{Pt}(\mathrm{II})$ compounds, namely, heteronuclear [PtPdPt] and [PdPtPd] complexes with diamine bridging linkers of the type $\left.\mathrm{H}_{2} \mathrm{~N}\left(\mathrm{CH}_{2}\right)_{n} \mathrm{NH}_{2}\right)_{2}(n=4,5,6$ or 7$)$ [253-255] (Table 2).

\section{The Structural Factor}

4.1. Structure-Activity Relationships. The biological activity of a compound does not rely solely on its chemical properties, being strongly dependent on its structure and conformational preferences. The numerous studies performed to this date on platinum and palladium compounds evidence a clear relationship between antineoplastic activity and structure/conformational preferences, being recognised that a simple chemical modification may drastically affect the drug's absorption and reactivity profile: solubility, pharmacokinetic behaviour, molecule's lipophilic versus hydrophilic character, acid-base equilibrium, biodistribution and intracellular activation kinetics, cellular uptake, DNA-binding properties, relative amount of intrastrand versus interstrand cross-links and degree of long-range interactions, and metabolising reactions possibly inducing toxicity and therefore limiting the clinical usefulness of the new drug (adsorption, distribution, metabolization, excretion, and toxicity behavior, ADMET).

Hence, a rational design of such metal-based drugs can only be accomplished in the light of accurate structural information, at physiological conditions, allowing to understand the biological behaviour of these systems at a molecular level. A thorough conformational analysis must therefore be carried out, for both the complexes and their DNA adducts, in order to establish the highly sensitive structure-activity relationships that underlie and control the drug's properties and function (pharmacokinetic and pharmacodynamic profiles). In addition, the design of new platinum and palladium drugs may envisage to functionalise DNA-binding modes, in order to achieve selectivity as well as enhanced cytotoxic ability (effective interaction with the target) coupled to a low toxicity (minimised interplay with other biomolecules) and a decreased acquired resistance (optimal bioavailability, maximum nonrepairable damaging effect).

Therefore, suitable analytical techniques are required for an accurate preclinical screening of new therapeutic candidates, aiming at the rapid assessment of their safety and efficiency. Upon cellular uptake of $\mathrm{Pt}(\mathrm{II}) / \mathrm{Pt}(\mathrm{IV})$ or Pd(II) complexes and metabolization [290], interaction with 
TABLE 2: Palladium polyamine complexes developed as anticancer agents.

\begin{tabular}{|c|c|c|c|}
\hline Compound & Number of metal centres & Successful in vitro screening (cell line) & Work \\
\hline $\begin{array}{l}{ }^{\mathrm{a}} \mathrm{Pd}(\mathrm{en})(\mathrm{XO})_{3} \\
\left(\mathrm{X}=\mathrm{SeO}_{3}{ }^{2-} \text { or } \mathrm{TeO}_{3}{ }^{2-}\right)\end{array}$ & 1 & $\begin{array}{l}\text { Murine lymphocytic leukemia } \\
\text { P-388 }\end{array}$ & {$[281]$} \\
\hline${ }^{\mathrm{b}} \mathrm{Pd}(\mathrm{Spd}) \mathrm{Cl}_{2}$ & 1 & $\begin{array}{l}\text { Human breast cancer } \\
\text { MDA-MB } 468\end{array}$ & [169] \\
\hline${ }^{\mathrm{b}} \mathrm{Pd}_{3}(\mathrm{Spd}) \mathrm{Cl}_{6}$ & 3 & $\begin{array}{l}\text { Human breast cancer } \\
\text { MDA-MB } 468\end{array}$ & {$[169]$} \\
\hline${ }^{\mathrm{b}} \mathrm{Pd}_{2}\left(\mathrm{Put}_{2}\right) \mathrm{Cl}_{4}$ & 2 & $\begin{array}{l}\text { Human breast cancer/leukemia } \\
\text { MDA-MB 468/HL-60 }\end{array}$ & {$[170]$} \\
\hline${ }^{\mathrm{b}} \mathrm{Pd}(\mathrm{Spm}) \mathrm{Cl}_{2}$ & 1 & $\begin{array}{l}\text { Human breast cancer/leukemia } \\
\text { MDA-MB 468/HL-60 }\end{array}$ & {$[170]$} \\
\hline${ }^{\mathrm{b}} \mathrm{Pd}_{2}(\mathrm{Spm}) \mathrm{Cl}_{4}$ & 2 & $\begin{array}{l}\text { Human breast cancer/leukemia } \\
\text { MDA-MB 468/HL-60 }\end{array}$ & {$[170]$} \\
\hline $\begin{array}{l}{ }^{\mathrm{c}}[\mathrm{Pd}(\mathrm{en}) \mathrm{Cl}]_{2}(\mathrm{~L}) \\
(\mathrm{L}=\text { bpse or bpsu) }\end{array}$ & 2 & $\begin{array}{l}\text { Human ileocecal adenocarcinoma } \\
\text { HCT-8 }\end{array}$ & {$[95]$} \\
\hline${ }^{\mathrm{c}} \mathrm{Pd}(\mathrm{en})(\mathrm{pyr}) \mathrm{Cl}$ & 1 & $\begin{array}{l}\text { Human leukemia } \\
\text { HL-60 }\end{array}$ & {$[93]$} \\
\hline $\mathrm{Pd}\left[\left(\mathrm{H}_{2} \mathrm{~N}\left(\mathrm{CH}_{2}\right)_{3} \mathrm{NH}\left(\mathrm{CH}_{2}\right)_{3} \mathrm{NH}_{2}\right)\right] \mathrm{Cl}$ & 1 & - & {$[258]$} \\
\hline $\mathrm{Pd}(\mathrm{Spd}) \mathrm{Cl}$ & 1 & - & {$[258]$} \\
\hline $\mathrm{Pd}(\mathrm{Spd}) \mathrm{Cl}_{2}$ & 1 & - & {$[258]$} \\
\hline $\mathrm{Pd}_{2}(\mathrm{Spm}) \mathrm{Cl}_{4}$ & 2 & - & {$[258]$} \\
\hline $\begin{array}{l}{\left[\text { trans }-\mathrm{PtCl}\left(\mathrm{NH}_{3}\right)_{2}\right]\left[\mu-\left(\mathrm{H}_{2} \mathrm{~N}\left(\mathrm{CH}_{2}\right)_{6} \mathrm{NH}_{2}\right)\right]} \\
{\left[\text { trans }-\mathrm{PdCl}\left(\mathrm{NH}_{3}\right)_{2}\right]}\end{array}$ & 2 & $\begin{array}{c}\text { Human ovarian cancer } \\
\mathrm{A} 2780,{ }^{\mathrm{d}} \mathrm{A} 2780^{\text {cisR }} \text {, and }{ }^{\mathrm{d}} \mathrm{A} 2780^{\mathrm{ZD} 0473 R}\end{array}$ & {$[253]$} \\
\hline $\begin{array}{l}{\left[\text { trans }-\mathrm{PtCl}\left(\mathrm{NH}_{3}\right)_{2}\right]_{2}\left[\mu \text {-trans- } \mathrm{Pd}\left(\mathrm{NH}_{3}\right)_{2}-\right.} \\
\left.\left.-\left(\mathrm{H}_{2} \mathrm{~N}\left(\mathrm{CH}_{2}\right)_{n} \mathrm{NH}_{2}\right)_{2}\right)_{2}\right](n=4-7)\end{array}$ & 3 & $\begin{array}{c}\text { Human ovarian cancer } \\
\mathrm{A} 2780, \mathrm{~A} 2780^{\mathrm{cisR}} \text {, and A2780 }\end{array}$ & {$[254]$} \\
\hline $\begin{array}{l}{\left[\text { trans- } \mathrm{PtCl}\left(\mathrm{NH}_{3}\right)\right]_{2}\left[\mu \text {-trans- } \mathrm{Pd}\left(\mathrm{NH}_{3}\right)-\right.} \\
\left.-(2 \text {-hydroxypyridine })-\left(\mathrm{H}_{2} \mathrm{~N}\left(\mathrm{CH}_{2}\right)_{6} \mathrm{NH}_{2}\right)_{2}\right]\end{array}$ & 3 & $\begin{array}{c}\text { Human ovarian cancer } \\
\mathrm{A} 2780, \mathrm{~A} 2780^{\mathrm{cisR}} \text {, and A2780 }\end{array}$ & [255] \\
\hline${ }^{\mathrm{e}} \mathrm{Pd}(\operatorname{dien})(1-\mathrm{MeCyt})$ & 1 & - & {$[97]$} \\
\hline${ }^{\mathrm{e}} \mathrm{Pd}($ dien $)(9-\mathrm{EtGH})$ & 1 & - & {$[97]$} \\
\hline $\mathrm{Pd}_{3}\left(\mathrm{Spd}_{2}\right) \mathrm{Cl}_{6}$ & 3 & $\begin{array}{l}\text { Human tongue epithelioma } \\
\text { HSC-3 }\end{array}$ & {$[165]$} \\
\hline $\mathrm{Pd}_{2}(\mathrm{Spm}) \mathrm{Cl}_{4}$ & 2 & $\begin{array}{l}\text { Human tongue epithelioma } \\
\text { HSC-3 }\end{array}$ & {$[168]$} \\
\hline $\mathrm{Pd}_{2}(\mathrm{Spm}) \mathrm{Cl}_{4}$ & 2 & $\begin{array}{l}\text { Human ovarian cancer } \\
\text { A2780 and A2780 }\end{array}$ & {$[175]$} \\
\hline $\mathrm{Pd}_{2}(\mathrm{Spm}) \mathrm{Cl}_{4}$ & 2 & $\begin{array}{l}\text { Human breast cancer } \\
\text { MDA-MB-231 and MCF-7 }\end{array}$ & {$[180]$} \\
\hline${ }^{\mathrm{f}} \mathrm{Pd}_{3}\left(\mathrm{NSpd}_{2}\right) \mathrm{Cl}_{6}$ & 3 & - & {$[77]$} \\
\hline${ }^{\mathrm{g}} \mathrm{Pd}_{2}(\mathrm{BENSpm}) \mathrm{Cl}_{4}$ & 2 & - & {$[77]$} \\
\hline
\end{tabular}

DNA - their recognised main biological target-is expected to occur, preferably through the adenine and guanine purine bases (via covalent binding to $\mathrm{N}_{7}$ ), causing deleterious conformational rearrangements. For polynuclear chelates, and according to their stereochemistry, bifunctional adducts involving two adjacent nucleobases or two residues of the paired DNA strands can be formed [38]. However, details of this pharmacodynamic process are scarcely known. 


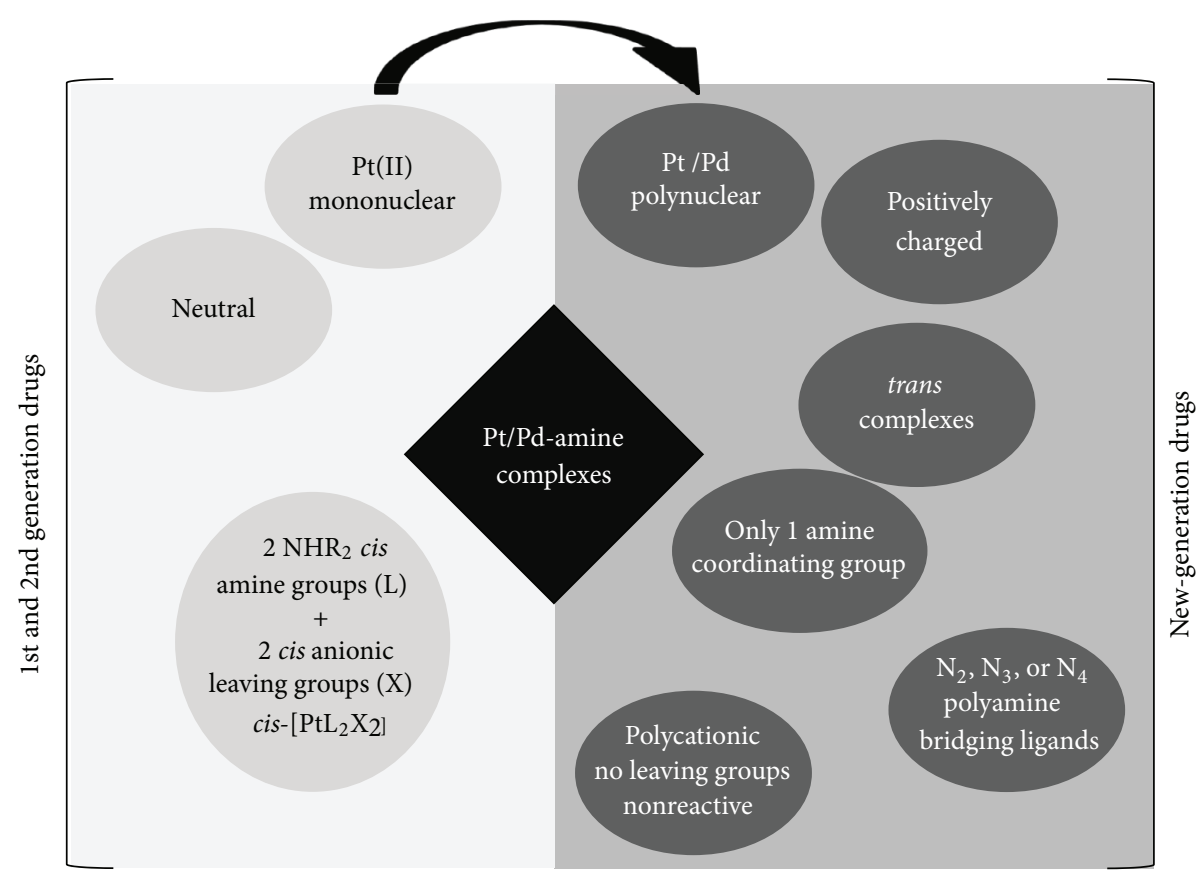

FIGURE 7: Evolution of the structure-activity relationships ruling the anticancer activity of platinum- and palladium-polyamine complexes.

Moreover, the characterisation of the adducts formed between these metallochemotherapeutics and DNA has been one of the main goals within this field, with a view to determine the most favourable structural requirements for an enhanced activity.

Consequently, and despite the high number of reported studies on platinum and palladium-based polyamine antitumor compounds, the relationship between their cytotoxicity and the nature of the ligand(s) and coordination pattern is the object of an intense research. When second-generation cisplatin-based drugs were first developed (in the 1980's), a set of empirical rules was suggested in order to guarantee cytotoxicity [291, 292]: (i) at least two cis-coordinated amino donor groups (L, each carrying one or more $\mathrm{NHR}_{2}$ residues), along with two cis anionic leaving groups (X, moderately bound)-yielding a cis- $\left[\mathrm{PtL}_{2} \mathrm{X}_{2}\right]$ configuration; (ii) zero total charge; (iii) $\mathrm{Pt}$ (II) as the metal centre. However, in the light of the current state of research, these are no longer considered as mandatory conditions for drug effectiveness, since many newly developed nonclassical platinum and palladium agents with promising anticancer activity do not conform to these early requisites [293] (Figure 7). Three striking examples of rule breakers are: (i) the numerous trans complexes which have been found to display high cytotoxic capacity, both $\mathrm{Pt}(\mathrm{II})$ [81, 195, 197, 234, 287, 294-297] and $\mathrm{Pd}(\mathrm{II})$ based, namely, trans platinum complexes with planar amine ligands (TPAs) [215, 234, 296, 298-300]; (ii) the highly positively charged noncovalent backbone binders without hydrolysable groups, such as AH44 [186, 216] or TriplatinNC [52, 163, 186, 188-191, 193, 194, 201, 202, 217, 219, 220]; (iii) numerous Pd(II) compounds, that have been verified to act as efficient anticancer drugs [247] (Table 2). Also, coordination compounds comprising only one amine ligand showed to be effective antineoplastic agents [293, 301].

Accordingly, based on the general formula, cis$\left[\mathrm{PtX}_{2}\left(\mathrm{NHR}_{2}\right)_{2}\right]$ ( $\mathrm{X}=$ leaving group; $\mathrm{R}=$ organic coordinating group), the main factors presently considered determinant for a proper ADMET profile are (Figure 8) (i) number, oxidation state and type of the metal centre(s); (ii) chain length and number of coordinating amine groups of the nonlabile ligand(s), as well as flexibility and bulkiness (e.g., type of substituents and/or degree of branching); (iii) chemical characteristics of the amine linker(s) between metal ions (e.g., length/flexibility and hydrogen-bonding capacity); (iv) nature and relative orientation of the leaving groups; (v) type of axial groups, in $\mathrm{Pt}(\mathrm{IV})$ complexes; (vi) total charge. In polynuclear noncovalent complexes, substitution of the labile chlorides by inert $\mathrm{NH}_{3}$ or alkylamine moieties leads to an overall high positive charge and allows preassociation of the complexes to the DNA helix prior to preassociation and backbone binding via phosphate clamps.

In summary, although no systematic pattern of structureactivity relationships is yet to be found, there are some activity-determinant geometrical and conformational parameters that should be considered in an amine-type ligand when designing novel metal-based antineoplastic agents (Figure 8), since they rule the effectiveness of the interplay between the resulting complex and its pharmacological target (DNA).

4.2. Vibrational Spectroscopy Studies. A rational drug design strategy demands the preclinical screening of new candidates, for the assessment of their efficiency and safety. Regarding $\mathrm{Pt}(\mathrm{II})$ and $\mathrm{Pd}(\mathrm{II})$-polyamine complexes, upon cellular 


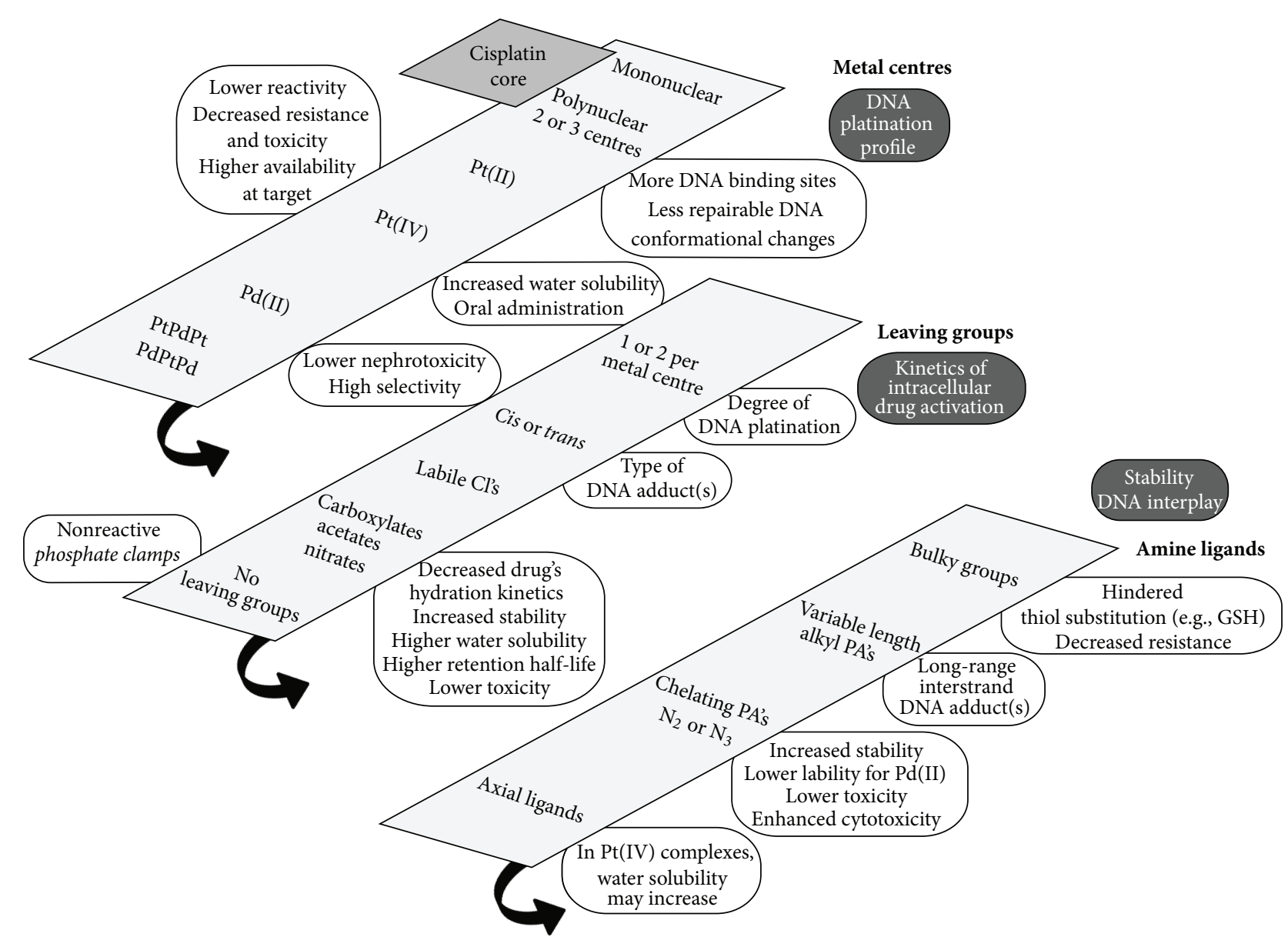

FIGURE 8: Main structural features of platinum and palladium polyamine anticancer agents. (PA polyamine; GSH-reduced glutathione).

uptake, drug activation via hydrolysis and interaction with DNA are expected to occur (covalent binding at the $\mathrm{N}_{7}$ of guanine and adenine), causing deleterious conformational rearrangements and thus preventing DNA transcription and replication. Although details of these pharmacokinetic and pharmacodynamic processes are still not completely understood, they are known to be greatly determined by the compounds' structural and conformational preferences under physiological conditions. Consequently, previous knowledge of these characteristics is essential to accurately predict the biological behaviour of the newly designed agents.

Although it is preferable, wherever possible, to determine structural parameters directly, via diffraction techniques, the lack of good quality crystals for this kind of inorganic compounds often hinders this approach. Actually, both platinum and palladium amine complexes are very sensitive to preparative conditions and several forms are often stabilised in the powders produced (polymorphism), such that single crystals are not easily obtained. Indeed, structural defects are typically found in this broad class of inorganic systems, which leads to failure of conventional diffraction techniques. The only crystal structures reported for Pt(II) drugs presently in clinical practice are those for cisplatin [302] and carboplatin $[303,304]$. However, conventional diffraction methods cannot yield the hydrogen atom positions, which is a major drawback for interpreting biochemical mechanisms, that frequently rely on H-bond type close contacts.

Under these circumstances, spectroscopy offers numerous advantages, especially when modern $a b$ initio quantum mechanical calculations can be exploited in order to predict the spectra of putative structures. Vibrational spectroscopic techniques, in particular, are particularly suited to this type of studies, since they yield unique fingerprint data for each investigated compound, comprising detailed and reliable structural evidence, based on the analysis of the vibrational modes associated with each chemical group within the molecule. Access to the complete range of vibrational spectroscopy techniques-infrared (FTIR, Fourier transform infrared), Raman, and Inelastic neutron scattering (INS) - allow to record and analyse the full vibrational profile of the systems under study. Moreover, the combined use of dedicated state-of-the-art theoretical approaches (e.g., quantum mechanical calculations) leads to an accurate interpretation of the spectroscopic data, yielding the precise conformational profile of a compound, including the intraand intermolecular network of interactions (e.g., H-bonding) responsible for its structural preferences at physiological conditions $[77,174,260,261,305]$. Also, not only the free 
metal-based agent can be studied, but also its DNA adducts, under different $\mathrm{pH}$ and temperature conditions (mimicking the physiological media at distinct organs and tissues of interest) $[179,306-310]$. In addition, the interplay with chosen biomolecules (e.g., glutathione, actin, human serum albumin, or hemoglobin $[311,312])$ or with membranes [313] can be investigated, as well as the drug's bioavailability (upon controlled delivery) and its effect at the subcellular level.

Raman, in particular, has been long recognised as a valuable tool in pharmaceutical and medicinal research [314317], since it is noninvasive and can be reliably applied to both in vitro and in vivo conditions (with virtually no interference from water). Additionally, it may be coupled to microscopy and attain confocality (at a very high spatial resolution, ca. $200 \mathrm{~nm}$ ), allowing the direct observation of living cells and their organelles [318-321] and the detection of the compounds in the intracellular media (drug's bioavailability and localisation) $[318,322,323]$. This capability has recently been exploited in order to determine distinct cell states such as viability, apoptosis, or necrosis [324, 325] and to differentiate normal from abnormal, drug resistant from nonresistant, or healthy from diseased cells [326-329], as well as to monitor processes as the intracellular uptake of drugcarrier systems [330], drug permeation through the human skin $[331,332]$, or cellular response to drugs (e.g., cisplatin) and stress factors [333-336]. Additionally, the combination of infrared spectroscopy and microscopy, developed during the last decade, has led to significant advances in tissue and cellular characterisation. In sum, coupling vibrational and microscopic techniques presents the advantage of allowing not only the determination of the structural characteristics of potential pharmacological agents, but also to determine their effect on living samples, either cells or tissues [332, 337, 338], both growth inhibiting in diseased (neoplastic) cells and toxic (deleterious side-effects) in healthy cells.

Inelastic neutron scattering spectroscopy, in turn, allows the observation of the low frequency vibrations of the complexes that encompass most of the modes associated with the metal (e.g., metal-ligand interactions in the free drug or metal-DNA bonds within the adducts). These are extremely difficult to observe with optical vibrational techniques (either Raman or FTIR) and are therefore usually unavailable except through INS. Furthermore, the technique is particularly well suited to the study of hydrogenous compounds, and the connection between the measured INS spectrum and that calculated by quantum mechanical techniques is quantitative and quite straightforward, enabling a reliable assignment of the experimental data and an accurate association to structural features. Hence, the combined application of the complementary FTIR, Raman, and INS spectroscopic techniques, coupled to dedicated theoretical methodologies, allows a thorough structural analysis of platinum and palladium polyamine complexes, yielding such relevant information as structure and conformational preferences, as a function of $\mathrm{pH}$, ionic strength, and temperature. When coupled to biological screening experiments, this approach connects molecular geometry to pharmacological activity, in a reliable and unequivocal manner.
The platinum drugs currently used in the clinic have been the object of conformational analysis through vibrational spectroscopy techniques and theoretical methods. Cisplatin, in particular, has been extensively studied as to its conformational preferences, mainly by infrared and Raman techniques. Three conformers have been identified-only one is stable at physiological conditions [260, 261, 339-341] - as well as two polymorphic species, $\alpha$ and $\beta$ [342]. A combined infrared, Raman, and INS study of cisplatin, in turn, has allowed the complete assignment of the vibrational features of the drug, through the observation of the whole spectral window of interest [305]. In addition, the pharmacokinetic behaviour of the drug has been investigated, namely, its intracellular hydration process which is known to be the main drug activation step [343]. Regarding the second-generation Pt(II) drugs, the most stable geometry was determined for both carboplatin [341, 344] and oxaliplatin [345], as well as their ligand exchange kinetics (at physiological conditions).

Many cisplatin-like complexes, both $\mathrm{Pt}(\mathrm{II})$ and $\mathrm{Pd}(\mathrm{II})$, have been investigated as to their structural and conformational behaviour by vibrational methods coupled to theoretical approaches-quantum mechanical calculations, mostly at the Density Functional Theory (DFT) level [174, 181, 260, 261, 305, 314, 346] (Table 3). Among these, di- and trinuclear platinum and palladium chelates with linear (including biogenic) amines [178, 181] and their modified homologues [77] were studied, leading to a better understanding of their interaction with DNA [179]. Apart from the structural analysis of the metal-based agent, the entities resulting from its interplay either with the target (DNA bases, mainly guanine and adenine) [179, 306-310] or with other biomolecules [311-313] are essential, and once more vibrational spectroscopy is the technique of choice for attaining a thorough conformational picture of these adducts. Raman is especially useful, as it allows the study under physiological conditions, that is, considering an aqueous medium at defined temperature, $\mathrm{pH}$, and ionic strength values.

Apart from vibrational methods, techniques such as EXAFS (extended X-ray absorption fine structure) spectroscopy are also very suitable for a thorough characterisation of metal-based potential drugs, since they are capable of yielding detailed information on the local atomic structure around the metal centre in this kind of inorganic noncrystalline materials [347-349]: either in the complexes, in their DNA adducts (where the hydrolysable ligands are substituted by one or more nitrogens from the purine bases) or in molecular associations with other biomolecules (such as glutathione) that may be involved in parallel reactions with the drug. State-of-the-art techniques such as synchrotron radiation-EXAFS greatly increases the quality of the results, due to the high brightness of the synchrotron radiation sources as compared to conventional ones-several orders of magnitude brighter than X-ray tubes-ensuring quick (as short as several milliseconds) EXAFS-spectrum measurement for very low densities of an element [350].

When combined with cytotoxicity screening assays, these spectroscopic studies aim at gathering reliable data on the SARs ruling the antineoplastic properties of cisplatin-like 
TABLE 3: Vibrational spectroscopy studies (coupled to theoretical calculations) on platinum and palladium complexes with amine ligands, developed as anticancer agents.

\begin{tabular}{|c|c|c|}
\hline Compound & ${ }^{\mathrm{g}}$ Technique & Work \\
\hline Cisplatin & $\begin{array}{c}\text { DFT calc. } \\
\text { Raman, FTIR }\end{array}$ & {$[260]$} \\
\hline Cisplatin & DFT/ECP calc. & {$[261]$} \\
\hline Cisplatin & DFT/ECP calc. & [339] \\
\hline Cisplatin & DFT/ECP calc. & {$[340]$} \\
\hline Cisplatin, carboplatin & $\begin{array}{c}\text { DFT/ECP calc } \\
\text { Raman }\end{array}$ & [341] \\
\hline Cisplatin, carboplatin & $\begin{array}{l}\text { DFT/ECP, PW calc } \\
\text { INS, Raman, FTIR }\end{array}$ & [305] \\
\hline Carboplatin & $\begin{array}{c}\text { DFT/ECP calc } \\
\text { FT-Raman, FTIR }\end{array}$ & [344] \\
\hline $\mathrm{Pt}(\mathrm{II})$-diaminopropane & $\begin{array}{c}\text { DFT/ECP calc } \\
\text { Raman, FTIR, INS }\end{array}$ & [181] \\
\hline cis-Pt(II)-diamine-orotato & $\begin{array}{c}\text { DFT/ECP calc } \\
\text { FT-Raman, FTIR }\end{array}$ & [346] \\
\hline${ }^{\mathrm{a}} \mathrm{Pd}_{3} \mathrm{Spd}_{2}$ & $\begin{array}{c}\text { AFM } \\
\text { voltammetry }\end{array}$ & {$[178]$} \\
\hline${ }^{\mathrm{b}} \mathrm{Pd}_{2} \mathrm{Spm}$ & $\begin{array}{c}\text { AFM } \\
\text { voltammetry }\end{array}$ & {$[178]$} \\
\hline${ }^{\mathrm{c}} \mathrm{Pt}_{3}\left(\mathrm{NSpd}_{2}\right) \mathrm{Cl}_{6}$ & Raman, FTIR & {$[77]$} \\
\hline${ }^{\mathrm{d}} \mathrm{Pt}_{2}(\mathrm{CPENSpm}) \mathrm{Cl}_{4}$ & Raman, FTIR & {$[77]$} \\
\hline $\mathrm{Pd}_{3}\left(\mathrm{NSpd}_{2}\right) \mathrm{Cl}_{6}$ & Raman, FTIR & {$[77]$} \\
\hline${ }^{\mathrm{e}} \mathrm{Pd}_{2}(\mathrm{BENSpm}) \mathrm{Cl}_{4}$ & Raman, FTIR & {$[77]$} \\
\hline Cisplatin-nucleotide adducts & Resonance Raman & {$[306]$} \\
\hline Cisplatin-DNA adducts & Raman & [309] \\
\hline Cisplatin-DNA adducts & SERS & {$[310]$} \\
\hline Cisplatin-guanine adducts & $\begin{array}{l}\text { DFT/ECP calc } \\
\text { SERS }\end{array}$ & {$[307,308]$} \\
\hline Carboplatin-guanine adducts & $\begin{array}{c}\text { Raman, SERS } \\
\text { DFT calc }\end{array}$ & [307] \\
\hline Carboplatin-nucleotide adducts & Resonance Raman & {$[306]$} \\
\hline${ }^{\mathrm{f}}$ Oxaliplatin-HSA interaction & FTIR & {$[312]$} \\
\hline $\mathrm{Pd}_{3} \mathrm{Spd}_{2}$-DNA adducts & $\begin{array}{c}\text { AFM } \\
\text { voltammetry }\end{array}$ & [179] \\
\hline $\mathrm{Pd}_{2} \mathrm{Spm}$-DNA adducts & $\begin{array}{c}\text { AFM } \\
\text { voltammetry }\end{array}$ & {$[179]$} \\
\hline Cisplatin-membrane interaction & Pressure tuning FTIR & {$[313]$} \\
\hline Cisplatin actin & FT-Raman & {$[311]$} \\
\hline Nanotube-encapsulated cisplatin & MicroRaman & {$[356]$} \\
\hline Response to cisplatin in leukemia & MicroRaman & {$[357]$} \\
\hline Response to cisplatin in gastric cancer & Raman & {$[358]$} \\
\hline Response to cisplatin in lung cancer & MicroRaman & {$[333,335]$} \\
\hline
\end{tabular}

Spd: spermidine. ${ }^{\mathrm{b}} \mathrm{Spm}$ : spermine. ${ }^{\mathrm{c}} \mathrm{NSpd}$ : norspermidine, $\mathrm{H}_{2} \mathrm{~N}\left(\mathrm{CH}_{2}\right)_{3} \mathrm{NH}\left(\mathrm{CH}_{2}\right)_{3} \mathrm{NH}_{2}$. ${ }^{\mathrm{d}} \mathrm{CPENSpm}: \mathrm{N}_{1}$-cyclopropyl-methyl- $\mathrm{N}_{11}$-ethylnorspermine, $\left(\mathrm{CH}_{2} \mathrm{C}_{3} \mathrm{H}_{5}\right) \mathrm{HN}\left(\mathrm{CH}_{2}\right)_{3} \mathrm{NH}\left(\mathrm{CH}_{2}\right)_{3} \mathrm{NH}\left(\mathrm{CH}_{2}\right)_{3} \mathrm{NH}\left(\mathrm{CH}_{3} \mathrm{CH}_{2}\right)$. ${ }^{e}$ BENSpm: $\mathrm{N}_{1}, \mathrm{~N}_{11}$-bis (ethyl)norspermine, $\quad\left(\mathrm{CH}_{3} \mathrm{CH}_{2}\right) \mathrm{HN}\left(\mathrm{CH}_{2}\right)_{3} \mathrm{NH}\left(\mathrm{CH}_{2}\right)_{3} \mathrm{NH}\left(\mathrm{CH}_{2}\right)_{3}$ $\mathrm{NH}\left(\mathrm{CH}_{3} \mathrm{CH}_{2}\right)$. ${ }^{\mathrm{f}} \mathrm{HSA}$ : human serum albumin. ${ }^{\mathrm{g}} \mathrm{DFT}$ : density functional theory; ECP: effective core potentials; PW: plane wave; FTIR: Fourier transform infrared spectroscopy; INS: inelastic neutron scattering spectroscopy; FT-Raman: Fourier transform Raman spectroscopy; SERS: surface enhanced Raman spectroscopy; AFM: atomic force microscopy. 
complexes, allowing a tailored design of novel polynuclear $\mathrm{Pt}$ and Pd polyamine anticancer agents, displaying an improved efficiency and a diminished toxicity.

\section{Conclusions and Future Trends}

Although metallopharmaceuticals are still a minor proportion of the currently marketed drugs, the elucidation of their mechanism of action will greatly contribute to the development of improved pharmacophores, with an enhanced cytotoxic capacity, namely, towards chemotherapy-insensitive tumours, coupled to a lower toxicity and a decreased acquired resistance. In order to achieve this goal, two main factors must be explored: (i) the strict and very sensitive relationship between structure/conformation and activity; (ii) use of delivery vehicles for controlling drug release and targeting (e.g., liposome encapsulation or use of specifically designed polymers). Changes in pharmaceutical formulations for achieving a customised release lead to an improved drug stability, an enhanced in vivo bioavailability and a higher degree of DNA complexation, directly correlated to a more efficient anticancer capacity. Despite the intense efforts placed in this field for the forty years since the discovery of cisplatin, only $6 \mathrm{Pt}$ drugs have gained marketing approval, while 14 were dropped during clinical trials.

The platinum-based compounds, either in clinical use or under clinical trials, share a common chemical structure: amine carrier ligands and chloride, nitrate, or dicarboxylate leaving groups. Research has shifted from mono- to polynuclear complexes with polyamine ligands (namely, linear alkylamines), aiming at a more effective DNA platination and an increased and less-repairable damage, as well as from platinum to palladium agents. In particular, polynuclear Pt(II) or $\mathrm{Pd}(\mathrm{II})$ chelates, containing two or three cisplatin-like metal centres and variable length polyamines as bridging linkers, constitute a group of new-generation drugs of great potential clinical importance-either coordinative compounds (yielding covalent adducts with DNA) or noncovalent, electrostatic backbone binders.

At present, reliable structure-activity relationships have been established for platinum and palladium amine antineoplastic agents, which constitute a precious contribution for attaining optimised chemopharmaceuticals. These extend beyond the previously accepted structural rules, in some cases even contradicting these, and can be summarised as follows: (i) polynuclear complexes (as compared to mononuclear homologues) are capable of an enhanced association with DNA bases (thus leading to an increased damage); (ii) alkylpolyamine bridging units with a long enough chain to render considerable flexibility allow the formation of longrange interstrand adducts with DNA, as opposed to short monodentate amine ligands; (iii) noncovalent interactions with DNA, by polycationic Pt(II) or Pd(II)-polyamine complexes, may be as effective as polynuclear cisplatin-like covalent binders; (iv) chloride or oxygen-containing hydrolysable groups modulate the kinetics of intracellular drug activation (via hydrolysis); (v) Pd(II) centres are responsible for an efficient interplay with DNA, leading to a quite high cytotoxicity with diminished side effects (e.g., parallel reactions with sulphur-containing biomolecules).

In this search for structurally new platinum and palladium polyamine complexes with suitable pharmacological properties, a molecular approach has been lately applied in which the search for more effective modes of interaction with DNA is based on the study of the structural features and conformational behaviour of the compounds, which are tailored according to the desired biological role-optimisation of their interaction with the therapeutic target. This kind of rational approach for the design of nextgeneration chemotherapeutics relies on the establishment of reliable SARs, that are of the utmost relevance in order to modulate the newly developed agent's activity-optimising the pharmacophore and minimising the toxicophore. Spectroscopic techniques, particularly vibrational spectroscopy, have succeeded in establishing a reliable connection between structure and function, through an accurate conformational analysis of the potential pharmacological agents. Hence, vibrational spectroscopy is presently undergoing a real boost, with its application to medicinal chemistry and pharmacology.

In summary, the development of improved platinum and palladium-based polyamine anticancer agents relies on a target-directed tailored drug design, with an emphasis on controlled delivery, as well as on drug reprofiling, with a view to enhance and extend cytotoxic activity with minimal toxicity $[145,146,351-354]$. Such an approach depends on accurate methods for determining structural and conformational behaviour, as well as for probing interaction with biological receptors and vibrational spectroscopy (preferably combining optical and acoustic techniques) being an invaluable tool in drug design.

\section{References}

[1] G. M. Cragg, P. G. Grothaus, and D. J. Newman, "Impact of natural products on developing new anti-cancer agents," Chemical Reviews, vol. 109, no. 7, pp. 3012-3043, 2009.

[2] A. E. Pegg, "Polyamine metabolism and its importance in neoplastic growth and as a target for chemotherapy," Cancer Research, vol. 48, no. 4, pp. 759-774, 1988.

[3] H. Köpf and P. Köpf-Maier, "Titanocene dichloride-the first metallocene with cancerostatic activity," Angewandte Chemie, vol. 18, no. 6, pp. 477-478, 1979.

[4] T. Rau and R. van Eldik, Metal Ions in Biological Systems, New York, NY, USA, 1996.

[5] C. Orvig and M. J. Abrams, "Medicinal inorganic chemistry: introduction," Chemical Reviews, vol. 99, no. 9, pp. 2202-2203, 1999.

[6] C. S. Allardyce, A. Dorcier, C. Scolaro, and P. J. Dyson, "Development of organometallic (organo-transition metal) pharmaceuticals," Applied Organometallic Chemistry, vol. 19, no. 1, pp. 1-10, 2005.

[7] P. J. Dyson and G. Sava, "Metal-based antitumour drugs in the post genomic era," Dalton Transactions, no. 16, pp. 1929-1933, 2006.

[8] K. B. Garbutcheon-Singh, M. P. Grant, B. W. Harper et al., "Transition metal based anticancer drugs," Current Topics in Medicinal Chemistry, vol. 11, no. 5, pp. 521-542, 2011. 
[9] S. Gomez-Ruiz, D. Maksimovic-Ivanic, S. Mijatovic, and G. N. Kaluderovic, "On the discovery, biological effects, and use of cisplatin and metallocenes in anticancer chemotherapy," Bioinorganic Chemistry and Applications, vol. 2012, Article ID 140284, 14 pages, 2012.

[10] M. Gielen, Metal Based Antitumor Drugs, Freud, London, UK, 1988.

[11] N. Farrell, Uses of Inorganic Chemistry in Medicine, Royal Society of Chemistry, Cambridge, UK, 1999.

[12] S. P. Fricker, "Metal based drugs: from serendipity to design," Dalton Transactions, no. 43, pp. 4903-4917, 2007.

[13] M. J. Hannon, "Metal-based anticancer drugs: from a past anchored in platinum chemistry to a post-genomic future of diverse chemistry and biology," Pure and Applied Chemistry, vol. 79, no. 12, pp. 2243-2261, 2007.

[14] S. H. van Rijt and P. J. Sadler, "Current applications and future potential for bioinorganic chemistry in the development of anticancer drugs," Drug Discovery Today, vol. 14, no. 23-24, pp. 1089-1097, 2009.

[15] N. Farrell, "Polynuclear platinum drugs," in Metal Complexes in Tumor Diagnosis and as Anticancer Agents, pp. 251-296, 2004.

[16] M. Galanski, V. B. Arion, M. A. Jakupec, and B. K. Keppler, "Recent developments in the field of tumor-inhibiting metal complexes," Current Pharmaceutical Design, vol. 9, no. 25, pp. 2078-2089, 2003.

[17] B. Rosenberg, L. Vancamp, and T. Krigas, "Inhibition of cell division in Escherichia coli by electrolysis products from a platinum electrode," Nature, vol. 205, no. 4972, pp. 698-699, 1965.

[18] B. Rosenberg, L. Vancamp, J. E. Trosko, and V. H. Mansour, "Platinum compounds: a new class of potent antitumour agents," Nature, vol. 222, no. 5191, pp. 385-386, 1969.

[19] B. Rosenberg and L. VanCamp, "The successful regression of large solid sarcoma 180 tumors by platinum compounds," Cancer Research, vol. 30, no. 6, pp. 1799-1802, 1970.

[20] M. Shimizu and B. Rosenberg, "A similar action to UV irradiation and a preferential inhibition of DNA synthesis in E. coli by antitumor platinum compounds," Journal of Antibiotics, vol. 26, no. 4, pp. 243-245, 1973.

[21] B. Rosenberg, "Platinum complexes for the treatment of cancer: why the search goes on?" in CisplatIn, pp. 1-27, Verlag Helvetica Chimica Acta, 1999.

[22] O. Heby and L. Persson, "Molecular genetics of polyamine synthesis in eukaryotic cells," Trends in Biochemical Sciences, vol. 15, no. 4, pp. 153-158, 1990.

[23] A. Tamori, S. Nishiguchi, T. Kuroki et al., "Point mutation of ornithine decarboxylase gene in human hepatocellular carcinoma," Cancer Research, vol. 55, no. 16, pp. 3500-3503, 1995.

[24] M. Auvinen, A. Paasinen, L. C. Andersson, and E. Holtta, "Ornithine decarboxylase activity is critical for cell transformation," Nature, vol. 360, no. 6402, pp. 355-358, 1992.

[25] J. Janne, L. Alhonen, and P. Leinonen, "Polyamines: from molecular biology to clinical applications," Annals of Medicine, vol. 23, no. 3, pp. 241-259, 1991.

[26] K. Nishioka, Polyamines in Cancer: Basic Mechanisms and Clinical Approaches, Springer, Berlin, Germany, 1966.

[27] A. Bonetti, T. Franceschi, P. Apostoli et al., "Cisplatin pharmacokinetics using a five-day schedule during repeated courses of chemotherapy in germ cell tumors," Therapeutic Drug Monitoring, vol. 17, no. 1, pp. 25-32, 1995.
[28] M. Lehman and G. Thomas, "Is concurrent chemotherapy and radiotherapy the new standard of care for locally advanced cervical cancer?" International Journal of Gynecological Cancer, vol. 11, no. 2, pp. 87-99, 2001.

[29] P. J. Loehrer and L. H. Einhorn, "Drugs 5 years later-cisplatin," Annals of Internal Medicine, vol. 100, no. 5, pp. 704-713, 1984.

[30] R. F. Ozols, "Current status of chemotherapy for ovarian cancer," Seminars in Oncology, vol. 22, no. 5, pp. 61-66, 1995.

[31] A. L. Pinto and S. J. Lippard, "Binding of the antitumor drug cisdiamminedichloroplatinum(II) (cisplatin) to DNA," Biochimica et Biophysica Acta, vol. 780, no. 3, pp. 167-180, 1985.

[32] J. L. Vanderveer and J. Reedijk, "Investigating antitumour drug mechanisms," Chemistry in Britain, vol. 24, no. 8, pp. 775-780, 1988.

[33] N. P. Johnson, J.-L. Butour, G. Villani et al., "Metal antitumor compounds: the mechanism of action of platinum complexes," Progress in Clinical Biochemistry and Medicine, vol. 10, pp. 1-24, 1989.

[34] P. M. Takahara, C. A. Frederick, and S. J. Lippard, "Crystal structure of the anticancer drug cisplatin bound to duplex DNA," Journal of the American Chemical Society, vol. 118, no. 49, pp. 12309-12321, 1996.

[35] T. W. Hambley, "Platinum binding to DNA: structural controls and consequences," Journal of the Chemical Society, Dalton Transactions, no. 19, pp. 2711-2718, 2001.

[36] R. N. Bose, "Biomolecular targets for platinum antitumor drugs," Mini Reviews in Medicinal Chemistry, vol. 2, no. 2, pp. 103-111, 2002.

[37] J. Reedijk, "New clues for platinum antitumor chemistry: kinetically controlled metal binding to DNA," Proceedings of the National Academy of Sciences of the United States of America, vol. 100, no. 7, pp. 3611-3616, 2003.

[38] D. Wang and S. J. Lippard, "Cellular processing of platinum anticancer drugs," Nature Reviews Drug Discovery, vol. 4, no. 4, pp. 307-320, 2005.

[39] Y. Jung and S. J. Lippard, "Direct cellular responses to platinuminduced DNA damage," Chemical Reviews, vol. 107, no. 5, pp. 1387-1407, 2007.

[40] A. M. Pizarro and P. J. Sadler, "Unusual DNA binding modes for metal anticancer complexes," Biochimie, vol. 91, no. 10, pp. 1198-1211, 2009.

[41] Y. P. Ho, S. C. F. Au-Yeung, and K. K. W. To, "Platinum-based anticancer agents: innovative design strategies and biological perspectives," Medicinal Research Reviews, vol. 23, no. 5, pp. 633-655, 2003.

[42] J. T. Hartmann and H. P. Lipp, "Toxicity of platinum compounds," Expert Opinion on Pharmacotherapy, vol. 4, no. 6, pp. 889-901, 2003.

[43] S. Raguz and E. Yagüe, "Resistance to chemotherapy: new treatments and novel insights into an old problem," British Journal of Cancer, vol. 99, no. 3, pp. 387-391, 2008.

[44] X. Yao, K. Panichpisal, N. Kurtzman, and K. Nugent, "Cisplatin nephrotoxicity: a review," The American Journal of the Medical Sciences, vol. 334, no. 2, pp. 115-124, 2007.

[45] A. M. Florea and D. Büsselberg, "Cisplatin as an anti-tumor drug: cellular mechanisms of activity, drug resistance and induced side effects," Cancers, vol. 3, no. 1, pp. 1351-1371, 2011.

[46] T. Boulikas and M. Vougiouka, "Cisplatin and platinum drugs at the molecular level," Oncology reports, vol. 10, no. 6, pp. 1663-1682, 2003. 
[47] G. Momekov and D. Momekova, "Recent developments in antitumor platinum coordination compounds," Expert Opinion on Therapeutic Patents, vol. 16, no. 10, pp. 1383-1403, 2006.

[48] L. Kelland, "The resurgence of platinum-based cancer chemotherapy," Nature Reviews Cancer, vol. 7, no. 8, pp. 573-584, 2007.

[49] N. J. Wheate, S. Walker, G. E. Craig, and R. Oun, "The status of platinum anticancer drugs in the clinic and in clinical trials," Dalton Transactions, vol. 39, no. 35, pp. 8113-8127, 2010.

[50] X. Wang, "Fresh platinum complexes with promising antitumor activity," Anti-Cancer Agents in Medicinal Chemistry, vol. 10, no. 5, pp. 396-411, 2010.

[51] U. Olszewski and G. Hamilton, "A better platinum-based anticancer drug yet to come?" Anti-Cancer Agents in Medicinal Chemistry, vol. 10, no. 4, pp. 293-301, 2010.

[52] S. Komeda, T. Moulaei, M. Chikuma et al., "The phosphate clamp: a small and independent motif for nucleic acid backbone recognition," Nucleic Acids Research, vol. 39, no. 1, pp. 325-336, 2011.

[53] C. Monneret, "Platinum anticancer drugs. From serendipity to rational design," Annales Pharmaceutiques Françaises, vol. 69, no. 6, pp. 286-295, 2011.

[54] P. C. Bruijnincx and P. J. Sadler, "New trends for metal complexes with anticancer activity," Current Opinion in Chemical Biology, vol. 12, no. 2, pp. 197-206, 2008.

[55] S. San-Marina, R. Gupta, and I. Iosif, "Computational strategies for drug reprofiling," Journal of Proteomics and Bioinformatics, vol. 4, no. 11, pp. 242-244, 2011.

[56] R. B. Weiss and M. C. Christian, "New cisplatin analogues in development: a review," Drugs, vol. 46, no. 3, pp. 360-377, 1993.

[57] I. Ott and R. Gust, "Preclinical and clinical studies on the use of platinum complexes for breast cancer treatment," Anti-Cancer Agents in Medicinal Chemistry, vol. 7, no. 1, pp. 95-110, 2007.

[58] R. Williams, "Discontinued drugs in 2010: oncology drugs," Expert Opinion on Investigational Drugs, vol. 20, no. 11, pp. 1479-1496, 2011.

[59] S. A. S. Ghazanfar, J. T. Edsall, and D. V. Myers, "Raman spectra of diamines and diammonium ions: effects of ionization on carbon-hydrogen stretching frequencies," Journal of the American Chemical Society, vol. 86, no. 4, pp. 559-564, 1964.

[60] A. Bertoluzza, C. Fagnano, P. Finelli, M. A. Morelli, R. Simoni, and R. Tosi, "Raman and infrared-spectra of spermidine and spermine and their hydrochlorides and phosphates as a basis for the study of the interactions between polyamines and nucleic-acids," Journal of Raman Spectroscopy, vol. 14, no. 6, pp. 386-394, 1983.

[61] L. A. E. Batista de Carvalho, A. M. Amorim da Costa, M. L. Duarte, and J. J. C. Teixeira-Dias, "Conformational studies of n-propylamine by combined $a b$ initio $\mathrm{MO}$ calculations and Raman spectroscopy," Spectrochimica Acta Part A: Molecular Spectroscopy, vol. 44, no. 7, pp. 723-732, 1988.

[62] L. A. E. Batista de Carvalho, A. M. Amorim da Costa, and J. J. C. Teixeira-Dias, "A comparative $a b$ initio MO study of internal rotations in ethylamine and n-propylamine," Journal of Molecular Structure: THEOCHEM, vol. 205, no. C, pp. 327-351, 1990.

[63] L. A. E. Batista de Carvalho, J. J. C. Teixeira-Dias, and R. Fausto, "A molecular mechanics force field for conformational analysis of aliphatic acyclic amines," Structural Chemistry, vol. 1, no. 6, pp. 533-542, 1990.
[64] L. A. E. Batista de Carvalho, L. E. Lourenço, and M. P. M. Marques, "Conformational study of 1,2-diaminoethane by combined ab initio MO calculations and Raman spectroscopy," Journal of Molecular Structure, vol. 482-483, pp. 639-646, 1999.

[65] M. P. M. Marques and L. A. E. Batista de Carvalho, "Theoretical approach to the conformational preferences of putrescine," in Cost 917: Biogenically Active Amines in Food, pp. 122-129, European Communities, Luxembourg, 2000.

[66] M. P. M. Marques, L. A. E. Batista de Carvalho, and J. Tomkinson, "Study of biogenic and $\alpha, \omega$-polyamines by combined inelastic neutron scattering and Raman spectroscopies and by ab initio molecular orbital calculations," The Journal of Physical Chemistry A, vol. 106, no. 11, pp. 2473-2482, 2002.

[67] A. M. Amorim da Costa, M. P. M. Marques, and L. A. E. Batista de Carvalho, "The carbon-hydrogen stretching region of the Raman spectra of 1,6-hexanediamine: N-deuteration, ionisation and temperature effects," Vibrational Spectroscopy, vol. 29, no. 1-2, pp. 61-67, 2002.

[68] A. M. Amorim da Costa, M. P. M. Marques, and L. A. E. Batista de Carvalho, "Raman spectra of putrescine, spermidine and spermine polyamines and their $\mathrm{N}$-deuterated and $\mathrm{N}$-ionized derivatives," Journal of Raman Spectroscopy, vol. 34, no. 5, pp. 357-366, 2003.

[69] A. M. Amorim da Costa, M. P. M. Marques, and L. A. E. Batista de Carvalho, "Intra- versus interchain interactions in $\alpha, \omega$-polyamines: a Raman spectroscopy study," Vibrational Spectroscopy, vol. 35, no. 1-2, pp. 165-171, 2004.

[70] A. M. Amado, J. C. Otero, M. P. M. Marques, and L. A. E. Batista de Carvalho, "Spectroscopic and theoretical studies on solid 1,2-ethylenediamine dihydrochloride salt," ChemPhysChem, vol. 5, no. 12, pp. 1837-1847, 2004.

[71] L. A. E. Batista de Carvalho, M. P. M. Marques, and J. Tomkinson, "Transverse acoustic modes of biogenic and $\alpha, \omega$ polyamines: a study by inelastic neutron scattering and raman spectroscopies coupled to DFT calculations," The Journal of Physical Chemistry A, vol. 110, no. 47, pp. 12947-12954, 2006.

[72] M. P. M. Marques and L. A. E. Batista de Carvalho, "Vibrational spectroscopy studies on linear polyamines," Biochemical Society Transactions, vol. 35, no. 2, pp. 374-380, 2007.

[73] E. W. Gerner and F. L. Meyskens, "Polyamines and cancer: old molecules, new understanding," Nature Reviews Cancer, vol. 4, no. 10, pp. 781-792, 2004.

[74] E. Agostinelli, M. P. M. Marques, R. Calheiros et al., "Polyamines: fundamental characters in chemistry and biology," Amino Acids, vol. 38, no. 2, pp. 393-403, 2010.

[75] C. W. Porter, R. J. Bernacki, J. Miller, and R. J. Bergeron, "Antitumor activity of N1,N11-bis(ethyl)norspermine against human melanoma xenografts and possible biochemical correlates of drug action," Cancer Research, vol. 53, no. 3, pp. 581-586, 1993.

[76] R. A. Casero and P. M. Woster, "Recent advances in the development of polyamine analogues as antitumor agents," Journal of Medicinal Chemistry, vol. 52, no. 15, pp. 4551-4573, 2009.

[77] T. M. Silva, S. Oredsson, L. Persson, P. Woster, and M. P. Marques, "Novel $\mathrm{Pt}(\mathrm{II})$ and $\mathrm{Pd}(\mathrm{II})$ complexes with polyamine analogues: synthesis and vibrational analysis," Journal of Inorganic Biochemistry, vol. 108, pp. 1-7, 2012.

[78] N. Seiler, "Thirty years of polyamine-related approaches to cancer therapy. Retrospect and prospect. Part 2. Structural analogues and derivatives," Current Drug Targets, vol. 4, no. 7, pp. 565-585, 2003. 
[79] N. P. Farrell, S. G. de Almeida, and K. A. Skov, "Bis(platinum) complexes containing two platinum cis-diammine units. Synthesis and initial DNA-binding studies," Journal of the American Chemical Society, vol. 110, no. 15, pp. 5018-5019, 1988.

[80] N. Farrell, Y. Qu, L. Feng, and B. van Houten, "Comparison of chemical reactivity, cytotoxicity, interstrand cross-linking and DNA sequence specificity of bis(platinum) complexes containing monodentate or bidentate coordination spheres with their monomeric analogues," Biochemistry, vol. 29, no. 41, pp. 9522-9531, 1990.

[81] N. Farrell, "Nonclassical platinum antitumor agents: perspectives for design and development of new drugs complementary to cisplatin," Cancer Investigation, vol. 11, no. 5, pp. 578-589, 1993.

[82] H. Rauter, R. Di Domenico, E. Mental, A. Oliva, Y. Qu, and N. Farrell, "Selective platination of biologically relevant polyamines. Linear coordinating spermidine and spermine as amplifying linkers in dinuclear platinum complexes," Inorganic Chemistry, vol. 36, no. 18, pp. 3919-3927, 1997.

[83] N. Farrell, "DNA binding of nonclassical platinum antitumor complexes," in Advances in DNA Sequence-Specific Agents, pp. 179-199, Elsevier, Philadelphia, Pa, USA, 1998.

[84] V. Brabec, J. Kašpárková, O. Vrána et al., "DNA modifications by a novel bifunctional trinuclear platinum Phase I anticancer agent," Biochemistry, vol. 38, no. 21, pp. 6781-6790, 1999.

[85] N. Farrell, "Polynuclear charged platinum compounds as a new class of anticancer agents. Toward a new paradigm," in Platinum-Based Drugs in Cancer Therapy, Human Press, Totowa, NJ, USA, 2000.

[86] C. Manzotti, G. Pratesi, E. Menta et al., "BBR 3464: a novel triplatinum complex, exhibiting a preclinical profile of antitumor efficacy different from cisplatin," Clinical Cancer Research, vol. 6, no. 7, pp. 2626-2634, 2000.

[87] A. S. Abu-Surrah and M. Kettunen, "Platinum group antitumor chemistry: design and development of new anticancer drugs complementary to cisplatin," Current Medicinal Chemistry, vol. 13, no. 11, pp. 1337-1357, 2006.

[88] A. S. Abu-Surrah, H. H. Al-Sa'doni, and M. Y. Abdalla, "Palladium-based chemotherapeutic agents: routes toward complexes with good antitumor activity," Cancer Therapy, vol. 6, pp. 1-10, 2008.

[89] A. Hegmans, S. J. Berners-Price, M. S. Davies, D. S. Thomas, A. S. Humphreys, and N. Farrell, "Long range 1,4 and 1,6interstrand cross-links formed by a trinuclear platinum complex. Minor groove preassociation affects kinetics and mechanism of cross-link formation as well as adduct structure," Journal of the American Chemical Society, vol. 126, no. 7, pp. 2166-2180, 2004.

[90] M. L. González, J. M. Tercero, A. Matilla et al., "Cisdichloro $(\alpha, \omega$-diamino carboxylate ethyl ester)palladium(II) as palladium(II) versus platinum(II) model anticancer drugs: synthesis, solution equilibria of their aqua, hydroxo, and/or chloro species, and in vitro/in vivo DNA-binding properties," Inorganic Chemistry, vol. 36, no. 9, pp. 1806-1812, 1997.

[91] B. B. Zmejkovski, G. N. Kaluderović, S. Gómez-Ruiz et al., "Palladium(II) complexes with R2edda-derived ligands. Part II. Synthesis, characterization and in vitro antitumoral studies of R2eddip esters and palladium(II) complexes," European Journal of Medicinal Chemistry, vol. 44, no. 9, pp. 3452-3458, 2009.

[92] J. M. Vujić, M. Cvijović, G. N. Kaluerović et al., "Palladium(II) complexes with R2edda derived ligands. Part IV. O, O'-dialkyl esters of (S,S)-ethylenediamine- $N, N^{\prime}$-di-2-(4-methyl)- pentanoic acid dihydrochloride and their palladium(II) complexes: synthesis, characterization and in vitro antitumoral activity against chronic lymphocytic leukemia (CLL) cells," European Journal of Medicinal Chemistry, vol. 45, no. 9, pp. 3601-3606, 2010.

[93] G. Zhao, H. Lin, P. Yu et al., "Ethylenediamine-palladium(II) complexes with pyridine and its derivatives: synthesis, molecular structure and initial antitumor studies," Journal of Inorganic Biochemistry, vol. 73, no. 3, pp. 145-149, 1999.

[94] N. Jain, R. Mittal, T. S. Srivastava, K. Satyamoorthy, and M. P. Chitnis, "Synthesis, characterization, DNA binding, and cytotoxic studies of dinuclear complexes of palladium(II) and platinum(II) with 2,2-bipyridine and $\alpha, \omega$-diaminoalkane$N, N^{\prime}$-diacetic acid," Journal of Inorganic Biochemistry, vol. 53, no. 2, pp. 79-94, 1994.

[95] G. Zhao, H. Lin, S. Zhu, H. Sun, and Y. Chen, "Dinuclear palladium(II) complexes containing two monofunctional $[\mathrm{Pd}(\mathrm{en})$ (pyridine) $\mathrm{Cl}]+$ units bridged by Se or S. Synthesis, characterization, cytotoxicity and kinetic studies of DNA-binding," Journal of Inorganic Biochemistry, vol. 70, no. 3-4, pp. 219-226, 1998.

[96] G. Faraglia, D. Fregona, S. Sitran et al., "Platinum(II) and palladium(II) complexes with dithiocarbamates and amines: synthesis, characterization and cell assay," Journal of Inorganic Biochemistry, vol. 83, no. 1, pp. 31-40, 2001.

[97] A. I. Anzellotti, M. Sabat, and N. Farrell, "Covalent and noncovalent interactions for [metal(dien)nucleobase] $2+$ complexes with L-tryptophan derivatives: formation of palladiumtryptophan species by nucleobase substitution under biologically relevant conditions," Inorganic Chemistry, vol. 45, no. 4, pp. 1638-1645, 2006.

[98] I. Kostova, "Platinum complexes as anticancer agents," Recent Patents on Anti-Cancer Drug Discovery, vol. 1, no. 1, pp. 1-22, 2006.

[99] N. P. Farrell, "Platinum formulations as anticancer drugs clinical and pre-clinical studies," Current Topics in Medicinal Chemistry, vol. 11, no. 21, pp. 2623-2631, 2011.

[100] S. Ahmad, A. A. Isab, and S. Ali, "Structural and mechanistic aspects of platinum anticancer agents," Transition Metal Chemistry, vol. 31, no. 8, pp. 1003-1016, 2006.

[101] J. E. Rosenberg, V. K. Weinberg, W. K. Kelly et al., "Activity of second-line chemotherapy in docetaxel-refractory hormonerefractory prostate cancer patients: randomized phase 2 study of ixabepilone or mitoxantrone and prednisone," Cancer, vol. 110, no. 3, pp. 556-563, 2007.

[102] S. Komeda, "Unique platinum-DNA interactions may lead to more effective platinum-based antitumor drugs," Metallomics, vol. 3, no. 7, pp. 650-655, 2011.

[103] M. M. Regan, E. K. O’Donnell, W. K. Kelly et al., "Efficacy of carboplatin-taxane combinations in the management of castration-resistant prostate cancer: a pooled analysis of seven prospective clinical trials," Annals of Oncology, vol. 21, no. 2, pp. 312-318, 2010.

[104] S. S. Hah, K. M. Stivers, R. W. de Vere White, and P. T. Henderson, "Kinetics of carboplatin-DNA binding in genomic DNA and bladder cancer cells as determined by accelerator mass spectrometry," Chemical Research in Toxicology, vol. 19, no. 5, pp. 622-626, 2006.

[105] Y. Kidani, K. Inagaki, R. Saito, and S. Tsukagoshi, "Synthesis and anti tumor activities of platinum (II) complexes of 1,2 
diaminocyclohexane isomers and their related derivatives," Journal of Clinical Hematology and Oncology, vol. 7, no. 1, pp. 197-209, 1977.

[106] Y. Kidani, M. Noji, and T. Tashiro, "Antitumor activity of platinum(II) complexes of 1,2-diamino-cyclohexane isomers," Gann, vol. 71, no. 5, pp. 637-643, 1980.

[107] E. Raymond, S. Faivre, S. Chaney, J. Woynarowski, and E. Cvitkovic, "Cellular and molecular pharmacology of oxaliplatin," Molecular Cancer Therapeutics, vol. 1, no. 3, pp. 227-235, 2002.

[108] B. Spingler, D. A. Whittington, and S. J. Lippard, " $2.4 \AA$ crystal structure of an oxaliplatin 1,2-d(GpG) intrastrand Cross-link in a DNA dodecamer duplex," Inorganic Chemistry, vol. 40, no. 22, pp. 5596-5602, 2001.

[109] T. A. K. Al-Allaf, L. J. Rashan, D. Steinborn, K. Merzweiler, and C. Wagner, "Platinum(II) and palladium(II) complexes analogous to oxaliplatin with different cyclohexyldicarboxylate isomeric anions and their in vitro antitumour activity. Structural elucidation of $\left[\mathrm{Pt}\left(\mathrm{C}_{2} \mathrm{O}_{4}\right)(\mathrm{cis}-\mathrm{dach})\right]$," Transition Metal Chemistry, vol. 28, no. 6, pp. 717-721, 2003.

[110] M. Galanski, A. Yasemi, S. Slaby et al., "Synthesis, crystal structure and cytotoxicity of new oxaliplatin analogues indicating that improvement of anticancer activity is still possible," European Journal of Medicinal Chemistry, vol. 39, no. 8, pp. 707-714, 2004.

[111] M. Noji, R. Kizu, Y. Takeda et al., "Preparation of antitumor oxaliplatin/cisplatin docking dinuclear platinum complex," Biomedicine \& Pharmacotherapy, vol. 59, no. 5, pp. 224-229, 2005.

[112] A. Bhargava and U. N. Vaishampayan, "Satraplatin: leading the new generation of oral platinum agents," Expert Opinion on Investigational Drugs, vol. 18, no. 11, pp. 1787-1797, 2009.

[113] L. R. Kelland, "An update on satraplatin: the first orally available platinum anticancer drug," Expert Opinion on Investigational Drugs, vol. 9, no. 6, pp. 1373-1382, 2000.

[114] L. Kelland, "Broadening the clinical use of platinum drug-based chemotherapy with new analogues: satraplatin and picoplatin," Expert Opinion on Investigational Drugs, vol. 16, no. 7, pp. 1009-1021, 2007.

[115] H. Choy, C. Park, and M. Yao, "Current status and future prospects for satraplatin, an oral platinum analogue," Clinical Cancer Research, vol. 14, no. 6, pp. 1633-1638, 2008.

[116] E. Fokkema, H. J. M. Groen, M. N. Helder, E. G. E. de Vries, and C. Meijer, "JM216-, JM118-, and cisplatin-induced cytotoxicity in relation to platinum-DNA adduct formation, glutathione levels and p53 status in human tumour cell lines with different sensitivities to cisplatin," Biochemical Pharmacology, vol. 63, no. 11, pp. 1989-1996, 2002.

[117] C. Sessa, C. Minoia, A. Ronchi et al., "Phase I clinical and pharmacokinetic study of the oral platinum analogue JM216 given daily for 14 days," Annals of Oncology, vol. 9, no. 12, pp. 1315-1322, 1998.

[118] M. Kalimutho, A. Minutolo, S. Grelli et al., "Satraplatin (JM216) mediates G2/M cell cycle arrest and potentiates apoptosis via multiple death pathways in colorectal cancer cells thus overcoming platinum chemo-resistance," Cancer Chemotherapy and Pharmacology, vol. 67, no. 6, pp. 1299-1312, 2011.

[119] G. Samimi and S. B. Howell, "Modulation of the cellular pharmacology of JM118, the major metabolite of satraplatin, by copper influx and efflux transporters," Cancer Chemotherapy and Pharmacology, vol. 57, no. 6, pp. 781-788, 2006.
[120] C. N. Sternberg, D. P. Petrylak, O. Sartor et al., "Multinational, double-blind, phase III study of prednisone and either satraplatin or placebo in patients with castrate-refractory prostate cancer progressing after prior chemotherapy: the SPARC trial," Journal of Clinical Oncology, vol. 27, no. 32, pp. 5431-5438, 2009.

[121] D. P. Petrylak, O. Sartor, J. Witjes et al., "A phase iii, randomized, double-blind trial of satraplatin and prednisone vs placebo and prednisone for patients with hormone refractory prostate cancer (HRPC)," in Proceedings of Prostate Cancer Symposium, 2007.

[122] J. Holford, F. Raynaud, B. A. Murrer et al., "Chemical, biochemical and pharmacological activity of the novel sterically hindered platinum co-ordination complex, cis-[amminedichloro(2-methylpyridine)] platinum(II) (AMD473)," AntiCancer Drug Design, vol. 13, no. 1, pp. 1-18, 1998.

[123] P. Beale, I. Judson, A. O’Donnell et al., “A phase I clinical and pharmacological study of cis-diamminedichloro(2methylpyridine) platinum II (AMD473)," British Journal of Cancer, vol. 88, no. 7, pp. 1128-1134, 2003.

[124] A. R. Battle, R. Choi, D. E. Hibbs, and T. W. Hambley, "Platinum(IV) analogues of AMD473 (cis- $\left[\mathrm{PtCl}_{2}\left(\mathrm{NH}_{3}\right)(2-\right.$ picoline)]): preparative, structural, and electrochemical studies," Inorganic Chemistry, vol. 45, no. 16, pp. 6317-6322, 2006.

[125] Y. Chen, Z. J. Guo, S. Parsons, and P. J. Sadler, "Stereospecific and kinetic control over the hydrolysis of a sterically hindered platinum picoline anticancer complex," Chemistry, vol. 4, no. 4, pp. 672-676, 1998.

[126] J. Holford, S. Y. Sharp, B. A. Murrer, M. Abrams, and L. R. Kelland, "In vitro circumvention of cisplatin resistance by the novel sterically hindered platinum complex AMD473," British Journal of Cancer, vol. 77, no. 3, pp. 366-373, 1998.

[127] K. A. Gelmon, D. Stewart, K. N. Chi et al., "A phase I study of AMD473 and docetaxel given once every 3 weeks in patients with advanced refractory cancer: a national cancer institute of Canada-clinical trials group trial, IND 131," Annals of Oncology, vol. 15, no. 7, pp. 1115-1122, 2004.

[128] S. Y. Sharp, C. F. O’Neill, P. Rogers, F. E. Boxall, and L. R. Kelland, "Retention of activity by the new generation platinum agent AMD0473 in four human tumour cell lines possessing acquired resistance to oxaliplatin," European Journal of Cancer, vol. 38, no. 17, pp. 2309-2315, 2002.

[129] C. T. Research, "Poniard pharmaceuticals announces final topline results from phase 1 trial demonstrating positive bioavailability with oral picoplatin," in Oncology Business Week, 2008.

[130] P. Sood, K. Bruce Thurmond 2nd, J. E. Jacob et al., "Synthesis and characterization of AP5346, a novel polymer-linked diaminocyclohexyl platinum chemotherapeutic agent," Bioconjugate Chemistry, vol. 17, no. 5, pp. 1270-1279, 2006.

[131] S. B. Howell, "The design and development of the tumortargeting nanopolymer dach platinum conjugate ap5346," in PlatInum and Other Heavy Metal Compounds in Cancer Chemotherapy, pp. 33-39, Humana Press, Totowa, NJ, USA, 2009.

[132] J. R. Rice, J. L. Gerberich, D. P. Nowotnik, and S. B. Howell, "Preclinical efficacy and pharmacokinetics of AP5346, a novel diaminocyclohexane-platinum tumor-targeting drug delivery system," Clinical Cancer Research, vol. 12, no. 7, pp. 2248-2254, 2006.

[133] D. P. Nowotnik and E. Cvitkovic, "Prolindac ${ }^{T M}$ (AP5346): a review of the development of an HPMA DACH platinum 
polymer therapeutic," Advanced Drug Delivery Reviews, vol. 61, no. 13, pp. 1214-1219, 2009.

[134] D. P. Nowotnik, "AP5346 (ProLindac), a dach platinum polymer conjugate in Phase II trials against ovarian cancer," Current Bioactive Compounds, vol. 7, no. 1, pp. 21-26, 2011.

[135] M. Campone, J. M. Rademaker-Lakhai, J. Bennouna et al., "Phase I and pharmacokinetic trial of AP5346, a DACHplatinum-polymer conjugate, administered weekly for three out of every 4 weeks to advanced solid tumor patients," Cancer Chemotherapy and Pharmacology, vol. 60, no. 4, pp. 523-533, 2007.

[136] G. P. Stathopoulos, T. Boulikas, M. Vougiouka et al., "Pharmacokinetics and adverse reactions of a new liposomal cisplatin (Lipoplatin): phase I study," Oncology Reports, vol. 13, no. 4, pp. 589-595, 2005.

[137] D. B. Fenske and P. R. Cullis, "Liposomal nanomedicines," Expert Opinion on Drug Delivery, vol. 5, no. 1, pp. 25-44, 2008.

[138] S. Bryde and A. I. P. M. de Kroon, "Nanocapsules of platinum anticancer drugs: development towards therapeutic use," Future Medicinal Chemistry, vol. 1, no. 8, pp. 1467-1480, 2009.

[139] M. I. Koukourakis, A. Giatromanolaki, M. Pitiakoudis et al., "Concurrent liposomal cisplatin (Lipoplatin), 5-fluorouracil and radiotherapy for the treatment of locally advanced gastric cancer: a phase I/II study," International Journal of Radiation Oncology Biology Physics, vol. 78, no. 1, pp. 150-155, 2010.

[140] N. Seetharamu, E. Kim, H. Hochster, F. Martin, and F. Muggia, "Phase II study of liposomal cisplatin (SPI-77) in platinumsensitive recurrences of ovarian cancer," Anticancer Research, vol. 30, no. 2, pp. 541-545, 2010.

[141] G. P. Stathopoulos, T. Boulikas, A. Kourvetaris, and J. Stathopoulos, "Liposomal oxaliplatin in the treatment of advanced cancer: a phase I study," Anticancer Research, vol. 26, no. 2 B, pp. 1489-1493, 2006.

[142] T. Tippayamontri, R. Kotb, B. Paquette, and L. Sanche, "Cellular uptake and cytoplasm / DNA distribution of cisplatin and oxaliplatin and their liposomal formulation in human colorectal cancer cell HCT116," Investigational New Drugs, vol. 29, no. 6, pp. 1321-1327, 2011.

[143] G. Charest, L. Sanche, D. Fortin, D. Mathieu, and B. Paquette, "Glioblastoma treatment: bypassing the toxicity of platinum compounds by using liposomal formulation and increasing treatment efficiency with concomitant radiotherapy," International Journal of Radiation Oncology Biology Physics, vol. 84, no. 1, pp. 244-249, 2012.

[144] I. Ali, Rahis-Uddin, K. Salim, M. A. Rather, W. A. Wani, and A. Haque, "Advances in nano drugs for cancer chemotherapy," Current Cancer Drug Targets, vol. 11, no. 2, pp. 135-146, 2011.

[145] S. Qian, C. Li, and Z. Zuo, "Pharmacokinetics and disposition of various drug loaded liposomes," Current Drug Metabolism, vol. 13, no. 4, pp. 372-395, 2012.

[146] S. P. Sahane, A. K. Nikhar, S. Bhaskaran, and D. R. Mundhada, "Nanotechnology in cancer chemotherapy," International Journal of Pharmacy and Technology, vol. 4, no. 2, pp. 2085-2099, 2012.

[147] T. Boulikas, "Low toxicity and anticancer activity of a novel liposomal cisplatin (lipoplatin) in mouse xenografts," Oncology Reports, vol. 12, no. 1, pp. 3-12, 2004.

[148] T. Boulikas, "Molecular mechanisms of cisplatin and its liposomally encapsulated form, lipoplatin ${ }^{\mathrm{TM}}$. lipoplatin $^{\mathrm{TM}}$ as a chemotherapy and antiangiogenesis drug," Cancer Therapy, vol. 5, pp. 351-376, 2007.
[149] T. Boulikas, G. P. Stathopoulos, N. Volakakis, and M. Vougiouka, "Systemic lipoplatin infusion results in preferential tumor uptake in human studies," Anticancer Research, vol. 25, no. 4, pp. 3031-3040, 2005.

[150] C. M. Lee, T. Tanaka, T. Murai et al., "Novel chondroitin sulfatebinding cationic liposomes loaded with cisplatin efficiently suppress the local growth and liver metastasis of tumor cells in vivo," Cancer Research, vol. 62, no. 15, pp. 4282-4288, 2002.

[151] P. Devarajan, R. Tarabishi, J. Mishra et al., "Low renal toxicity of lipoplatin compared to cisplatin in animals," Anticancer Research, vol. 24, no. 4, pp. 2193-2200, 2004.

[152] C. Arienti, A. Tesei, A. Ravaioli et al., "Activity of lipoplatin in tumor and in normal cells in vitro," Anti-Cancer Drugs, vol. 19, no. 10, pp. 983-990, 2008.

[153] T. Boulikas, "Clinical overview on lipoplatin ${ }^{\text {TM }}$ : a successful liposomal formulation of cisplatin," Expert Opinion on Investigational Drugs, vol. 18, no. 8, pp. 1197-1218, 2009.

[154] G. P. Stathopoulos, D. Antoniou, J. Dimitroulis, J. Stathopoulos, K. Marosis, and P. Michalopoulou, "Comparison of liposomal cisplatin versus cisplatin in non-squamous cell non-small-cell lung cancer," Cancer Chemotherapy and Pharmacology, vol. 68, no. 4, pp. 945-950, 2011.

[155] N. J. Wheate and J. G. Collins, "Multi-nuclear platinum complexes as anti-cancer drugs," Coordination Chemistry Reviews, vol. 241, no. 1-2, pp. 133-145, 2003.

[156] N. J. Wheate and J. G. Collins, "Multi-nuclear platinum drugs: a new paradigm in chemotherapy," Current Medicinal Chemistry-Anti-Cancer Agents, vol. 5, no. 3, pp. 267-279, 2005.

[157] J. B. Mangrum and N. P. Farrell, "Excursions in polynuclear platinum DNA binding," Chemical Communications, vol. 46, no. 36, pp. 6640-6650, 2010.

[158] R. A. Ruhayel, J. S. Langner, M. J. Oke, S. J. Berners-Price, I. Zgani, and N. P. Farrell, "Chimeric platinum-polyamines and DNA binding. Kinetics of DNA interstrand cross-link formation by dinuclear platinum complexes with polyamine linkers," Journal of the American Chemical Society, vol. 134, no. 16, pp. 7135-7146, 2012.

[159] Y. Qu, N. J. Scarsdale, M. C. Tran, and N. P. Farrell, "Cooperative effects in long-range 1,4 DNA-DNA interstrand cross-links formed by polynuclear platinum complexes: an unexpected syn orientation of adenine bases outside the binding sites," Journal of Biological Inorganic Chemistry, vol. 8, no. 1-2, pp. 19-28, 2003.

[160] K. Chvalova, J. Kasparkova, N. Farrell, and V. Brabec, "Deoxyribonuclease I footprinting reveals different DNA binding modes of bifunctional platinum complexes," The FEBS Journal, vol. 273, no. 15 , pp. 3467-3478, 2006.

[161] E. Monti, M. Gariboldi, A. Maiocchi et al., "Cytotoxicity of cisplatinum(II) conjugate models. The effect of chelating arms and leaving groups on cytotoxicity: a quantitative structure-activity relationship approach," Journal of Medicinal Chemistry, vol. 48, no. 3, pp. 857-866, 2005.

[162] M. R. Costa Couri, M. Vieira de Almeida, A. P. Soares Fontes et al., "Synthesis of polyamines from ethylenediamine and their platinum(II) complexes, potential antitumor agents," European Journal of Inorganic Chemistry, no. 9, pp. 1868-1874, 2006.

[163] Q. Liu, Y. Qu, R. van Antwerpen, and N. Farrell, "Mechanism of the membrane interaction of polynuclear platinum anticancer agents. Implications for cellular uptake," Biochemistry, vol. 45, no. 13, pp. 4248-4256, 2006.

[164] J. W. Williams, Y. Qu, G. H. Bulluss, E. Alvorado, and N. P. Farrell, "Dinuclear platinum complexes with biological relevance 
based on the 1,2-diaminocyclohexane carrier ligand," Inorganic Chemistry, vol. 46, no. 15, pp. 5820-5822, 2007.

[165] S. M. Fiuza, A. M. Amado, P. J. Oliveira, V. A. Sardão, L. A. E. Batista de Carvalho, and M. P. M. Marques, "Pt(II) vs Pd(II) polyamine complexes as new anticancer drugs: a structureactivity study," Letters in Drug Design and Discovery, vol. 3, no. 3, pp. 149-151, 2006.

[166] L. J. Teixeira, M. Seabra, E. Reis et al., "Cytotoxic activity of metal complexes of biogenic polyamines: polynuclear platinum(II) chelates," Journal of Medicinal Chemistry, vol. 47, no. 11, pp. 2917-2925, 2004.

[167] M. P. M. Marques, T. Girão, M. C. Pedroso de Lima, A. Gameiro, E. Pereira, and P. Garcia, "Cytotoxic effects of metal complexes of biogenic polyamines. I. Platinum(II) spermidine compounds: prediction of their antitumour activity," Biochimica et Biophysica Acta-Molecular Cell Research, vol. 1589, no. 1, pp. 63-70, 2002.

[168] A. S. Soares, S. M. Fiuza, M. J. Gonçalves, L. A. E. Batista de Carvalho, M. P. M. Marques, and A. M. Urbano, "Effect of the metal center on the antitumor activity of the analogous dinuclear spermine chelates $\left(\mathrm{PdCl}_{2}\right)_{(2)}($ Spermine $)$ and $\left(\mathrm{PtCl}_{2}\right)_{(2)}($ Spermine)," Letters in Drug Design and Discovery, vol. 4, no. 7, pp. 460-463, 2007.

[169] C. Navarro-Ranninger, F. Zamora, J. M. Perez et al., "Palladium(II) salt and complexes of spermidine with a six-member chelate ring. Synthesis, characterization, and initial DNAbinding and antitumor studies," Journal of Inorganic Biochemistry, vol. 46, no. 4, pp. 267-279, 1992.

[170] C. Navarro-Ranninger, J. M. Perez, F. Zamora, V. M. Gonzalez, J. R. Masaguer, and C. Alonso, "Palladium(II) compounds of putrescine and spermine. Synthesis, characterization, and DNA-binding and antitumor properties," Journal of Inorganic Biochemistry, vol. 52, no. 1, pp. 37-49, 1993.

[171] C. Navarro-Ranninger, P. Amo Ochoa, J. R. Masaguer, J. M. Pérez, V. M. González, and C. Alonso, "Platinum (II) and (IV) spermidine complexes. Synthesis, characterization, and biological studies," Journal of Inorganic Biochemistry, vol. 53, no. 3, pp. 177-190, 1994.

[172] M. Navarro, N. P. Peña, I. Colmenares, T. González, M. Arsenak, and P. Taylor, "Synthesis and characterization of new palladium-clotrimazole and palladium-chloroquine complexes showing cytotoxicity for tumor cell lines in vitro," Journal of Inorganic Biochemistry, vol. 100, no. 1, pp. 152-157, 2006.

[173] A. Hegmans, J. Kasparkova, O. Vrana, L. R. Kelland, V. Brabec, and N. P. Farrell, "Amide-based prodrugs of spermidinebridged dinuclear platinum. Synthesis, DNA binding, and biological activity," Journal of Medicinal Chemistry, vol. 51, no. 7, pp. 2254-2260, 2008.

[174] S. M. Fiuza, A. M. Amado, H. F. dos Santos, M. P. M. Marques, and L. A. E. Batista de Carvalho, "Conformational and vibrational study of cis-diamminedichloropalladium(ii)," Physical Chemistry Chemical Physics, vol. 12, no. 42, pp. 14309-14321, 2010.

[175] R. Tummala, P. Diegelman, S. M. Fiuza et al., "Characterization of Pt-, Pd-spermine complexes for their effect on polyamine pathway and cisplatin resistance in A2780 ovarian carcinoma cells," Oncology Reports, vol. 24, no. 1, pp. 15-24, 2010.

[176] R. Tummala, P. Diegelman, S. Hector et al., "Combination effects of platinum drugs and N1, N11 diethylnorspermine on spermidine/spermine N1-acetyltransferase, polyamines and growth inhibition in A2780 human ovarian carcinoma cells and their oxaliplatin and cisplatin-resistant variants," Cancer
Chemotherapy and Pharmacology, vol. 67, no. 2, pp. 401-414, 2011.

[177] A. Tassoni, N. Bagni, M. Ferri et al., "Helianthus tuberosus and polyamine research: past and recent applications of a classical growth model," Plant Physiology and Biochemistry, vol. 48, no. 7, pp. 496-505, 2010.

[178] O. Corduneanu, A. M. Chiorcea-Paquim, S. M. Fiuza, M. P. M. Marques, and A. M. Oliveira-Brett, "Polynuclear palladium complexes with biogenic polyamines: AFM and voltammetric characterization," Bioelectrochemistry, vol. 78, no. 2, pp. 97-105, 2010.

[179] O. Corduneanu, A. M. Chiorcea-Paquim, V. Diculescu, S. M. Fiuza, M. P. M. Marques, and A. M. Oliveira-Brett, "DNA interaction with palladium chelates of biogenic polyamines using atomic force microscopy and voltammetric characterization," Analytical Chemistry, vol. 82, no. 4, pp. 1245-1252, 2010.

[180] S. M. Fiuza, J. Holy, L. A. E. Batista de Carvalho, and M. P. M. Marques, "Biologic activity of a dinuclear Pd(II)-spermine complex toward human breast cancer," Chemical Biology and Drug Design, vol. 77, no. 6, pp. 477-488, 2011.

[181] A. L. M. Batista de Carvalho, S. M. Fiuza, J. Tomkinson, L. A. E. Batista de Carvalho, and M. P. M. Marques, "Pt(II) complexes with linear diamines-part i: vibrational study of Ptdiaminopropane," International Journal of Spectroscopy, vol. 27, no. 5-6, pp. 403-413, 2012.

[182] E. Escribano, M. Font-Bardia, T. Calvet, J. Lorenzo, P. Gamez, and V. Moreno, "DNA binding studies of a series of cis$\left[\mathrm{Pt}(\mathrm{Am})_{2} \mathrm{X}_{2}\right]$ complexes $(\mathrm{Am}=$ inert amine, $\mathrm{X}=$ labile carboxylato ligand)," Inorganica Chimica Acta, vol. 394, pp. 65-76, 2013.

[183] U. Bierbach, T. W. Hambley, and N. Farrell, "Modification of platinum(II) antitumor complexes with sulfur ligands. 1. Synthesis, structure, and spectroscopic properties of cationic complexes of the types $\left[\mathrm{PtCl}\left(\right.\right.$ diamine) $(\mathrm{L}) \mathrm{NO}_{3}$ and $\left[\{\mathrm{PtCl}(\text { diamine })\}_{2}(\mathrm{~L}-\mathrm{L})\right]\left(\mathrm{NO}_{3}\right)_{2}(\mathrm{~L}=$ monofunctional thiourea derivative; $\mathrm{L}-\mathrm{L}=$ bifunctional thiourea derivative)," Inorganic Chemistry, vol. 37, no. 4, pp. 708-716, 1998.

[184] L. Gatti, P. Perego, R. Leone et al., "Novel bis-platinum complexes endowed with an improved pharmacological profile," Molecular Pharmaceutics, vol. 7, no. 1, pp. 207-216, 2010.

[185] P. Perego, C. Caserini, L. Gatti et al., "A novel trinuclear platinum complex overcomes cisplatin resistance an osteosarcoma cell system," Molecular Pharmacology, vol. 55, no. 3, pp. 528-534, 1999.

[186] S. Komeda, T. Moulaei, K. K. Woods, M. Chikuma, N. P. Farrell, and L. D. Williams, "A third mode of DNA binding: phosphate clamps by a polynuclear platinum complex," Journal of the American Chemical Society, vol. 128, no. 50, pp. 16092-16103, 2006.

[187] Y. Qu, A. Harris, A. Hegmans et al., "Synthesis and DNA conformational changes of non-covalent polynuclear platinum complexes," Journal of Inorganic Biochemistry, vol. 98, no. 10, pp. 1591-1598, 2004.

[188] A. Harris, Y. Qu, and N. Farrell, "Unique cooperative binding interaction observed between a minor groove binding $\mathrm{Pt}$ antitumor agent and hoeschst dye 33258," Inorganic Chemistry, vol. 44, no. 5, pp. 1196-1198, 2005.

[189] A. L. Harris, X. Yang, A. Hegmans et al., "Synthesis, characterization, and cytotoxicity of a novel highly charged trinuclear platinum compound. Enhancement of cellular uptake with charge," Inorganic Chemistry, vol. 44, no. 26, pp. 9598-9600, 2005. 
[190] G. Pratesi, P. Perego, D. Polizzi et al., "A novel charged trinuclear platinum complex effective against cisplatinresistant tumours: hypersensitivity of p53-mutant human tumour xenografts," British Journal of Cancer, vol. 80, no. 12, pp. 1912-1919, 1999.

[191] T. D. McGregor, A. Hegmans, J. Kasparkova et al., "A comparison of DNA binding profiles of dinuclear platinum compounds with polyamine linkers and the trinuclear platinum phase II clinical agent BBR3464," Journal of Biological Inorganic Chemistry, vol. 7, no. 4-5, pp. 397-404, 2002.

[192] Y. Qu and N. Farrell, "Effect of diamine linker on the chemistry of bis(platinum) complexes. A comparison of the aqueous solution behavior of 1,4-butanediamine and 2,5-dimethyl-2,5hexanediamine complexes," Journal of Inorganic Biochemistry, vol. 40, no. 3, pp. 255-264, 1990.

[193] N. Farrell, Y. Qu, J. Kasparkova et al., "Chemical studies and DNA binding of charged polynuclear platinum complexes," Proceedings of the American Association for Cancer Research, vol. 38, pp. 310-315, 1997.

[194] Y. Qu, H. Rauter, A. P. S. Fontes, R. Bandarage, L. R. Kelland, and N. Farrell, "Synthesis, characterization, and cytotoxicity of trifunctional dinuclear platinum complexes: comparison of effects of geometry and polyfunctionality on biological activity," Journal of Medicinal Chemistry, vol. 43, no. 16, pp. 3189-3192, 2000.

[195] U. Bierbach and N. Farrell, "Modulation of nucleotide binding of trans platinum(II) complexes by planar ligands. A combined proton NMR and molecular mechanics study," Inorganic Chemistry, vol. 36, no. 17, pp. 3657-3665, 1997.

[196] N. Farrell, "DNA-binding and chemistry of dinuclear platinum complexes," Comments on Inorganic Chemistry, vol. 16, no. 6, pp. 373-389, 1995.

[197] N. Farrell, "Current status of structure-activity relationships of platinum anticancer drugs: activation of the trans geometry," Metal Ions in Biological Systems, vol. 32, pp. 603-639, 1996.

[198] C. Hofr, N. Farrell, and V. Brabec, "Thermodynamic properties of duplex DNA containing a site-specific $\mathrm{d}(\mathrm{GpG})$ intrastrand crosslink formed by an antitumor dinuclear platinum complex," Nucleic Acids Research, vol. 29, no. 10, pp. 2034-2040, 2001.

[199] J. Zehnulova, J. Kasparkova, N. Farrell, and V. Brabec, "Conformation, recognition by high mobility group domain proteins, and nucleotide excision repair of DNA intrastrand cross-links of novel antitumor trinuclear platinum complex BBR3464," The Journal of Biological Chemistry, vol. 276, no. 25, pp. 22191-22199, 2001.

[200] A. Hegmans, Y. Qu, L. R. Kelland, J. D. Roberts, and N. Farrell, "Novel approaches to polynuclear platinum pro-drugs. Selective release of cytotoxic platinum-spermidine species through hydrolytic cleavage of carbamates," Inorganic Chemistry, vol. 40, no. 24, pp. 6108-6114, 2001.

[201] J. Kasparkova, J. Zehnulova, N. Farrell, and V. Brabec, "DNA interstrand cross-links of the novel antitumor trinuclear platinum complex BBR3464. Conformation, recognition by high mobility group domain proteins, and nucleotide excision repair," The Journal of Biological Chemistry, vol. 277, no. 50, pp. 48076-48086, 2002.

[202] J. Kasparkova, M. Fojta, N. Farrell, and V. Brabec, "Differential recognition by the tumor suppressor protein p53 of DNA modified by the novel antitumor trinuclear platinum drug BBR3464 and cisplatin," Nucleic Acids Research, vol. 32, no. 18, pp. 5546-5552, 2004.
[203] C. Billecke, S. Finniss, L. Tahash et al., "Polynuclear platinum anticancer drugs are more potent than cisplatin and induce cell cycle arrest in glioma," Neuro-Oncology, vol. 8, no. 3, pp. 215-226, 2006.

[204] J. Zhang, L. Wang, Z. Xing et al., "Status of Bi- and multi-nuclear platinum anticancer drug development," Anti-Cancer Agents in Medicinal Chemistry, vol. 10, no. 4, pp. 272-282, 2010.

[205] T. Muchova, S. M. Quintal, N. P. Farrell, V. Brabec, and J. Kasparkova, "Antitumor bifunctional dinuclear Pt(II) complex BBR 3535 forms interduplex DNA cross-links under molecular crowding conditions," Journal of Biological Inorganic Chemistry, vol. 17, no. 2, pp. 239-245, 2012.

[206] P. Perego, L. Gatti, C. Caserini et al., "The cellular basis of the efficacy of the trinuclear platinum complex BBR 3464 against cisplatin-resistant cells," Journal of Inorganic Biochemistry, vol. 77, no. 1-2, pp. 59-64, 1999.

[207] M. B. G. Kloster, J. C. Hannis, D. C. Muddiman, and N. Farrell, "Consequences of nucleic acid conformation on the binding of a trinuclear platinum drug," Biochemistry, vol. 38, no. 45, pp. 14731-14737, 1999.

[208] J. Kasparkova, O. Vrana, N. Farrell, and V. Brabec, "Effect of the geometry of the central coordination sphere in antitumor trinuclear platinum complexes on DNA binding," Journal of Inorganic Biochemistry, vol. 98, no. 10, pp. 1560-1569, 2004.

[209] P. Kabolizadeh, J. Ryan, and N. Farrell, "Differences in the cellular response and signaling pathways of cisplatin and BBR3464 ([\{trans-PtCl( $\left.\left.\mathrm{NH}_{3}\right)_{2}\right\}_{2} \mu$-(trans$\left.\left.\left.\mathrm{Pt}\left(\mathrm{NH}_{3}\right)_{2}\left(\mathrm{H}_{2} \mathrm{~N}\left(\mathrm{CH}_{2}\right)_{6}-\mathrm{NH}_{2}\right)_{2}\right)\right]^{4+}\right)$ influenced by copper homeostasis," Biochemical Pharmacology, vol. 73, no. 9, pp. 1270-1279, 2007.

[210] Y. Qu, M. C. Tran, and N. P. Farrell, "Structural consequences of a $3^{\prime} \rightarrow 3^{\prime}$ DNA interstrand cross-link by a trinuclear platinum complex: unique formation of two such cross-links in a 10-mer duplex," Journal of Biological Inorganic Chemistry, vol. 14, no. 6, pp. 969-977, 2009.

[211] J. Malina, N. P. Farrell, and V. Brabec, "DNA interstrand cross-links of an antitumor trinuclear platinum(II) complex: thermodynamic analysis and chemical probing," Chemistry, vol. 6, no. 6, pp. 1566-1574, 2011.

[212] J. Kjellstrom, S. M. Oredsson, and J. Wennerberg, "Increased toxicity of a trinuclear Pt-compound in a human squamous carcinoma cell line by polyamine depletion," Cancer Cell International, vol. 12, no. 20, pp. 1-9, 2012.

[213] D. I. Jodrell, T. R. J. Evans, W. Steward et al., "Phase II studies of BBR3464, a novel tri-nuclear platinum complex, in patients with gastric or gastro-oesophageal adenocarcinoma," European Journal of Cancer, vol. 40, no. 12, pp. 1872-1877, 2004.

[214] E. I. Montero, B. T. Benedetti, J. B. Mangrum, M. J. Oehlsen, Y. Qu, and N. P. Farrell, "Pre-association of polynuclear platinum anticancer agents on a protein, human serum albumin. Implications for drug design," Dalton Transactions, no. 43, pp. 4938-4942, 2007.

[215] B. T. Benedetti, E. J. Peterson, P. Kabolizadeh, A. Martínez, R. Kipping, and N. P. Farrell, "Effects of noncovalent platinum drug-protein interactions on drug efficacy: use of fluorescent conjugates as probes for drug metabolism," Molecular Pharmaceutics, vol. 8, no. 3, pp. 940-948, 2011.

[216] H. Silva, F. Frezard, E. J. Peterson, P. Kabolizadeh, J. J. Ryan, and N. P. Farrell, "Heparan sulfate proteoglycan-mediated entry pathway for charged tri-platinum compounds: differential cellular accumulation mechanisms for platinum," Molecular Pharmaceutics, vol. 9, no. 6, pp. 1795-1802, 2012. 
[217] H. Cheng, F. Huq, P. Beale, and K. Fisher, "Synthesis and activity of a trinuclear platinum complex: [\{trans$\left.\mathrm{PtCl}\left(\mathrm{NH}_{3}\right)_{2}\right\}_{2}$ mu- $\left\{\right.$ trans- $\mathrm{Pt}(3 \text {-hydroxypyridine })_{2}\left(\mathrm{H}_{2} \mathrm{~N}\left(\mathrm{CH}_{2}\right)_{6}\right.$ $\left.\left.\left.\mathrm{NH}_{2}\right)_{2}\right\}\right] \mathrm{Cl}_{4}$ in ovarian cancer cell lines," European Journal of Medicinal Chemistry, vol. 40, no. 8, pp. 772-781, 2005.

[218] A. L. Harris, J. J. Ryan, and N. Farrell, "Biological consequences of trinuclear platinum complexes: comparison of [\{trans$\left.\mathrm{PtCl}\left(\mathrm{NH}_{3}\right)_{2}\right\}_{2} \mu$-(trans-Pt $\left.\left.\left(\mathrm{NH}_{3}\right)_{2}\left(\mathrm{H}_{2} \mathrm{~N}\left(\mathrm{CH}_{2}\right)_{6}-\mathrm{NH}_{2}\right)_{2}\right)\right]^{4+}(\mathrm{BBR}$ 3464) with its noncovalent congeners," Molecular Pharmacology, vol. 69, no. 2, pp. 666-672, 2006.

[219] H. Tayyem, F. Huq, J. Q. Yu, P. Beale, and K. Fisher, "Synthesis and activity of a trinuclear platinum complex: [\{trans$\left.\mathrm{PtCl}\left(\mathrm{NH}_{3}\right)_{2}\right\}_{2} \mu$ - $\{\text { trans-Pt(3-hydroxypyrdine })_{2}\left(\mathrm{H}_{2} \mathrm{~N}\left(\mathrm{CH}_{2}\right)_{6}\right.$ $\left.\left.\left.\mathrm{NH}_{2}\right)_{2}\right\}\right] \mathrm{Cl}_{4}$ in ovarian cancer cell lines," ChemMedChem, vol. 3, no. 1, pp. 145-151, 2008.

[220] J. Malina, J. Kasparkova, N. P. Farrell, and V. Brabec, "Walking of antitumor bifunctional trinuclear PtII complex on doublehelical DNA," Nucleic Acids Research, vol. 39, no. 2, pp. 720-728, 2011.

[221] G. Pratesi, L. Dal Bo, A. Paolicchi, P. Tonarelli, R. Tongiani, and F. Zunino, "The role of the glutathione-dependent system in tumor sensitivity to cisplatin: a study of human tumor xenografts," Annals of Oncology, vol. 6, no. 3, pp. 283-289, 1995.

[222] H. H. W. Chen and M. T. Kuo, "Role of glutathione in the regulation of cisplatin resistance in cancer chemotherapy," Metal-Based Drugs, vol. 2010, Article ID 430939, 2010.

[223] S. M. Quintal, Q. A. Depaula, and N. P. Farrell, "Zinc finger proteins as templates for metal ion exchange and ligand reactivity. Chemical and biological consequences," Metallomics, vol. 3, no. 2, pp. 121-139, 2011.

[224] Q. A. Depaula, S. D. Tsotsoros, Y. Qu, C. A. Bayse, and N. P. Farrell, "Platinum-nucleobase Ptn 4 complexes as chemotypes for selective pePtide reactions with biomolecules," Inorganica Chimica Acta, vol. 393, pp. 222-229, 2012.

[225] G. B. Deacon, Platinum and Other Metal Coordination Compound in Cancer Cemotherapy, Plenum, New York, NY, USA, 1991.

[226] Q. Zhang, W. Zhong, B. Xing, W. Tang, and Y. Chen, "Binding properties and stoichiometries of a palladium(II) complex to metallothioneins in vivo and in vitro," Journal of Inorganic Biochemistry, vol. 72, no. 3-4, pp. 195-200, 1998.

[227] P. A. Andrews, M. P. Murphy, and S. B. Howell, "Differential potentiation of alkylating and platinating agent cytotoxicity in human ovarian carcinoma cells by glutathione depletion," Cancer Research, vol. 45, no. 12, part 1, pp. 6250-6253, 1985.

[228] J. K. Lau and D. V. Deubel, "Loss of amine from platinum(II) complexes: implications for cisplatin inactivation, storage, and resistance," Chemistry, vol. 11, no. 9, pp. 2849-2855, 2005.

[229] X. Wang and Z. Guo, "The role of sulfur in platinum anticancer chemotherapy," Anti-Cancer Agents in Medicinal Chemistry, vol. 7, no. 1, pp. 19-34, 2007.

[230] J. Reedijk, "Why does cisplatin reach guanine-N7 with competing S-donor ligands available in the cell?" Chemical Reviews, vol. 99, no. 9, pp. 2499-2510, 1999.

[231] L. Giovagnini, L. Ronconi, D. Aldinucci, D. Lorenzon, S. Sitran, and D. Fregona, "Synthesis, characterization, and comparative in vitro cytotoxicity studies of platinum(II), palladium(II), and gold(III) methylsarcosinedithiocarbamate complexes," Journal of Medicinal Chemistry, vol. 48, no. 5, pp. 1588-1595, 2005.

[232] S. van Zutphen, M. Kraus, C. Driessen, G. A. van der Marel, H. S. Overkleeft, and J. Reedijk, "Probing the potential of
platinum(II) complexes for the inhibition of thiol-dependent enzymatic activity," Journal of Inorganic Biochemistry, vol. 99, no. 6, pp. 1384-1389, 2005.

[233] P. Umapathy, "The chemical and biochemical consequences of the binding of the antitumour drug cisplatin and other platinum group metal complexes to DNA," Coordination Chemistry Reviews, vol. 95, no. 2, pp. 129-181, 1989.

[234] T. A. K. Al-Allaf and L. J. Rashan, "Cis- and trans- platinum and palladium complexes: a comparative study review as antitumour agents," Bollettino Chimico Farmaceutico, vol. 140, no. 3, pp. 205-210, 2001.

[235] F. Huq, H. Tayyem, A. Abdullah, P. Beale, and K. Fisher, "Synthesis and characterization and binding of amine-palladium(II) complexes and their interaction with DNA," Asian Journal of Chemistry, vol. 18, no. 1, pp. 65-78, 2006.

[236] S. Ray, R. Mohan, J. K. Singh et al., "Anticancer and antimicrobial metallopharmaceutical agents based on palladium, gold, and silver N-heterocyclic carbene complexes," Journal of the American Chemical Society, vol. 129, no. 48, pp. 15042-15053, 2007.

[237] A. Garoufis, S. K. Hadjikakou, and N. Hadjiliadis, "Palladium coordination compounds as anti-viral, anti-fungal, antimicrobial and anti-tumor agents," Coordination Chemistry Reviews, vol. 253, no. 9-10, pp. 1384-1397, 2009.

[238] E. Gao, C. Liu, M. Zhu, H. Lin, Q. Wu, and L. Liu, "Current development of pd(II) complexes as potential antitumor agents," Anti-Cancer Agents in Medicinal Chemistry, vol. 9, no. 3, pp. 356-368, 2009.

[239] A. Chevry, M. L. Teyssot, A. Maisonial et al., "Click chelators-the behavior of platinum and palladium complexes in the presence of guanosine and DNA," European Journal of Inorganic Chemistry, no. 22, pp. 3513-3519, 2010.

[240] J. L. Butour, S. Wimmer, F. Wimmer, and P. Castan, "Palladium(II) compounds with potential antitumour properties and their platinum analogues: a comparative study of the reaction of some erotic acid derivatives with DNA in vitro," ChemicoBiological Interactions, vol. 104, no. 2-3, pp. 165-178, 1997.

[241] P. Banerjee, "Interaction of nitrogen bases with some platinum(ii) and palladium(ii) complexes-usual and unusual features," Coordination Chemistry Reviews, vol. 190-192, pp. 19-28, 1999.

[242] H. Mansuri-Torshizi, S. Ghadimy, and N. Akbarzadeh, "Synthesis, characterization, DNA binding and cytotoxic studies of platinum(II) and palladium(II) complexes of the 2,2' -bipyridine and an anion of 1,1-cyclobutanedicarboxylic acid," Chemical and Pharmaceutical Bulletin, vol. 49, no. 12, pp. 1517-1520, 2001.

[243] E. Budzisz, U. Krajewska, and M. Rózalski, "Cytotoxic and proapoptotic effects of new $\mathrm{Pd}(\mathrm{II})$ and $\mathrm{Pt}(\mathrm{II})$-complexes with 2-ethanimidoyl-2-methoxy-2H-1,2-benzoxaphosphinin4-ol-2-oxide," Polish Journal of Pharmacology, vol. 56, no. 4, pp. 473-478, 2004.

[244] F. L. Wimmer, S. Wimmer, P. Castan, S. Cros, N. Johnson, and E. Colacio-Rodrigez, "The antitumor activity of some palladium(II) complexes with chelating ligands," Anticancer Research, vol. 9, no. 3, pp. 791-793, 1989.

[245] M. R. Shehata, "Mixed ligand complexes of diaquo $(2,2$ ' bipyridine)palladium(II) with cyclobutane-1,1-dicarboxylic acid and DNA constituents," Transition Metal Chemistry, vol. 26, no. 1-2, pp. 198-204, 2001. 
[246] J. Kuduk-Jaworska, A. Puszko, M. Kubiak, and M. Pelczyńska, "Synthesis, structural, physico-chemical and biological properties of new palladium(II) complexes with 2,6-dimethyl-4nitropyridine," Journal of Inorganic Biochemistry, vol. 98, no. 8, pp. 1447-1456, 2004.

[247] A. C. F. Caires, "Recent advances involving palladium (II) complexes for the cancer therapy," Anti-Cancer Agents in Medicinal Chemistry, vol. 7, no. 5, pp. 484-491, 2007.

[248] J. Zhang, F. Zhang, H. Li et al., "Recent progress and future potential for metal complexes as anticancer drugs targeting gquadruplex DNA," Current Medicinal Chemistry, vol. 19, no. 18, pp. 2957-2975, 2012.

[249] R. T. Dorr, "A review of the modulation of cisplatin toxicities by chemoprotectants, platinum and other metal coordination compounds in cancer chemotherapy," in PlatInum and Other Metal CoordInation Compounds in Cancer Chemotherapy, vol. 2, pp. 131-154, Plenum Press, New York, NY, USA, 1996.

[250] J. Bünger, J. Stork, and K. Stalder, "Cyto- and genotoxic effects of coordination complexes of platinum, palladium and rhodium in vitro," International Archives of Occupational and Environmental Health, vol. 69, no. 1, pp. 33-38, 1996.

[251] M. Zeizinger, J. V. Burda, J. Šponer, V. Kapsa, and J. Leszczynski, "A systematic ab initio study of the hydration of selected palladium square-planar complexes. A comparison with platinum analogues," The Journal of Physical Chemistry A, vol. 105, no. 34, pp. 8086-8092, 2001.

[252] C. Bazzicalupi, A. Bencini, A. Bianchi, C. Giorgi, and B. Valtancoli, "Pd(II) complexes of aliphatic polyamine ligands in aqueous solution: thermodynamic and structural features," Coordination Chemistry Reviews, vol. 184, no. 1, pp. 243-270, 1999.

[253] F. Huq, H. Daghriri, J. Q. Yu, H. Tayyem, P. Beale, and M. Zhang, "Synthesis, characterisation, activities, cell uptake and DNA binding of [\{trans-PtCl $\left.\left(\mathrm{NH}_{3}\right)_{2}\right\}\left\{\mu-\left(\mathrm{H}_{2} \mathrm{~N}\left(\mathrm{CH}_{2}\right)_{6}\right.\right.$ $\left.\left.\mathrm{NH}_{2}\right)\right\}\left\{\right.$ trans-PdCl$\left.\left(\mathrm{NH}_{3}\right)_{2}\right]\left(\mathrm{NO}_{3}\right) \mathrm{Cl}$," European Journal of Medicinal Chemistry, vol. 39, no. 11, pp. 947-958, 2004.

[254] H. Daghriri, F. Huq, and P. Beale, "Studies on activities, cell up take and DNA binding of four multinuclear complexes of the form: [\{trans- $\left.\mathrm{PtCl}\left(\mathrm{NH}_{3}\right)_{2}\right\}_{2} \mu$ - $\left\{\right.$ trans- $\mathrm{Pd}\left(\mathrm{NH}_{3}\right)_{2}$ $\left.\left.\left(\mathrm{H}_{2} \mathrm{~N}\left(\mathrm{CH}_{2}\right) \mathrm{nNH}_{2}\right)_{2}\right\}\right] \mathrm{Cl}_{4}$ where $n=4-7$," Journal of Inorganic Biochemistry, vol. 98, no. 11, pp. 1722-1733, 2004.

[255] H. Cheng, F. Huq, P. Beale, and K. Fisher, "Synthesis, characterisation, activities, cell uptake and DNA binding of a trinuclear complex: $\left[\left\{\text { trans- } \mathrm{PtCl}\left(\mathrm{NH}_{3}\right)\right\}_{2} \mu\right.$ - $\left\{\right.$ trans- $\mathrm{Pd}\left(\mathrm{NH}_{3}\right)(2-$ hydroxypyridine)-( $\left.\left.\mathrm{H}_{2} \mathrm{~N}\left(\mathrm{CH}_{2}\right)_{6} \mathrm{NH}_{2}\right)_{2}\right] \mathrm{Cl}_{4}$," European Journal of Medicinal Chemistry, vol. 41, no. 7, pp. 896-903, 2006.

[256] T. Rau, R. Alsfasser, A. Zahl, and R. van Eldik, "Structural and kinetic studies on the formation of platinum(II) and palladium(II) complexes with L-cysteine-derived ligands," Inorganic Chemistry, vol. 37, no. 17, pp. 4223-4230, 1998.

[257] E. Holló-Sitkei, G. Tárkányi, L. Párkányi, T. Megyes, and G. Besenyei, "Steric effects in the self-assembly of palladium complexes with chelating diamine ligands," European Journal of Inorganic Chemistry, no. 10, pp. 1573-1583, 2008.

[258] G. Codina, A. Caubet, C. López, V. Moreno, and E. Molins, "Palladium(ii) and platinum(ii) polyamine complexes: $\mathrm{X}$-ray crystal structures of (sp-4-2)-chloro\{N-[(3-amino$\kappa N)$ propyl]propane-1, 3-diamine- $\left.\kappa N, \kappa N^{\prime}\right\}$ palladium $(1+)$ tetrachloropalladate $(2-) \quad(2: 1)$ and $(\mathrm{r}, \mathrm{s})$-tetrachloro[ $\mu$ (spermine) $]$ dipalladium(ii) $\quad\left(=\left\{\mu\right.\right.$ - $\left\{N, N^{\prime}\right.$-bis[(3-amino $\left.\kappa N\right)$ propyl]butane-1, 4-diamine- $\left.\kappa N, \kappa N^{\prime}\right\}$ tetrachlorodipalladium)," Helvetica Chimica Acta, vol. 82, pp. 1025-1037, 1999.
[259] P. Amo-Ochoa, V. M. González, J. M. Pérez, J. R. Masaguer, C. Alonso, and C. Navarro-Ranninger, "Cytotoxicity, DNA binding, and reactivity against nucleosides of platinum (II) and (IV) spermine compounds," Journal of Inorganic Biochemistry, vol. 64, no. 4, pp. 287-299, 1996.

[260] A. M. Amado, S. M. Fiuza, M. P. M. Marques, and L. A. E. Batista de Carvalho, "Conformational and vibrational study of platinum(II) anticancer drugs: cis-diamminedichloroplatinum (II) as a case study," Journal of Chemical Physics, vol. 127, no. 18, Article ID 185104, 2007.

[261] S. M. Fiuza, A. M. Amado, M. P. M. Marques, and L. A. E. Batista de Carvalho, "Use of effective core potential calculations for the conformational and vibrational study of platinum(II) anticancer drugs-cis- diamminedichloroplatinum(II) as a case study," The Journal of Physical Chemistry A, vol. 112, no. 14, pp. 3253-3259, 2008.

[262] R. D. Graham and D. R. Williams, “The synthesis and screening for anti-bacterial, -cancer, -fungicidal and -viral activities of some complexes of palladium and nickel," Journal of Inorganic and Nuclear Chemistry, vol. 41, no. 8, pp. 1245-1249, 1979.

[263] N. Farrell, Transition Metal Complexes as Drugs and Chemotherapeutic Agents, Kluwer Academic Publishers, London, UK, 1989.

[264] A. G. Quiroga, J. M. Pérez, I. López-Solera et al., "Novel tetranuclear orthometalated complexes of $\mathrm{Pd}(\mathrm{II})$ and $\mathrm{Pt}(\mathrm{II})$ derived from p-isopropylbenzaldehyde thiosemicarbazone with cytotoxic activity in cis-DDP resistant tumor cell lines. Interaction of these complexes with DNA," Journal of Medicinal Chemistry, vol. 41, no. 9, pp. 1399-1408, 1998.

[265] A. G. Quiroga, J. M. Pérez, E. I. Montero, D. X. West, C. Alonso, and C. Navarro-Ranninger, "Synthesis and characterization of $\mathrm{Pd}(\mathrm{II})$ and $\mathrm{Pt}(\mathrm{II})$ complexes of p-isopropylbenzaldehyde Nprotected thiosemicarbazones. Cytotoxic activity against rastransformed cells," Journal of Inorganic Biochemistry, vol. 75, no. 4, pp. 293-301, 1999.

[266] D. Kovala-Demertzi, A. Domopoulou, M. A. Demertzis, G. Valle, and A. Papageorgiou, "Palladium(II) complexes of 2-acetylpyridine N(4)-methyl, N(4)-ethyl and $\mathrm{N}(4)$-phenyl-thiosemicarbazones. Crystal structure of chloro(2-acetylpyridine N(4)-methylthiosemicarbazonato) palladium(II). Synthesis, spectral studies, in vitro and in vivo antitumour activity," Journal of Inorganic Biochemistry, vol. 68, no. 2, pp. 147-155, 1997.

[267] M. A. Ali, A. H. Mirza, R. J. Butcher, and K. A. Crouse, "The preparation, characterization and biological activity of palladium(II) and platinum(II) complexes of tridentate NNS ligands derived from S-methyl- and S-benzyldithiocarbazates and the X-ray crystal structure of the $[\mathrm{Pd}$ (mpasme)Cl] complex," Transition Metal Chemistry, vol. 31, no. 1, pp. 79-87, 2006.

[268] M. J. Cleare and P. C. Hydes, "Metal complexes as anticancer agents," in Metal Ions in Biological Systems, pp. 1-62, Marcel Dekker, New York, NY, USA, 1980.

[269] J. D. Higgins, L. Neely, and S. Fricker, "Synthesis and cytotoxicity of some cyclometallated palladium complexes," Journal of Inorganic Biochemistry, vol. 49, no. 2, pp. 149-156, 1993.

[270] D. Kovala-Demertzi, M. A. Demertzis, J. R. Miller, C. S. Frampton, J. P. Jasinski, and D. X. West, "Structure of bis(2acetylpyridine 3-hexamethyleneiminylthiosemicarbazonato) palladium(II), a potential antitumor complex," Journal of Inorganic Biochemistry, vol. 92, no. 2, pp. 137-140, 2002.

[271] L. Tušek-Božić, I. Matijašić, G. Bocelli et al., "Preparation, characterization and activity of palladium(II) halide complexes 
with diethyl 2-quinolylmethylphosphonate (2-dqmp). X-ray crystal structures of trans-[Pd(2-dqmp $\left.)_{2} \mathrm{X}_{2}\right](\mathrm{X}=\mathrm{Cl}$ or $\mathrm{Br})$, Journal of the Chemical Society, Dalton Transactions, no. 2, pp. 195-201, 1991.

[272] C. Mock, I. Puscasu, M. J. Rauterkus, G. Tallen, J. E. A. Wolff, and B. Krebs, "Novel Pt(II) anticancer agents and their Pd(II) analogues: syntheses, crystal structures, reactions with nucleobases and cytotoxicities," Inorganica Chimica Acta, vol. 319, no. 1-2, pp. 109-116, 2001.

[273] G. B. Onoa, V. Moreno, M. Font-Bardia, X. Solans, J. M. Pérez, and C. Alonso, "Structural and cytotoxic study of new Pt(II) and $\mathrm{Pd}(\mathrm{II})$ complexes with the bi-heterocyclic ligand mepirizole," Journal of Inorganic Biochemistry, vol. 75, no. 3, pp. 205-212, 1999.

[274] N. Dodoff, S. Varbanov, G. Borisov, and N. Spassovska, "Platinum (II), platinum (IV), and palladium (II) complexes of amino substituted phosphine oxides: synthesis, characterization, and antitumor activity," Journal of Inorganic Biochemistry, vol. 39, no. 3, pp. 201-208, 1990.

[275] M. Z. Wiśniewski and T. Gtowiak, "The structure and properties of a palladium(II) complex of 2-mercapto-1-methylimidazole," Polish Journal of Chemistry, vol. 72, no. 3, pp. 514-518, 1998.

[276] M. Z. Wiśniewski, J. Wietrzyk, and A. Opolski, "Novel Ru(III), $\mathrm{Rh}(\mathrm{III}), \mathrm{Pd}(\mathrm{II})$ and $\mathrm{Pt}(\mathrm{II})$ complexes with ligands incorporating azole and pyrimidine rings. I. Antiproliferative activity in vitro," Archivum Immunologiae et Therapiae Experimentalis, vol. 48, no. 1 , pp. $51-55,2000$.

[277] D. Kovala-Demertzi, M. A. Demertzis, E. Filiou et al., "Platinum(II) and palladium(II) complexes with 2 -acetyl pyridine $4 \mathrm{~N}$-ethyl thiosemicarbazone able to overcome the cis-platin resistance. Structure, antibacterial activity and DNA strand breakage," BioMetals, vol. 16, no. 3, pp. 411-418, 2003.

[278] A. G. Quiroga and C. N. Ranninger, "Contribution to the SAR field of metallated and coordination complexes: studies of the palladium and platinum derivatives with selected thiosemicarbazones as antitumoral drugs," Coordination Chemistry Reviews, vol. 248, no. 1-2, pp. 119-133, 2004.

[279] K. Akdi, R. A. Vilaplana, S. Kamah, J. A. R. Navarro, J. M. Salas, and F. González-Vílchez, "Study of the biological effects and DNA damage exerted by a new dipalladium-Hmtpo complex on human cancer cells," Journal of Inorganic Biochemistry, vol. 90, no. 1-2, pp. 51-60, 2002.

[280] J. Dupont, C. S. Consorti, and J. Spencer, "The potential of palladacycles: more than just precatalysts," Chemical Reviews, vol. 105, no. 6, pp. 2527-2571, 2005.

[281] H. Mansuri-Torshizi, R. Mital, T. S. Srivastava, H. Parekh, and M. P. Chitnis, "Synthesis, characterization, and cytotoxic studies of $\alpha$-diimine/1,2- diamine platinum(II) and palladium(II) complexes of selenite and tellurite and binding of some of these complexes to DNA," Journal of Inorganic Biochemistry, vol. 44, no. 4, pp. 239-247, 1991.

[282] A. S. Abu-Surrah, M. Kettunen, K. Lappalainen, U. Piironen, M. Klinga, and M. Leskelä, "Synthesis of new chiral diimine palladium(II) and nickel(II) complexes bearing oxazoline- and myrtanyl-based nitrogen ligands. Crystal structure of the C2symmetric complex $\left[\{(1 \mathrm{R}, 2 \mathrm{~S})\right.$-inda-box $\left.\} \mathrm{PdCl}_{2}\right]$," Polyhedron, vol. 21, no. 1, pp. 27-31, 2002.

[283] B. T. Khan, J. Bhatt, K. Najmuddin, S. Shamsuddin, and K. Annapoorna, "Synthesis, antimicrobial, and antitumor activity of a series of palladium(II) mixed ligand complexes," Journal of Inorganic Biochemistry, vol. 44, no. 1, pp. 55-63, 1991.
[284] H. Mansuri-Torshizi, T. S. Srivastava, H. K. Parekh, and M. P. Chitnis, "Synthesis, spectroscopic, cytotoxic, and DNA binding studies of binuclear 2,2' -bipyridine-platinum(II) and -palladium(II) complexes of meso- $\alpha, \alpha$-diaminoadipic and meso- $\alpha, \alpha$-diaminosuberic acids," Journal of Inorganic Biochemistry, vol. 45, no. 2, pp. 135-148, 1992.

[285] H. Hohmann and R. van Eldik, "Rate and equilibrium data for substitution reactions of diaqua(ethylenediamine)palladium(II) with chloride in aqueous solution," Inorganica Chimica Acta, vol. 174, no. 1, pp. 87-92, 1990.

[286] H. Hohmann, S. Suvachittanont, and R. van Eldik, "A kinetic study of the substitution behaviour of aqua and chloro complexes of ethylenediaminepalladium(II) in aqueous solution," Inorganica Chimica Acta, vol. 177, no. 1, pp. 51-58, 1990.

[287] F. Huq, H. Tayyem, P. Beale, and J. Q. Yu, "Studies on the activity of three palladium(II) compounds of the form: trans$\mathrm{PdL}_{2} \mathrm{Cl}_{2}$ where $\mathrm{L}=2$-hydroxypyridine, 3-hydroxypyridine, and 4-hydroxypyridine," Journal of Inorganic Biochemistry, vol. 101, no. 1, pp. 30-35, 2007.

[288] A. S. Abu-Surrah, T. A. K. Al-Allaf, M. Klinga, and M. Ahlgrend, "Chiral palladium(II) and platinum(II) complexes of diaminocyclohexane: X-ray structures of (1R,2R)-(-)-1,2diaminocyclohexane dihydrochloride and its corresponding oxalato platinum(II) complex," Polyhedron, vol. 22, no. 12, pp. 1529-1534, 2003.

[289] G. Zhao, H. Lin, P. Yu, H. Sun, S. Zhu, and Y. Chen, "Comparison of the mode of action of a dinuclear platinum complex containing a pyridine derivative with its monomeric analog," Chemico-Biological Interactions, vol. 116, no. 1-2, pp. 19-29, 1998.

[290] I. F. Duarte, I. Lamego, J. Marques, M. P. M. Marques, B. J. Blaise, and A. M. Gil, "Nuclear magnetic resonance (NMR) study of the effect of cisplatin on the metabolic profile of MG-63 osteosarcoma cells," Journal of Proteome Research, vol. 9, no. 11, pp. 5877-5886, 2010.

[291] M. J. Cleare and J. D. Hoeschele, "Studies on the antitumor activity of group VIII transition metal complexes. I. Platinum (II) complexes," Bioinorganic Chemistry, vol. 2, no. 3, pp. 187-210, 1973.

[292] T. W. Hambley, "The influence of structure on the activity and toxicity of Pt anti-cancer drugs," Coordination Chemistry Reviews, vol. 166, pp. 181-223, 1997.

[293] J. Zhang, D. Liu, Y. Li, J. Sun, L. Wang, and A. Zang, "Status of non-classical mononuclear platinum anticancer drug development," Mini-Reviews in Medicinal Chemistry, vol. 9, no. 11, pp. 1357-1366, 2009.

[294] N. Farrell, L. R. Kelland, J. D. Roberts, and M. van Beusichem, "Activation of the trans geometry in platinum antitumor complexes: a survey of the cytotoxicity of trans complexes containing planar ligands in murine L1210 and human tumor panels and studies on their mechanism of action," Cancer Research, vol. 52, no. 18, pp. 5065-5072, 1992.

[295] S. Radulovic, Z. Tesic, and S. Manic, "Trans-platinum complexes as anticancer drugs: recent developments and future prospects," Current Medicinal Chemistry, vol. 9, no. 17, pp. 1611-1618, 2002.

[296] M. Coluccia and G. Natile, "Trans-platinum complexes in cancer therapy," Anti-Cancer Agents in Medicinal Chemistry, vol. 7, no. 1, pp. 111-123, 2007.

[297] S. M. Aris and N. P. Farrell, "Towards antitumor active transplatinum compounds," European Journal of Inorganic Chemistry, vol. 2009, no. 10, pp. 1293-1302, 2009. 
[298] B. T. Benedetti, S. Quintal, and N. P. Farrell, "Modulation of drug activation profiles through carboxylate ligand modification in cytotoxic trans-platinum planar amine compounds," Dalton Transactions, vol. 40, no. 41, pp. 10983-10988, 2011.

[299] C. Musetti, A. A. Nazarov, N. P. Farrell, and C. Sissi, "DNA reactivity profile of trans-platinum planar amine derivatives," ChemMedChem, vol. 6, no. 7, pp. 1283-1290, 2011.

[300] R. F. Murphy, E. Komlodi-Pasztor, R. Robey, F. M. Balis, N. P. Farrell, and T. Fojo, "Retained platinum uptake and indifference to p53 status make novel transplatinum agents active in platinum-resistant cells compared to cisplatin and oxaliplatin," Cell Cycle, vol. 11, no. 5, pp. 963-973, 2012.

[301] M. T. Johnson, E. W. Neuse, C. E. J. van Rensburg, and E. Kreft, "Cell growth-inhibiting properties of selected carrier-bound, monoamine-coordinated platinum(II) compounds," Journal of Inorganic and Organometallic Polymers and Materials, vol. 13, no. 2, pp. 55-67, 2003.

[302] G. H. W. Milburn and M. R. Truter, "The crystal structures of cis- and trans-dichlorodiammineplatinum(II)," Journal of the Chemical Society A: Inorganic, Physical, Theoretical, pp. 1609-1616, 1966.

[303] S. Neidle, I. M. Ismail, and P. J. Sadler, "The structure of the antitumor complex cis(diammino) (1,1-cyclobutanedicarboxylato)-Pt(II): X ray and nmr studies," Journal of Inorganic Biochemistry, vol. 13, no. 3, pp. 205-212, 1980.

[304] B. Beagley, D. W. J. Cruickshank, C. A. McAuliffe et al., "The crystal and molecular structure of cis-diammine-1,1cyclobutanedicarboxoplatinum(II) [cis- $\mathrm{Pt}\left(\mathrm{NH}_{3}\right)_{2} \mathrm{CBDCA}$. Dynamic puckering of the cyclobutane ring," Journal of Molecular Structure, vol. 130, no. 1-2, pp. 97-102, 1985.

[305] L. A. E. Batista de Carvalho, M. P. M. Marques, C. Martin, S. F. Parker, and J. Tomkinson, "Inelastic neutron scattering study of PtII complexes displaying anticancer properties," ChemPhysChem, vol. 12, no. 7, pp. 1334-1341, 2011.

[306] R. L. Benson and T. L. Gustafson, "Comparative study of the interactions of cisplatin and carboplatin with nucleotides using UV resonance Raman spectroscopy," Biopolymers, vol. 33, no. 11, pp. 1631-1641, 1993.

[307] B. Giese, G. B. Deacon, J. Kuduk-Jaworska, and D. McNaughton, "Density functional theory and surface enhanced Raman spectroscopy characterization of novel platinum drugs," Biopolymers, vol. 67, no. 4-5, pp. 294-297, 2002.

[308] B. Giese and D. McNaughton, "Interaction of anticancer drug cisplatin with guanine: density functional theory and surfaceenhanced raman spectroscopy study," Biopolymers, vol. 72, no. 6, pp. 472-489, 2003.

[309] O. Vrána, V. Mašek, V. Dražan, and V. Brabec, "Raman spectroscopy of DNA modified by intrastrand cross-links of antitumor cisplatin," Journal of Structural Biology, vol. 159, no. 1, pp. 1-8, 2007.

[310] A. Barhoumi, D. Zhang, F. Tam, and N. J. Halas, "Surfaceenhanced raman spectroscopy of DNA," Journal of the American Chemical Society, vol. 130, no. 16, pp. 5523-5529, 2008.

[311] H. H. Zeng, Z. H. Xu, and K. Wang, "FT-Raman studies on the transformation of G-actin to F-actin, the binding of cisplatin and transplatin to F-actin and the effects of the conformation of F-actin," International Journal of Biological Macromolecules, vol. 20, no. 2, pp. 107-113, 1997.

[312] Y. Yue, X. Chen, J. Qin, and X. Yao, “Spectroscopic investigation on the binding of antineoplastic drug oxaliplatin to human serum albumin and molecular modeling," Colloids and Surfaces B: Biointerfaces, vol. 69, no. 1, pp. 51-57, 2009.
[313] K. D. Taylor, R. Goel, F. H. Shirazi et al., "Pressure tuning infrared spectroscopic study of cisplatin-induced structural changes in a phosphatidylserine model membrane," British Journal of Cancer, vol. 72, no. 6, pp. 1400-1405, 1995.

[314] M. P. M. Marques, F. Borges, A. M. Amorim da Costa, and L. A. E. Batista de Carvalho, "Vibrational spectroscopy studies on biologically relevant molecules: from anticancer agents to drugs of abuse," in New Approaches in Biomedical Spectroscopy, pp. 338-363, American Chemical Society, 2007.

[315] A. M. Amado, M. M. Nolasco, and P. J. A. Ribeiro-Claro, "Probing pseudopolymorphic transitions in pharmaceutical solids using Raman spectroscopy: hydration and dehydration of theophylline," Journal of Pharmaceutical Sciences, vol. 96, no. 5, pp. 1366-1379, 2007.

[316] C. Gendrin, Y. Roggo, and C. Collet, "Pharmaceutical applications of vibrational chemical imaging and chemometrics: a review," Journal of Pharmaceutical and Biomedical Analysis, vol. 48, no. 3, pp. 533-553, 2008.

[317] F. Paiva-Martins, V. Rodrigues, R. Calheiros, and M. P. Marques, "Characterization of antioxidant olive oil biophenols by spectroscopic methods," Journal of the Science of Food and Agriculture, vol. 91, no. 2, pp. 309-314, 2011.

[318] L. A. E. Batista de Carvalho and M. P. M. Marques, "Raman microspectroscopy: applications in life sciences," in Image Analysis in Life Sciences, Research Signpost, 2009.

[319] Y. Wu, G. D. McEwen, S. Harihar, S. M. Baker, D. B. DeWald, and A. Zhou, "BRMS1 expression alters the ultrastructural, biomechanical and biochemical properties of MDA-MB-435 human breast carcinoma cells: an AFM and Raman microspectroscopy study," Cancer Letters, vol. 293, no. 1, pp. 82-91, 2010.

[320] V. V. Pully, A. Lenferink, and C. Otto, "Hybrid Rayleigh, Raman and two-photon excited fluorescence spectral confocal microscopy of living cells," Journal of Raman Spectroscopy, vol. 41, no. 6, pp. 599-608, 2010.

[321] A. B. Zoladek, R. K. Johal, S. Garcia-Nieto et al., "Labelfree molecular imaging of immunological synapses between dendritic and $\mathrm{T}$ cells by Raman micro-spectroscopy," The Analyst, vol. 135, no. 12, pp. 3205-3212, 2010.

[322] M. M. Mariani, P. J. R. Day, and V. Deckert, "Applications of modern micro-Raman spectroscopy for cell analyses," Integrative Biology, vol. 2, no. 2-3, pp. 94-101, 2010.

[323] F. Draux, C. Gobinet, J. Sulé-Suso et al., "Raman spectral imaging of single cancer cells: probing the impact of sample fixation methods," Analytical and Bioanalytical Chemistry, vol. 397, no. 7, pp. 2727-2737, 2010.

[324] S. Verrier, I. Notingher, J. M. Polak, and L. L. Hench, "In situ monitoring of cell death using Raman microspectroscopy," Biopolymers, vol. 74, no. 1-2, pp. 157-162, 2004.

[325] L. Buriankova, Z. Nadova, D. Jancura et al., "Synchrotron based fourier-transform infrared microspectroscopy as sensitive technique for the detection of early apoptosis in U-87 MG cells," Laser Physics Letters, vol. 7, no. 8, pp. 613-620, 2010.

[326] C. Pezzei, J. D. Pallua, G. Schaefer et al., "Characterization of normal and malignant prostate tissue by Fourier transform infrared microspectroscopy," Molecular BioSystems, vol. 6, no. 11, pp. 2287-2295, 2010.

[327] K. Wehbe, R. Pineau, S. Eimer, A. Vital, H. Loiseau, and G. Déléris, "Differentiation between normal and tumor vasculature of animal and human glioma by FTIR imaging," The Analyst, vol. 135, no. 12, pp. 3052-3059, 2010. 
[328] G. Tosi, C. Conti, E. Giorgini et al., "FTIR microspectroscopy of melanocytic skin lesions: a preliminary study," The Analyst, vol. 135, no. 12, pp. 3213-3219, 2010.

[329] J. Sulé-Suso and G. Cinque, "Infrared microspectroscopy in cancer diagnosis. Do we need synchrotron light?" Microscopy and Analysis, vol. 24, pp. 17-20, 2010.

[330] C. Matthäus, A. Kale, T. Chernenko, V. Torchilin, and M. Diem, "New ways of imaging uptake and intracellular fate of liposomal drug carrier systems inside individual cells, based on raman microscopy," Molecular Pharmaceutics, vol. 5, no. 2, pp. 287-293, 2008.

[331] A. Tfayli, O. Piot, F. Pitre, and M. Manfait, "Follow-up of drug permeation through excised human skin with confocal Raman microspectroscopy," European Biophysics Journal, vol. 36, no. 8, pp. 1049-1058, 2007.

[332] F. Draux, P. Jeannesson, A. Beljebbar et al., "Raman spectral imaging of single living cancer cells: a preliminary study," The Analyst, vol. 134, no. 3, pp. 542-548, 2009.

[333] H. Nawaz, F. Bonnier, A. D. Meade, F. M. Lyng, and H. J. Byrne, "Comparison of subcellular responses for the evaluation and prediction of the chemotherapeutic response to cisplatin in lung adenocarcinoma using Raman spectroscopy," The Analyst, vol. 136, no. 12, pp. 2450-2463, 2011.

[334] J. Sulé-Suso, D. Skingsley, G. D. Sockalingum et al., "FT-IR microspectroscopy as a tool to assess lung cancer cells response to chemotherapy," Vibrational Spectroscopy, vol. 38, no. 1-2, pp. 179-184, 2005.

[335] H. Nawaz, F. Bonnier, P. Knief et al., "Evaluation of the potential of Raman microspectroscopy for prediction of chemotherapeutic response to cisplatin in lung adenocarcinoma," The Analyst, vol. 135, no. 12, pp. 3070-3076, 2010.

[336] L. Corte, P. Rellini, L. Roscini, F. Fatichenti, and G. Cardinali, "Development of a novel, FTIR (Fourier transform infrared spectroscopy) based, yeast bioassay for toxicity testing and stress response study," Analytica Chimica Acta, vol. 659, no. 1-2, pp. 258-265, 2010.

[337] A. Saha and V. V. Yakovlev, "Towards a rational drug design: Raman micro-spectroscopy analysis of prostate cancer cells treated with an aqueous extract of Nerium Oleander," Journal of Raman Spectroscopy, vol. 40, no. 11, pp. 1459-1460, 2009.

[338] G. Bellisola, M. Della Peruta, M. Vezzalini et al., "Tracking infrared signatures of drugs in cancer cells by fourier transform microspectroscopy," The Analyst, vol. 135, no. 12, pp. 3077-3086, 2010.

[339] H. Gao, F. Xia, C. Huang, and K. Lin, "Density functional theory calculations on the molecular structures and vibration spectra of platinum(II) antitumor drugs," Spectrochimica Acta A: Molecular and Biomolecular Spectroscopy, vol. 78, no. 4, pp. 1234-1239, 2011.

[340] N. I. Dodoff, "A dft/ecp-small basis set modelling of cisplatin: molecular structure and vibrational spectrum," Computational Molecular Bioscience, vol. 2, no. 2, pp. 35-44, 2012.

[341] D. Michalska and R. Wysokiński, "The prediction of Raman spectra of platinum(II) anticancer drugs by density functional theory," Chemical Physics Letters, vol. 403, no. 1-3, pp. 211-217, 2005.

[342] V. P. Ting, M. Schmidtmann, C. C. Wilson, and M. T. Weller, "Cisplatin: polymorphism and structural insights into an important chemotherapeutic drug," Angewandte Chemie International Edition, vol. 49, no. 49, pp. 9408-9411, 2010.

[343] J. V. Burda, M. Zeizinger, and J. Leszczynski, "Hydration process as an activation of trans- and cisplatin complexes in anticancer treatment. DFT and $a b$ initio computational study of thermodynamic and kinetic parameters," Journal of Computational Chemistry, vol. 26, no. 9, pp. 907-914, 2005.

[344] R. Wysokiński, J. Kuduk-Jaworska, and D. Michalska, "Electronic structure, Raman and infrared spectra, and vibrational assignment of carboplatin. Density functional theory studies," Journal of Molecular Structure: THEOCHEM, vol. 758, no. 2-3, pp. 169-179, 2006.

[345] E. C. Beret, R. R. Pappalardo, D. Marx, and E. S. Marcos, "Characterizing Pt-derived anticancer drugs from first principles: the case of oxaliplatin in aqueous solution," ChemPhysChem, vol. 10, no. 7, pp. 1044-1052, 2009.

[346] R. Wysokiński, K. Hernik, R. Szostak, and D. Michalska, "Electronic structure and vibrational spectra of cisdiammine(orotato)platinum(II), a potential cisplatin analogue: DFT and experimental study," Chemical Physics, vol. 333, no. 1, pp. 37-48, 2007.

[347] D. Bouvet, A. Michalowicz, S. Crauste-Manciet, D. Brossard, and K. Provost, "EXAFS and IR structural study of platinumbased anticancer drugs' degradation by diethyl dithiocarbamate," Inorganic Chemistry, vol. 45, no. 8, pp. 3393-3398, 2006.

[348] M. Obata, M. Harada, H. Ohi, S. Hirohara, M. Gottchaldt, and S. Yano, "Extended X-ray absorption fine structure study on reaction of anti-tumor platinum complexes with reduced glutathione," Chemical and Pharmaceutical Bulletin, vol. 57, no. 10, pp. 1107-1109, 2009.

[349] K. Provost, D. Bouvet-Muller, S. Crauste-Manciet et al., "EXAFS structural study of platinum-based anticancer drugs degradation in presence of sulfur nucleophilic species," Biochimie, vol. 91, no. 10, pp. 1301-1306, 2009.

[350] E. Dartyge, C. Depautex, J. M. Dubuisson et al., "X-ray absorption in dispersive mode: a new spectrometer and a data acquisition system for fast kinetics," Nuclear Instruments and Methods in Physics Research Section A: Accelerators, Spectrometers, Detectors and Associated Equipment, vol. 246, no. 1-3, pp. 452-460, 1986.

[351] G. Cossa, L. Gatti, F. Zunino, and P. Perego, "Strategies to improve the efficacy of platinum compounds," Current Medicinal Chemistry, vol. 16, no. 19, pp. 2355-2365, 2009.

[352] E. Gabano, M. Ravera, and D. Osella, "The drug targeting and delivery approach applied to Pt-antitumour complexes. A coordination point of view," Current Medicinal Chemistry, vol. 16, no. 34, pp. 4544-4580, 2009.

[353] G. N. C. Chiu, M. Y. Wong, L. U. Ling et al., "Lipid-based nanoparticulate systems for the delivery of anti-cancer drug cocktails: implications on pharmacokinetics and drug toxicities," Current Drug Metabolism, vol. 10, no. 8, pp. 861-874, 2009.

[354] N. P. Farrell, "Platinum formulations as anticancer drugs clinical and pre-clinical studies," Current Topics in Medicinal Chemistry, vol. 11, no. 21, pp. 2623-2631, 2011.

[355] C. Sessa, C. Minoia, A. Ronchi et al., "Phase I clinical and pharmacokinetic study of the oral platinum analogue JM216 given daily for 14 days," Annals of Oncology, vol. 9, no. 12, pp. 1315-1322, 1998.

[356] A. A. Bhirde, S. Patel, A. A. Sousa et al., "Distribution and clearance of PEG-single-walled carbon nanotube cancer drug delivery vehicles in mice," Nanomedicine, vol. 5, no. 10, pp. 1535-1546, 2010.

[357] J. Lin, Y. Li, S. Feng et al., "Raman spectroscopic analysis of cytotoxic effect of cisplatin-treated leukemic cells," in 8th International Conference on Photonics and Imaging in Biology 
and Medicine (PIBM '09), Proceedings of SPIE, Wuhan, China, August 2009.

[358] Z. H. Tao, H. L. Yao, G. W. Wang et al., "Using Raman spectroscopy to analyze apoptosis of gastric cancer cells induced by cisplatin," Guang Pu Xue Yu Guang Pu Fen Xi, vol. 29, no. 9, pp. 2442-2445, 2009. 

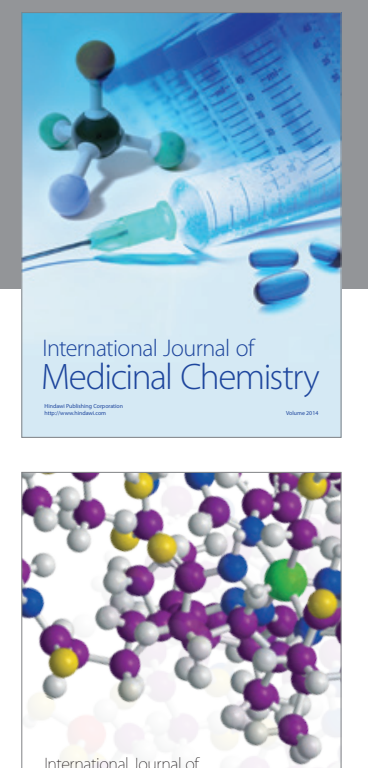

\section{Carbohydrate} Chemistry

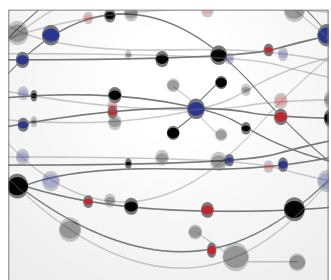

The Scientific World Journal
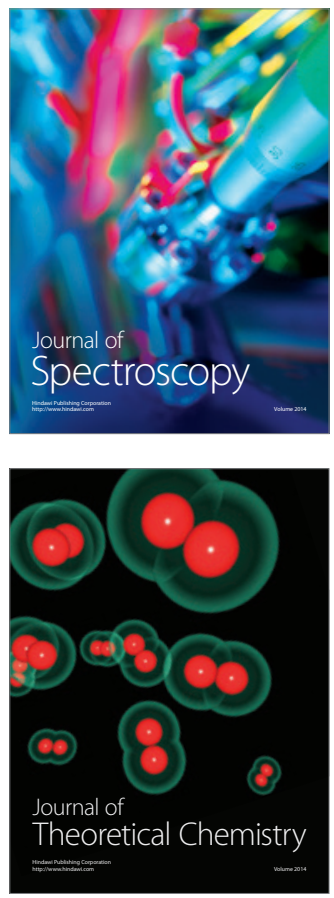
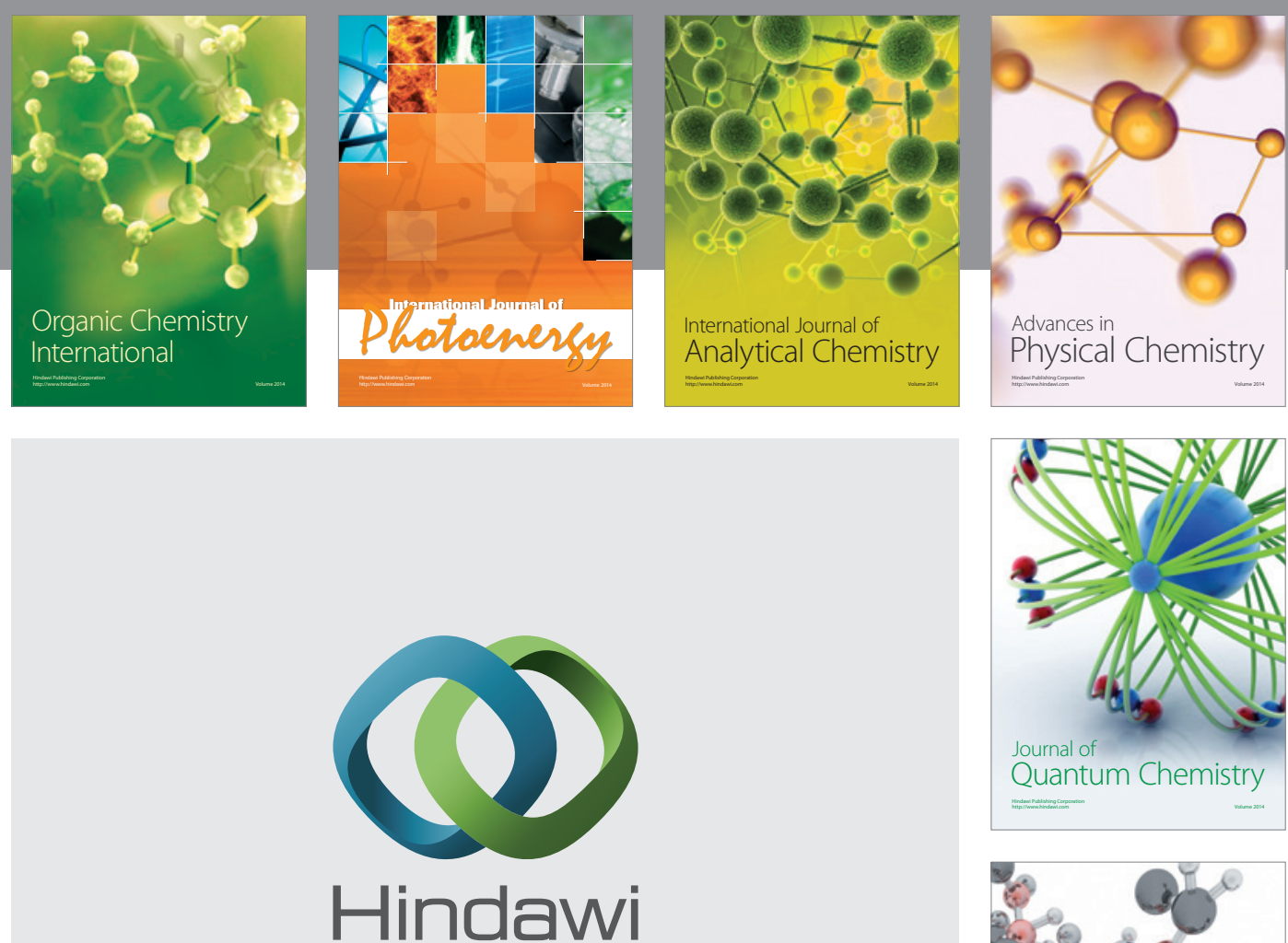

Submit your manuscripts at

http://www.hindawi.com

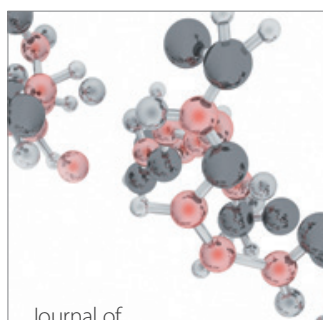

Analytical Methods

in Chemistry

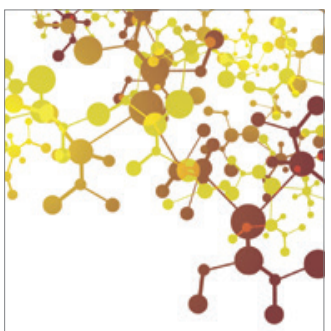

Journal of

Applied Chemistry

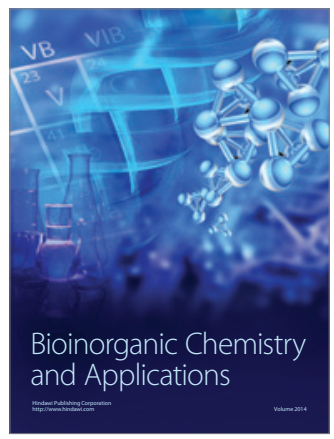

Inorganic Chemistry
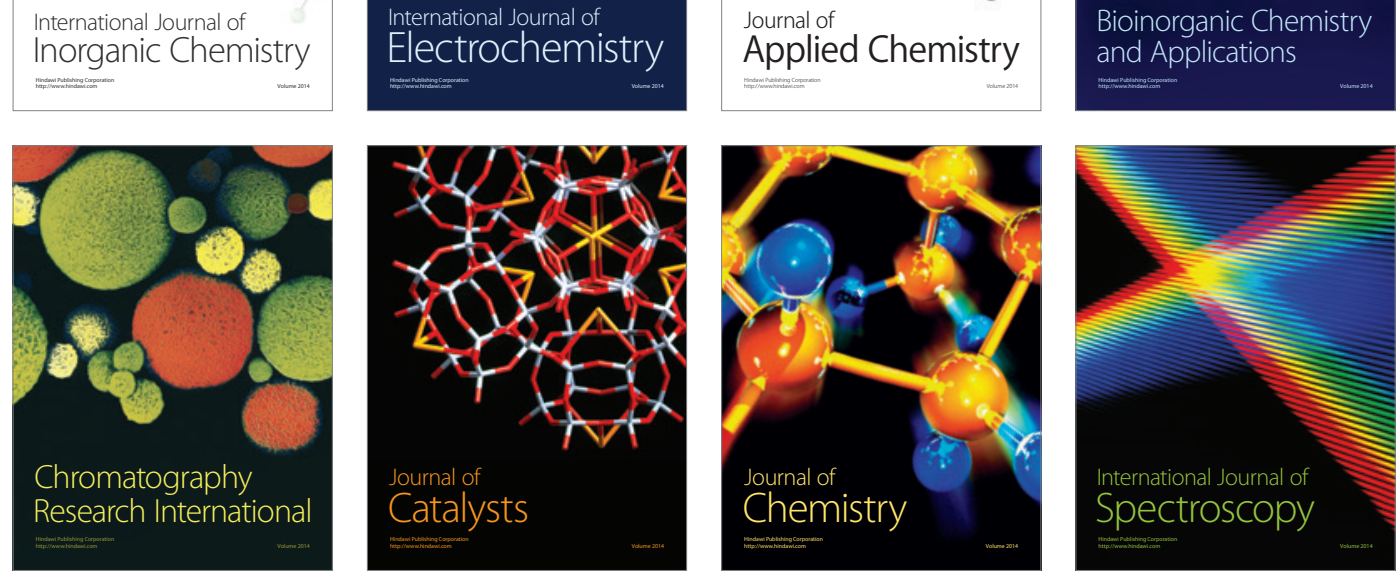